Universidade de São Paulo

Instituto de Física

\title{
Modelagem Ab Initio da Interação Proteína-Carboidrato
}

\author{
Filipe Camargo Dalmatti Alves Lima
}

Orientadora: Profa. Dra. Helena Maria Petrilli

\begin{abstract}
Dissertação apresentada ao Instituto de Física da Universidade de São Paulo como parte dos requisitos para obtenção do título de Mestre em Física.
\end{abstract}

Comissão examinadora:

Profa. Dra. Maria Teresa de Moura Lamy (IF-USP)

Prof. Dr. Ronei Miotto (UFABC)

Financiado pela FAPESP

São Paulo - 2010 


\section{FICHA CATALOGRÁFICA}

Preparada pelo Serviço de Biblioteca e Informação do Instituto de Física da Universidade de São Paulo

Lima, Filipe Camargo Dalmatti Alves

Modelagem ab initio da interação proteína-carboidrato São Paulo, 2010

Dissertação (Mestrado) - Universidade de São Paulo. Instituto de Física - Depto. de Física dos Materiais e Mecânica.

Orientador: Profa. Dra. Helena Maria Petrilli

Área de Concentração: Física

Unitermos: 1. Física; 2. Física da Matéria Condensada;

3. Biofísica; 4. Física Computacional. 
De alguém assim me gloriarei eu, mas de mim mesmo não me gloriarei, senão nas minhas fraquezas.

2 Coríntios 2:12 



\section{Agradecimentos}

Uma vez que "o bater de asas de uma simples borboleta poderia influenciar o curso natural das coisas", eu não posso agradecer especificamente esta ou aquela pessoa, pois eu creio que todos aqueles que participaram são importantes em todos os aspectos da minha vida.

De fato, algumas pessoas contribuíram muito mais para a minha formação, e estes eu os considero como verdadeiros heróis para mim, pessoas a quem eu sempre terei um imenso respeito, carinho, amor e gratidão. Alguns deles já não estão mais aqui nesta terra, mas continuam vivos e serão sempre lembrados por mim pelos grandes feitos realizados e pelos ensinamentos que aprendi deles. Entretanto, sendo eles heróis para mim, não posso agradecê-los publicamente, pois estaria colocando a vida dos meus heróis em risco ao revelar a sua identidade secreta. Além do mais, estas pessoas sabem o quanto são importantes para mim, de forma que eu não preciso ficar declarando a minha gratidão através de um texto. Eu creio que o meu amor, por mais falho que ele é, seja suficiente a todos estes que mereciam que seus nomes estivessem aqui.

Mesmo assim gostaria de dedicar essa dissertação, e eu as dedico para as mulheres da minha vida. Àquelas que me criam, me educam, me dão carinho, fazem companhia, dão atenção, me abraçam, me corrigem, às vezes brigam comigo, mas que, sobretudo, me amam. É engraçado um homem com seus vinte e tantos anos dizer "me criam", mas eu sou homem o suficiente para dizer que ainda não estou pronto e talvez nunca esteja pronto o suficiente para viver sem uma mulher ao meu lado. Não são todas as mulheres que eu conheço que se incluem nesta dedicatória, apenas aquelas que eu amo. A todas estas heroínas, fica aqui para vocês um dos frutos que vocês cultivaram junto comigo.

Uma vez eu aprendi que "Tu se tornas eternamente responsável por aquilo que cativas", por isso, a cada um que cativei, me perdoe por nem sempre estar presente. Isto não significa que eu deixei de amá-los ou me esqueci de vocês, infelizmente eu não sou Deus para estar presente com vocês o tempo todo. Mas creio que Deus ainda me dará a oportunidade de reencontro, seja aqui nesta terra ou no céu, tudo ao Seu tempo determinado.

Aproveito esta oportunidade para agradecer a FAPESP pelo suporte financeiro, ao LCCA-USP e o CENAPAD/SP pelo suporte computacional, ao Prof. Valtencir Zucolotto (e o grupo de Biofísica Molecular no IFSC-USP) e a profa. Antonia Tavares do Amaral (e o seu grupo no IQ-USP) pela colaboração neste trabalho. 



\section{Resumo}

A Frutalina é uma proteína tetramérica ligante de carboidratos obtida através de sementes Artocarpus incisa. Os interesses biomédicos da Frutalina estão em sua alta afinidade de ligação por carboidratos presentes em algumas células tumorais específicas. Até agora, nenhum estudo teórico computacional foi realizado para investigar as características de ligação da Frutalina. Neste trabalho, através de um estudo multidisciplinar, investigamos as propriedades de ligação e óticas da Frutalina com carboidratos. Utilizamos um "modelo-corte" teórico, considerando apenas o sítio ativo de ligação com o carboidrato construído com o auxílio de docking molecular e mecânica molecular clássica. As energias de ligação são obtidas através de uma abordagem quânticaab initio all electron, dentro da Teoria do Funcional da Densidade (DFT), no espaço recíproco que combina o método Projector Augmented Waves (PAW) e a dinâmica molecular de Car-Parrinello (CP). Uma metodologia Hartree-Fock (HF) semi-empírica é utilizada para obter as propriedades óticas. A investigação deste problema muito complexo pode ser dividido em seis etapas principais: a) estudamos as propriedades estruturais da proteína para avaliar a sua mobilidade e escolhemos um conjunto de dados de raios-X para descrever o sistema; b) aplicamos a técnica de docking molecular para ligar quatro carboidratos $(\alpha$-metil-D-galactose, $\beta$-D-galactose, O1-metil-manose e $\alpha$-metil-D-glucopiranose) na proteína; c) otimizamos a geometria do sistema lectina-carboidrato utilizando mecânica molecular clássica; d) criamos o "modelo-corte"; e) investigamos as propriedades óticas utilizando HF; f) estudamos as propriedades eletrônicas do sistema proteína-carboidrato e calculamos energias de ligação através do cálculo DFT. O modelo aqui proposto, além de apresentar uma adequada concordância com dados experimentais, abre a possibilidade de investigar propriedades eletrônicas através de uma abordagem quântica "estado da arte" na área de estrutura eletrônica. 



\begin{abstract}
Frutalin is a tetrameric carbohydrate-binding protein obtained from breadfruit seeds. Biomedical interest on Frutalin comes from the high affinity exhibited by these molecules toward carbohydrates expressed by specific tumor cells. So far, no theoretical computational studies have been carried out to investigate the binding characteristics of frutalin, which is probably due to the large number of atoms that should be considered for in silico calculations. We investigate the binding of frutalin and optical properties with specific carbohydrate molecules using a theoretical "cutmodel" considering only the carbohydrate binding site. This model has been constructed with the aid of molecular docking and classical molecular mechanics. We use the ab initio all electron reciprocal space Projector Augmented Waves (PAW) method and the CarParrinello scheme as embodied in the CP-PAW code to obtain the binding energies.To evaluate the optical properties, we employed the Hartree-Fock Semi-empirical ZINDO method from the Materials Studio 4.0 computational package. The investigation of this very complex problem can be divided into 6 main steps. Firstly, we study the structural properties of the protein to evaluate its mobility and we choose a x-ray data to describe reliably the system. In the second step, we performed molecular docking to link up four carbohydrates (alpha-methyl-D-galactoside, beta-D-galactoside, O1-methyl-mannose and methyl-alpha-D-glucopyranoside) in the protein. We optimize the geometry of the system lectin-carbohydrate using molecular mechanics in the third step. In the fourth step, we created the "cutmodel" based on the final geometries obtained in the previous step. In the fifth and sixth steps we investigate the quantum interaction of the protein with each carbohydrate. Our theoretical results are compared with available measurements in each step. The study of the interaction between the active binding site and carbohydrates allows us to demonstrate that our methodology is well suited to predict the electronic properties of the system.
\end{abstract}





\section{Conteúdo}

1 Introdução 1

1.1 As Proteínas. . . . . . . . . . . . . . . . 8

1.1 .1 Os Aminoácidos . . . . . . . . . . . . . . . . 8

1.1.2 Estruturas das Proteínas _. . . . . . . . . . . 10

1.1 .3 As Lectinas . . . . . . . . . . . . . . . . 10

1.1.4 A Frutalina e a Jacalina . . . . . . . . . . . . . . . . . 11

1.2 Os Carboidratos aqui Selecionados ................ 11

2 Metodologia $\quad 15$

2.1 Teoria do Funcional da Densidade . . . . . . . . . . . . 16

2.1.1 Fundamentos para o tratamento da função de onda . . . . . . 18

2.2 Base de Ondas Planas . . . . . . . . . . . . . . . . . 20

2.3 Projector Augmented Wave . . . . . . . . . . . . . . . 21

2.3.1 Transformação da função de onda . . . . . . . . . . . . . . . 21

2.3.2 Valores Esperados . . . . . . . . . . . . . 25

2.3 .3 Densidade de Carga . . . . . . . . . . . . . . 27

2.3 .4 Energia Total . . . . . . . . . . . . . . . 28

2.3.5 O operador Hamiltoniano _. . . . . . . . . . . . 29

2.3.6 Aproximações Práticas Para a Metodologia PAW . . . . . . . 30

2.4 Dinâmica Molecular de Primeiros Princípios . . . . . . . . . . . . 31

2.4.1 Dinâmica Molecular de Car e Parrinello . . . . . . . . . . . . . 31

2.4.2 O controle da Adiabaticidade . . . . . . . . . . . . 33

2.4.3 Otimização da Função de Onda Através da Dinâmica Molecular Car-Parrinello . . . . . . . . . . . . . 34 
2.5 Funcional de Troca e Correlação . . . . . . . . . . . . . . 35

2.6 Outros Códigos Computacionais Utilizados . . . . . . . . . . . 36

3 Resultados e Discussão $\quad 39$

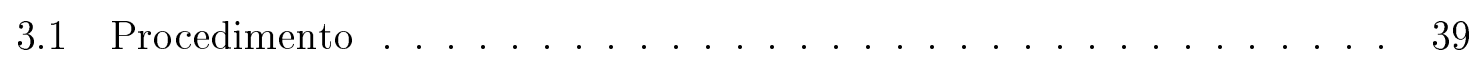

3.2 Estudo dos modelos cristalográficos . . . . . . . . . . . . . . 40

3.3 Inserção dos Carboidratos na Proteína . . . . . . . . . . . . . . . 41

3.3.1 Docking Molecular ................. 41

3.3 .2 Mecânica Molecular . . . . . . . . . . . . . . . 43

3.4 Recorte do Sítio Ativo . . . . . . . . . . . . . . . 44

3.5 Estrutura Eletrônica . . . . . . . . . . . . . . . 50

3.6 Absorção UV/Vis . . . . . . . . . . . . . . . . . . 50

3.7 Energias de Ligação . . . . . . . . . . . . . . . . . . 53

3.8 Densidade Eletrônica . . . . . . . . . . . . . . . . . 57

3.9 Densidade de Estados . . . . . . . . . . . . . . . . . . 64

3.10 Propriedades Eletrônicas na Região de Energia Interna . . . . . . . . 66

4 Conclusões $\quad 71$

A Modelo Clássico para a Interação Lectina-Carboidrato $\quad 73$

B O Algoritmo de Verlet para a Dinâmica Molecular $\quad 75$

$\begin{array}{ll}\text { C Espectro UV/Vis } & 77\end{array}$

$\begin{array}{ll}\text { D DOS Projetadas } & 79\end{array}$

E DOS Projetadas nas ligações de Hidrogênio $\quad 81$

$\begin{array}{lr}\text { Bibliografia } & 83\end{array}$ 


\section{Lista de Figuras}

1.1 Aminoácidos essenciais para o corpo humano. As abreviações usuais para cada aminoácido estão entre parênteses. . . . . . . . . . . 9 9

1.2 Representação cartoon da Estrutura cristalográfica de Raios-X para a Jacalina: (a) isolada; (b) evidenciando os quatro sítios ativos e exemplificando como um carboidrato pode estar inserido neles. . . . . . . . 12

1.3 Conformações anoméricas para o carboidrato glucopiranose. . . . . . . 13

1.4 Ilustração dos 4 carboidratos selecionados para os estudos das propriedades eletrônicas e estruturais no presente trabalho. Os átomos de carbono, hidrogênio e oxigênio são representados pelas cores verde, branca e vermelha respectivamente. . . . . . . . . . . . . 14

3.1 Superposição cristalográfica das estruturas 1JAC, 1TP8,1UGW e 1WS4. As cores distintas representam as diferentes estruturas obtidas segundo a literatura. (a) Representação dos monômeros cristalográficos considerando apenas os carbonos $\alpha$.(b)Representação dos monômeros considerando a estrutura completa. . . . . . . . . . . .

3.2 Posições atômicas da proteína antes e após a otimização de geometria para os diferentes carboidratos. Os traços azuis representam os carbonos, e suas ligações, antes da otimização de geometria e os traços em laranja representam os carbonos, e suas ligações, após a otimização de geometria. Os átomos de hidrogênio e oxigênio são representados pelas cores branca e vermelha respectivamente. . . . . . . . . . . .

3.3 Modelo 1 em duas representações distintas: (a) no formato de traços representando ligações químicas e (b) no formato de esferas atômicas evidenciando o sítio ativo. . . . . . . . . . . . . . . . 47

3.4 Modelo 2 no formato de traços representando ligações químicas. . . . . 48

3.5 Modelo 3 em duas representações distintas: (a) no formato de traços representando ligações químicas e (b) no formato de esferas atômicas evidenciando o sítio ativo. . . . . . . . . . . . . . 
3.6 Resultados obtidos para absorção UV e exemplo visual respectivamente para: (a) e (b) Modelo 1; (c) e (d) Modelo 2; (e) e (f) Modelo 3. Repetimos os resultados experimentais em todos os gráficos por motivos de clareza. . . . . . . . . . . . . . . . . . . . 52

3.7 Isosuperfície de densidade eletrônica HOMO e LUMO do sítio ativo ligada à GAL obtida utilizando o modelo 2. . . . . . . . . . . . . . . 59

3.8 Isosuperfície de densidade eletrônica HOMO e LUMO do sítio ativo ligada à GAL obtida utilizando o modelo 2. . . . . . . . . . . . . . 60

3.9 Isosuperfície de densidade eletrônica HOMO e LUMO do sítio ativo ligada à GAL obtida utilizando o modelo 2. . . . . . . . . . . . . . . . 61

3.10 Isosuperfície de densidade eletrônica HOMO e LUMO do sítio ativo ligada à GAL obtida utilizando o modelo 2. . . . . . . . . . . . . 62

3.11 Isosuperfície de densidade eletrônica HOMO e LUMO do sítio ativo ligada à GAL obtida utilizando o modelo 1. . . . . . . . . . . 63

3.12 Densidades de estados para os sistemas GAL, AMG, MMA e GYP utilizando o modelo 2. Traços em vermelho representam a contribuição dos carboidratos e traços pretos representam as DOS totais. As energias HOMO e LUMO estão indicas por traços pontilhados em cada

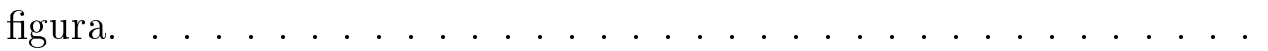

3.13 DOS projetadas sobre a GAL (traço vermelho), Asp125 (traço verde), Gly1 (traço azul) e os outros aminoácidos (traço preto) utilizando o modelo 2. As energias HOMO e LUMO estão indicas por traços pontilhados verticais. . . . . . . . . . . . . .

3.14 DOS projetada sobre a GAL utilizando o modelo 2. Os traços em preto e vermelho representam a contribuição total e projeção na GAL respectivamente. Os níveis de energia obtidos pelo CP-PAW estão indicados pelos traços azuis na figura. . . . . . . . . . . . . . .

3.15 Densidade eletrônica do sítio ativo ligado com a GAL obtido utilizando o modelo 2. O índices das figuras são os autovalores de KS. . . . . . . 68

3.16 DOS projetadas sobre os $\mathbf{O}$ do carboidrato e sobre os $\mathbf{H}$ do sítio ativo que são responsáveis pela formação das ligações de hidrogênio no sistema GAL. ......................... 70

C.1 Resultados obtidos para Absorção UV/Vis para o Modelo 2 em uma outra escala. . . . . . . . . . . . . . . . . 77 
D.1 DOS projetadas sobre a AMG (traço vermelho), Asp125 (traço verde), Gly1 (traço azul) e os outros aminoácidos (traço preto) utilizando o modelo 2. As energias HOMO e LUMO estão indicadas por traços pontilhados verticais. . . . . . . . . . . . . . . 79

D.2 DOS projetadas sobre a GYP (traço vermelho), Asp125 (traço verde), Gly1 (traço azul) e os outros aminoácidos (traço preto) utilizando o modelo 2. As energias HOMO e LUMO estão indicadas por traços pontilhados verticais. . . . . . . . . . . . . . 80

D.3 DOS projetadas sobre a MMA (traço vermelho), Asp125 (traço verde), Gly1 (traço azul) e os outros aminoácidos (traço preto) utilizando o modelo 2. As energias HOMO e LUMO estão indicadas por traços pontilhados verticais.

E.1 DOS projetadas sobre os $\mathbf{O}$ do carboidrato e sobre os $\mathbf{H}$ do sítio ativo que são responsáveis pela formação das ligações de hidrogênio no sistema AMG. ..................... 81

E.2 DOS projetadas sobre os $\mathbf{O}$ do carboidrato e sobre os $\mathbf{H}$ do sítio ativo que são responsáveis pela formação das ligações de hidrogênio no sistema

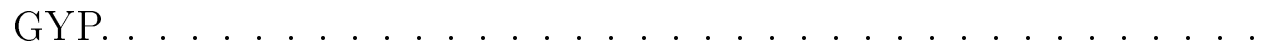

E.3 DOS projetadas sobre os $\mathbf{O}$ do carboidrato e sobre os $\mathbf{H}$ do sítio ativo que são responsáveis pela formação das ligações de hidrogênio no sistema MMA. 



\section{Capítulo 1}

\section{Introdução}

As lectinas compõem um vasto grupo de proteínas ligantes de carboidratos, que são largamente encontradas na natureza, incluindo plantas, animais e micro-organismos Quando extraída de plantas, as lectinas são obtidas em grandes quantidades e são largamente utilizadas como ferramentas para a investigação dos aspectos estruturais e funcionais do sistema biológico. Adotamos a referência [1] como principal fonte para elucidar o tema tanto sob o ponto de vista teórico como experimental, visto que é uma revisão da literatura bastante recente.

Nas últimas décadas, o interesse pelas interações entre lectinas e carboidratos tem aumentado consideravelmente. Este tipo de interação foi inicialmente negligenciado em favor da investigação de sequências de peptídeos, proteínas, DNA e outras interações análogas. Isto aconteceu porque os aminoácidos e nucleotídeos podem ser considerados como as primeiras letras do alfabeto da vida e a informação sobre qualquer organismo deveria ser, supostamente, encontrada nos oligômeros, polímeros de aminoácidos e nucleotídeos. Entretanto, por causa das muitas conformações monoméricas entre os açúcares, os carboidratos possuem um elevado potencial para armazenar ou transcrever informações assim como os nucleotídeos e aminoácidos [2], desta forma, em muitos processos biológicos são as interações proteína-carboidrato que desempenham o papel fundamental. Levando em conta as diferentes conformações dos carboidratos simples é possível aumentar ainda mais as informações biológicas que podem vir a ser utilizadas.

Do ponto de vista farmacêutico, as interações entre carboidratos e lectinas são interessantes já que podem ser aplicadas para melhorar os mecanismos de Drug De- 
livery. Com respeito à Drug Delivery na forma oral, as lectinas ostentam promessas como bioadesivos específicos de segunda geração [3]. Dada uma especificidade apropriada, os bioadesivos podem ser ligados com maior probabilidade em regiões glicosiladas de interesse dentro do organismo, o que pode ser realizado através do desenvolvimento de funcionalizações para transformar as lectinas em carreadoras de drogas avançadas, por exemplo, funcionalização com nanopartículas, lipossomos, etc. Este tipo de aplicação pode ser particularmente interessante para a entrega de produtos biológicos macromoleculares (por exemplo, peptídeos, proteínas, agentes inibidores ou genes plasmídios) através das barreiras biológicas entre o sítio ativo de ação e o sítio ativo de administração da droga. Além disso, por causa de sua capacidade de se ligar na membrana celular, as lectinas bioadesivas também podem transportar drogas para as células por processos vesiculares. Comparada com alguns conhecidos receptores e transportadores, como a vitamina B12 ou a transferrina, as lectinas exibem menor versatilidade com relação ao número de ligantes, entretanto, este fato pode ser compensado pela sua alta capacidade de ligação. Esta característica pode ser importante se considerarmos a entrega de significantes quantidades de um composto bioativo através de barreiras epiteliais. As lectinas não atuam simplesmente como bioadesivos na membrana celular, elas também informam sinais biológicos às células ativando o processo de endocitose e outras rotinas intracelulares. Outro detalhe importante é que o potencial adesivo das lectinas não está restrito à administração oral, podendo ser usada em outras locais como, por exemplo, nos olhos.

Podemos encontrar na literatura uma grande variedade de lectinas capazes de manter sua atividade de ligação após ter passado pelo sistema gastrointestinal, sendo que os efeitos das lectinas em organismos de ratos são muito bem documentados [4].

Culturas em células demonstram que as lectinas podem ser proliferativas, antiproliferativas ou tóxicas, dependendo da concentração. Do um modo geral, efeitos colaterais costumam ser muito graves e imprevisíveis, o que é indesejável em novas drogas. Sendo assim, é importante investigar a existência de moléculas que não possuam os aspectos negativos das lectinas mas que mantenham as suas propriedades, tais como a alta afinidade por açúcares. Estes miméticos de lectinas podem, então, ser utilizados na criação de novos fármacos ou sistemas transportadores de drogas. Além disso, se o caminho dentro de uma célula depende das propriedades da lectina, miméticos de lectinas com a mesma especificidade podem ser adaptados para distintos 
compartimentos celulares. Focalizando o desenvolvimento para as distintas rotas de transporte intracelulares, um mimético de lectina pode induzir o transporte intracelular de drogas, enquanto outro mimético de lectina com a mesma especificidade, mas com diferentes propriedades, pode induzir a absorção pelo endossomo ${ }^{1}$.

Com base na sua estrutura, as lectinas podem ser divididas em quatro tipos básicos distintos: Merolectinas, Hololectinas, Quimerolectinas e Superlectinas. As Merolectinas são compostas por apenas um sítio ativo de ligação de carboidratos, enquanto que as Hololectinas possuem dois ou mais sítios ativos de ligação de carboidrato; as Quimerolectinas consistem em um domínio de ligação de carboidrato e outro domínio que não se liga a açúcares mas é possivelmente responsável por outras funções moleculares; as Superlectinas são proteínas de fusão que possuem dois ou mais domínios de ligação de carboidrato que reconhecem açúcares estruturalmente independentes. Em 2002, houve uma ampliação do termo Superlectina para Multilectina [5], quando os sítios ativos são idênticos mas capazes de se ligar a diferentes carboidratos. Este é o caso da Jacalina (lectina de sementes Artocarpus integrifolia [6]) e da Frutalina (lectina de sementes de Artocarpus incisa [7]), que são as proteínas que escolhemos para estudar, neste trabalho, a interação com carboidratos. Hololectinas, Superlectinas, dímeros e oligômeros de lectinas possuem mais de um sítio de ligação de carboidratos e, portanto, podem interagir com mais de um receptor simultaneamente. Da mesma forma, se a lectina está vinculada a uma superfície transportadora de drogas, cada lectina pode interagir com um ou mais moléculas ligantes. Além dos principais locais de ligação (com uma afinidade ligação relativamente elevada) as lectinas podem possuir outros sítios de ligação menores. Finalmente, a maioria das lectinas é grande o suficiente para estabelecer fortes interações proteína-proteína, o que pode aumentar ainda mais a complexidade da interação lectina-célula.

A precisa modelagem de todos os passos do complexo processo de ligação entre células e lectinas é extremamente difícil. Assim, a maioria das abordagens se concentra sobre o evento-chave da interação lectina-célula e a interação lectina-açúcar têm sido amplamente estudada através de várias técnicas experimentais e ferramentas computacionais.

\footnotetext{
${ }^{1}$ Endossomos são organelas com várias formas, localizados entre o complexo de Golgi e a membrana plasmática. Os endossomos são responsáveis pelo transporte e digestão de partículas e macromoléculas que são captadas pela célula por processos conhecidos como endocitose.
} 
Segundo a literatura, a termodinâmica da interação lectina-carboidrato é governada por fatores entálpicos e entrópicos. As interações lectina-carboidratos fornecem as principais contribuições para a entalpia de ligação, enquanto que as interações dos tipos lectina-solvente e carboidrato-solvente fornecem parcelas de contribuições que variam de acordo com o sistema estudado. De acordo com a referência [8], a organização do solvente pode variar entre $25 \%$ a $100 \%$ da entalpia de ligação.

Em solução, perto do mínimo de energia conformacional, é possível que as geometrias dos carboidratos ligados apresentem grandes alterações conformacionais comparadas às geometrias preferenciais em estado solvente. Portanto, a entalpia de um carboidrato ligado pode diferir da entalpia do mesmo em estado isolado. Também existe um decréscimo na entropia devido à redução da mobilidade e flexibilidade dos carboidratos quando estes se ligam no sítio ativo. Esta perda na entropia compensa a entalpia de ligação e alguns autores sugerem uma correlação linear entre entropia e a entalpia, sendo um fenômeno conhecido como "compensação entalpia/entropia" que vem sendo discutido controvertidamente na literatura [9-11].

Um complexo lectina-carboidrato não possui uma única conformação estrutural. Uma vez que o complexo é formado, as posições das moléculas podem mudar, isto é, o carboidrato pode se mover dentro do sítio ativo, as cadeias secundárias dos carboidratos podem rotacionar e também, o carboidrato pode eventualmente deixar o sítio ativo e interagir com outras partes da proteína. Assim, um conjunto de estados contribui para a medida macroscópica termodinâmica observável, fato este que não pode ser descrito corretamente apenas por uma estrutura, muito menos para complexos com baixa afinidade de ligação. Para complicar ainda mais este problema, a energia livre entre o açúcar e a lectina pode depender do $\mathrm{pH}$, força iônica ou presença de íons livres.

As interações entre as proteínas e os carboidratos têm sido obtidas através de diversas técnicas experimentais que são: Cristalografia de Raios-X, Microcalorimetria ITC e Espectroscopia UV/Vis. Mencionaremos brevemente algumas características importantes destas técnicas relacionadas ao presente estudo.

a) cristalografia de raios-X é um dos métodos padrões para determinar a estrutura proteica. O requisito principal, e também a principal limitação da técnica, é a cristalização da lectina com o complexo ligante que são então submetidos à 
radiação de raios-X. O resultado do padrão de difração é então registrado e inicia-se um processo computacional para reconstrução da estrutura tridimensional da proteína, usualmente com uma resolução espacial dada em termos do desvio quadrático médio (Root Mean Square Deviation - RMSD) nas coordenadas entre 1.5 Ae $2.5 \AA$. Os hidrogênios usualmente não são observados através da cristalografia devido a sua baixa densidade eletrônica. As estruturas tridimensionais de um grande número de lectinas foram determinadas por difração de raios-X e fornecem importantes informações sobre a estrutura geral das lectinas e também sobre a estrutura e a função do sítio de ligação. A comparação direta entre as estruturas é particularmente reveladora, pois permite uma avaliação direta da flexibilidade dos resíduos envolvidos na ligação. A posição do ligante com relação a estas cadeias laterais fornecem informações precisas sobre a presença de ligações de hidrogênio, a exposição a solventes orgânicos e moléculas de águas relevantes para a interação. A análise destas estruturas e as correlações entre as interações termodinâmicas ocorridas com as ligações permitem uma melhor compreensão das forças motrizes do processo de ligação [8], entretanto, não fornecem nenhuma informação a respeito dos aspectos quânticos das interações.

b) A Microcalorimetria ITC é um método padrão para determinar as constantes de ligação $\left(K_{a}\right)$ e variações na entalpias de ligação $(\Delta H)$, bem como o número de sítios de ligação para uma dada lectina. O termo ITC se refere a Isotermal Titration Calorimetry, sendo uma técnica aplicada principalmente para investigar a termodinâmica das interações lectina-carboidrato. Uma solução com lectina é titulada durante o experimento pela adição de pequenas quantidades de ligante até a sua saturação, onde o calor absorvido ou produzido durante o processo está sendo registrado. A análise do resultado é dada pela curva de titulação obtida de onde se extrai um conjunto de parâmetros termodinâmicos. A variação de entalpia $\Delta H$ e constante de ligação $K_{a}$ são quantidades diretamente acessíveis no experimento. Outras quantidades são obtidas a partir de $\Delta H$ e $K_{a}$, como a energia livre de Gibbs que é usualmente modelada através de um ajuste na curva de titulação dada pela equação: $\Delta G=-R T \ln K_{a}$ ( $\mathrm{T}$ é a temperatura do experimento e $\mathrm{R}$ é uma constante de gás). A variação de entropia $\Delta S$ segue imediatamente da relação de Gibbs-Helmholtz: $\Delta G=\Delta H-T \Delta S$. Uma revisão bastante detalhada desta técnica pode ser encontrada na referência [12]. 
c) A espectroscopia ultravioleta/visível (UV/Vis) se refere à espectroscopia de absorção na região do ultravioleta-visível do espectro eletromagnético. A principal característica deste tipo de experimento está na frequência utilizada, pois permite investigar diretamente as transições eletrônicas. Para experimentos considerando interações lectina-carboidrato os resultados de absorção fornecem poucas informações, uma vez que grande parte da contribuição se deve ao aminoácido triptofano, aliada ao fato de que a presença dos carboidratos não altera significativamente o espectro [13].

Os modelos computacionais da interação lectina-carboidrato requerem uma boa descrição da estrutura do complexo e também uma predição correta dos seus parâmetros termodinâmicos. Um breve resumo de um modelo clássico para a interação proteína-carboidrato pode ser encontrado no Apêndice A. Nota-se entretanto que, até o momento, não encontramos nenhum trabalho que utilizasse uma metodologia similar para estudar a energia de ligação que é proposta nesta dissertação.

Existem muitos trabalhos que estudam a interação lectina-carboidrato utilizando dinâmica molecular de forma qualitativa. Estes estudos se concentram na formação de ligações de hidrogênio e moléculas de água que interagem com a lectina e o carboidrato [14-17]. Com o avanço da metodologia na área, alguns autores também realizaram estudos quantitativos. Neste caso, comparam a entalpia de ligação, onde

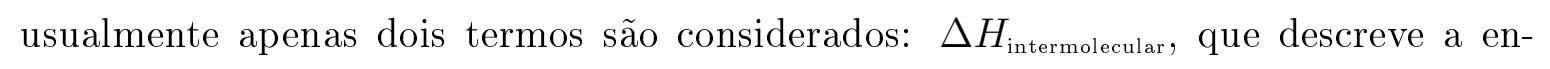
talpia de ligação entre lectina e carboidrato e $\Delta H_{\text {conformacional,c }}$, que define as alterações na conformação do carboidrato após a ligação no sítio ativo. Para uma breve ideia dos resultados obtidos com esta metodologia, vamos avaliar um exemplo da literatura: o estudo da lectina Concanavalina A (Con A), na referência [18], utilizando o campo de força AMBER 4.0 e os parâmetros GLYCAM93 para os carboidratos. A entalpia

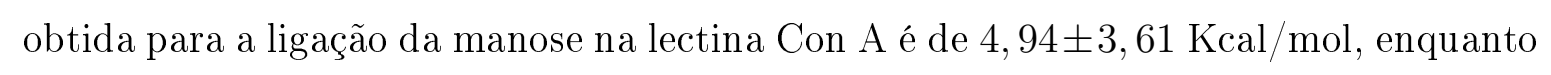
os resultados experimentais para o mesmo sistema é de 2, $65 \mathrm{Kcal} / \mathrm{mol}$ [19]. Após uma série de estudos, os autores concluíram que este resultado pode ser melhorado se forem calculadas simulações acima de 500ps e com campos de força mais sofisticados. Uma compilação destes resultados a respeito de simulações utilizando dinâmica molecular podem ser vistos na referência [1].

Um outro método de baixo custo computacional que é capaz de predizer as in- 
terações receptor-ligante é o docking molecular. Esta metodologia busca uma posição do ligante no sítio ativo dentro do espaço conformacional disponível. Após este procedimento, as melhores geometrias resultantes passam pelo processo de otimização de geometria através de mecânica molecular onde é considerada a conformação que apresente a menor energia. Usualmente, a influência do solvente é ignorada ou considerada implicitamente através de uma constante dielétrica. O sítio ativo da proteína é considerado rígido, sendo assim o ligante pode não varrer todo o espaço conformacional possível, portanto, pode não descrever o comportamento correto do complexo lectina-carboidrato. Ainda assim, os resultados fornecem informações satisfatórias entre o carboidrato e os resíduos das lectinas que contribuem para a entalpia de ligação, permitindo assim, classificar os ligantes de acordo com dados experimentais [1].

Dentro deste cenário, combinando as técnicas experimentais e as técnicas clássicas aqui apresentadas, propomos no presente trabalho uma nova metodologia para estudar a interação lectina-carboidrato num modelo que fornece as informações quânticas do sistema. Os dados cristalográficos servem como base para a descrição estrutural da lectina, apresentando assim as possíveis conformações e graus de liberdade da proteína. A espectroscopia UV/Vis fornece resultados que podem ser comparados aos resultados obtidos com as técnicas quânticas, fornecendo assim uma descrição das transições eletrônicas do sistema. Utilizamos também dados de microcalorimetria para avaliar e propor uma forma de se obter entalpia de ligação $\Delta H_{\text {intermolecular }}$ utilizando um método ab initio. As ferramentas computacionais clássicas servem como base para preparar o sistema, inserindo o carboidrato dentro da proteína e ajustando todo o espaço conformacional para que a descrição quântica seja possível dentro do modelo proposto.

Uma vez definidas as posições ocupadas pelos átomos, sabemos hoje que cálculos bastante precisos da mecânica quântica podem ser utilizados. Nosso objetivo aqui não é esgotar o assunto, mas fornecer uma importante contribuição para a avaliação da interação proteína-carboidrato utilizando cálculos de estrutura eletrônica ab initio dentro da Teoria do Funcional da Densidade (DFT).

As próximas seções da introdução tem por objetivo esclarecer algumas nomenclaturas e definições utilizadas neste trabalho que estão vinculadas ao conhecimento de bioquímica. 


\subsection{As Proteínas}

As proteínas são materiais orgânicos de estrutura complexa e massa molecular elevada (estimativa entre 5.000 a 1.000 .000 ou mais unidades de massa atômica) que desempenham inúmeras funções nas células de todos os seres vivos. Elas representam também cerca de $50 \%$ a $80 \%$ do peso seco da célula, sendo o composto orgânico mais abundante presente na matéria viva [20]. Existem muitas espécies diferentes de proteínas, sendo cada uma destas especializada numa dada função biológica. Em geral, uma proteína é caracterizada por um conjunto de no mínimo 100 aminoácidos, mas sabe-se que uma proteína possui muito mais que essa quantidade, sendo os conjuntos menores denominados Polipeptídios.

Dentro do contexto de alimentação dos seres humanos é possível distinguir proteínas de origem vegetal e de origem animal. As proteínas de origem animal estão presentes nos ovos, lácteos em geral, carnes e peixes; as de origem vegetal podem ser encontradas em abundância nas frutas secas, na soja, nos legumes, nos cogumelos e em alguns tipos de cereais.

\subsubsection{Os Aminoácidos}

Existem cerca de 300 tipos de aminoácidos, aproximadamente, porém somente 20 são utilizados no organismo humano, sendo denominados aminoácidos primários [20]. Entretanto, os seres humanos não são capazes de sintetizar nenhum aminoácido que devem ser então fornecidos através de uma dieta alimentar. Os aminoácidos são compostos quaternários formados principalmente por carbono $(\mathrm{C})$, hidrogênio $(\mathrm{H})$, oxigênio (O) e nitrogênio $(\mathrm{N})$. A representação dos aminoácidos é apresentadas na Figura 1.1 
<smiles>CC(N)C(=O)OC(=N)NCCCC(N)C(=O)O</smiles>
(a) Alanina
(b) Arginina (R)(Arg)
(c) Asparagina (N)(Asn) (d) Aspartato (D)(Asp)

(A) (Ala)<smiles>NC(CS)C(=O)O</smiles><smiles>NCC(=O)O</smiles>
(e) Cisteína
(C) (Cys)
(f) Fenilalanina $(\mathrm{F})(\mathrm{Phe})$
(g) Glicina
(h) Glutamato (E)(Glu)<smiles>NC(=O)CCC(N)C(=O)O</smiles><smiles>CCC(C)C(N)C(=O)O</smiles><smiles>CC(C)CC(N)C(=O)O</smiles>

(i) Glutamina $(\mathrm{Q})(\mathrm{Gln})$

(j) Histidina $(\mathrm{H})(\mathrm{His})$

(k) Isoleucina (I)(Ile)

(l) Leucina $(\mathrm{L})(\mathrm{Leu})$<smiles>CSCCC(N)C(=O)O</smiles>
(m) Lisina (K)(Lys)

(n) Metionina (M)(Met)
(o)
Prolina (p) Serina (S)(Ser) (P)(Pro)<smiles>CC(O)C(N)C(=O)O</smiles>

(q) Tirosina (Y)(Tyr) (r) Treonina (T)(Thr)<smiles>CC(C)C(N)C(=O)O</smiles>

(s) Triptofano (W)(Trp)

(t) Valina $(\mathrm{V})(\mathrm{Val})$

Figura 1.1: Aminoácidos essenciais para o corpo humano. As abreviações usuais para cada aminoácido estão entre parênteses. 


\subsubsection{Estruturas das Proteínas}

As proteínas são caracterizadas por quatro estruturas diferentes:

- Estrutura primária: formada pela seqüência de aminoácidos presentes na cadeia polipeptídica.

- Estrutura secundária: formada pelo arranjo espacial dos aminoácidos vizinhos de acordo com a sequência primária, podendo ser regulares ou irregulares. Os dois tipos de conformações espaciais regulares são chamados de $\alpha$-hélice e folha$\beta$.

- Estrutura terciária: resultante do enovelamento da $\alpha$-hélice ou da folha- $\beta$, sendo estabilizado por pontes de hidrogênio e pontes de enxofre. Este tipo de estrutura é responsável por fornecer atividade biológica às proteínas.

- Estrutura quaternária: é caracterizada quando duas ou mais cadeias polipeptídicas se combinam formando um novo arranjo tridimensional para exercer uma determinada função biológica.

\subsubsection{As Lectinas}

O termo lectina é referente a uma classe de proteínas ou glicoproteínas de origem não imunológica, geralmente sem atividade catalítica, que têm a habilidade de se ligar a carboidratos específicos expressos em superfícies celulares diferentes. As lectinas podem atuar como sítios de reconhecimento celular em muitos processos biológicos e estão presentes em todos os tipos de organismos, desde organismos complexos como humanos até vírus. Dependendo de sua estrutura, as lectinas ligam-se a esses carboidratos por um ou mais sítios de ligação de maneira rápida, seletiva e reversível. Também possuem a propriedade de aglutinar grupos sanguíneos. A aplicação das lectinas pode ser ampla e variada, como por exemplo, na investigação estrutural e funcional de carboidratos complexos, na observação de mudanças que ocorrem na superfície celular durante os processos fisiológicos e patológicos, desde a diferenciação celular ao câncer, na avaliação de toxicidade para células e animais, bem como no efeito imunossupressor in vivo. 


\subsubsection{A Frutalina e a Jacalina}

A Frutalina [7] e a Jacalina [6] que apresentam uma estrutura muito similar, diferindo apenas por três aminoácidos em sua estrutura primária, são derivadas das sementes Artocarpus incisa e Artocarpus integrifolia respectivamente. Estes aminoácidos distintos não estão presentes na região do sítio ativo da proteína, e, por este motivo, o presente estudo engloba simultaneamente as duas proteínas. Os esforços experimentais têm se concentrado no estudo da Frutalina, pois esta apresenta uma estabilidade superior sob efeitos físico-químicos [21]. Entretanto, como a Frutalina ainda não possui estrutura cristalográfica resolvida, extraímos estes dados da Jacalina uma vez que não é o escopo deste trabalho estudar propriedades físico-químicas, nos limitando apenas a entender a estrutura eletrônica e os mecanismos de ligação entre o sítio ativo da proteína e carboidratos.

\subsection{Os Carboidratos aqui Selecionados}

Os carboidratos são moléculas orgânicas conhecidas também como hidratos de carbono. Sua composição química consiste basicamente de 2 hidrogênios e 1 oxigênio para cada carbono [20]. Apesar de sua simplicidade, os carboidratos são as biomoléculas mais abundantes na natureza e participam na formação de estruturas de células e ácidos nucléicos importantes para o funcionamento cardiovascular e todo o sistema nervoso, além de ser a única fonte de energia aceita pelo cérebro. Os açúcares, como a glicose, a frutose e a sacarose são os carboidratos mais conhecidos, por causa da sua abundância em alimentos. Estes compreendem desde estruturas pequenas até macromoléculas, como a celulose e o amido, sendo caracterizados por unidades cetônicas $^{2}$. Por exemplo, podemos citar os monossacarídeos que são constituídos apenas por uma unidade cetônica. Os dissacarídeos são resultantes da união de dois monossacarídeos, por uma ligação denominada glicosídica, e, generalizando, a formação de polissacarídeos é dada pela união de monossacarídeos.

Particularmente, os carboidratos investigados em ligações com lectinas são he-

\footnotetext{
${ }^{2}$ As cetonas são compostos orgânicos caracterizados pela presença do grupamento $-C=O$, ligado a dois radicais orgânicos e apresentam uma fórmula geral $R_{1}-(C=O)-R_{2}$. $R_{1}$ e $R_{2}$ podem também estar unidos, nesse caso, compõem um ciclo (cetonas cíclicas)
} 


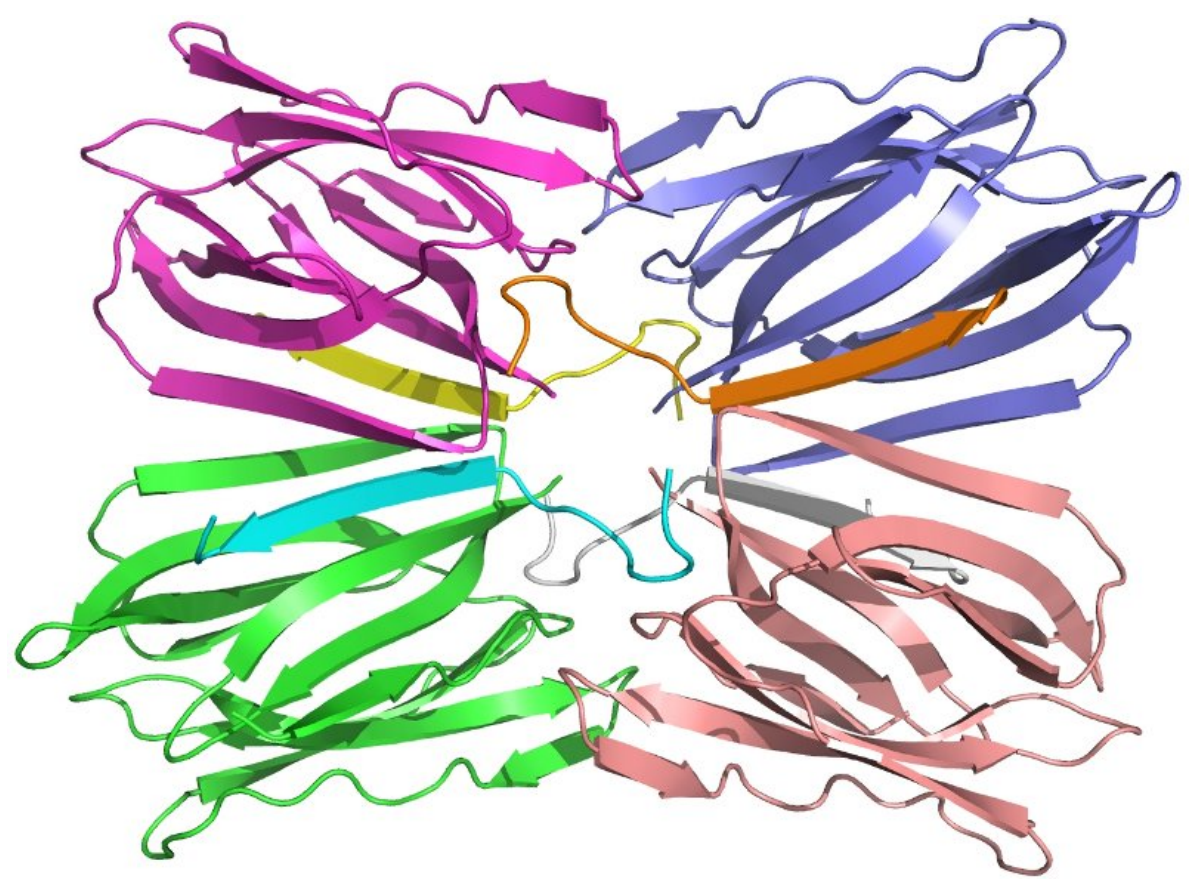

(a)

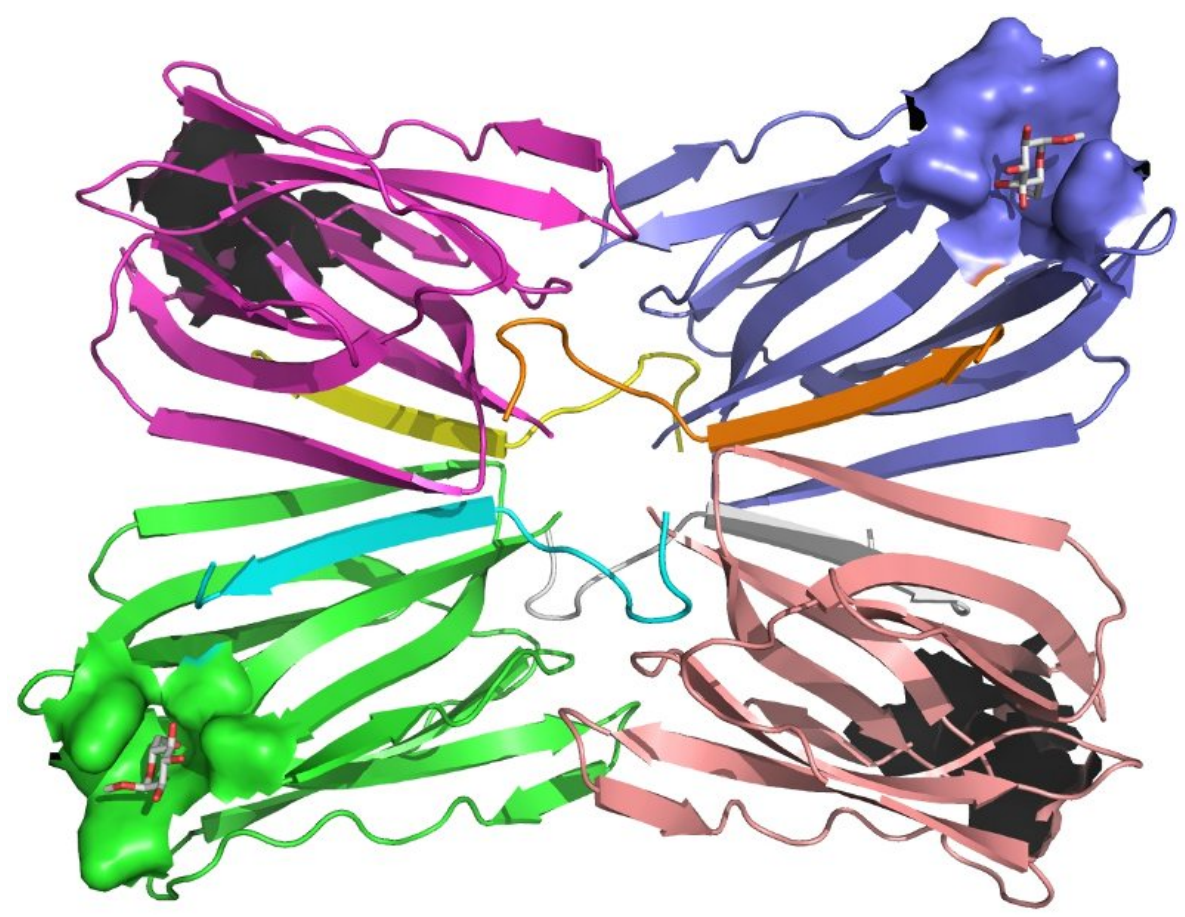

(b)

Figura 1.2: Representação cartoon da Estrutura cristalográfica de Raios-X para a Jacalina: (a) isolada; (b) evidenciando os quatro sítios ativos e exemplificando como um carboidrato pode estar inserido neles. 
xoses ou oligômeros de hexoses. Em solução, as hexoses estabelecem ligações intramoleculares resultando em anéis de seis átomos. Uma das conformações mais estáveis para estes anéis é a conformação cadeira. Este tipo de conformação pode ser formado através de dois caminhos diferentes, resultando em duas conformações distintas, $\alpha$ e $\beta$. Em muitos casos o anômero ${ }^{3} \alpha$ é mais estável que a conformação $\beta$, sendo este evento chamado de efeito anomérico. A Figura 1.3 apresenta uma imagem esquemática que exemplifica a diferença entre estas conformações.

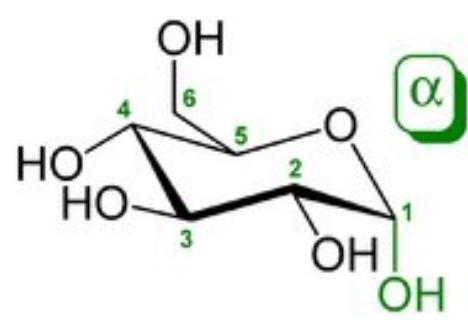

(a) $\alpha$-D-glucopiranose

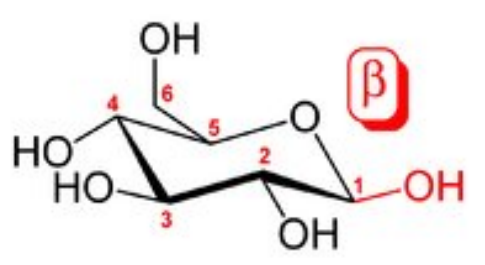

(b) $\beta$-D-glucopiranose

Figura 1.3: Conformações anoméricas para o carboidrato glucopiranose.

Em temperatura ambiente, os anômeros $\alpha$ e $\beta$ estão usualmente em um equilíbrio dinâmico na solução. A predominância anomérica depende do açúcar e do solvente. O efeito anomérico diminui com o crescimento da polarização do solvente, que pode tornar o anômero $\beta$ como forma predominante. Por causa das distintas conformações para um dado carboidrato e da baixa energia de ligação entre os carboidratos e proteínas, este tipo de estudo acaba se tornando tão difícil quanto a determinação da interação entre duas proteínas.

Na Figura 1.4 apresentamos os quatro carboidratos escolhidos a partir de resultados experimentais de microcalorimetria, para o presente trabalho: $\alpha$-metil-galactose (AMG), $\beta$-D-galactose (GAL), O1-metil-D-manose (MMA) e $\alpha$-metil-D-glucopiranose (GYP). Todos estes carboidratos apresentam uma fórmula química idêntica, com exceção da GAL, neste caso, a diferença está na ausência de um grupo metil. A única diferença entre AMG, MMA e GYP é a posição espacial do anel aromático central.

\footnotetext{
${ }^{3}$ Os anômeros são um tipo específico de isômeros que se diferem somente na configuração do carbono que vem do grupo carbonila do aldeído.
} 


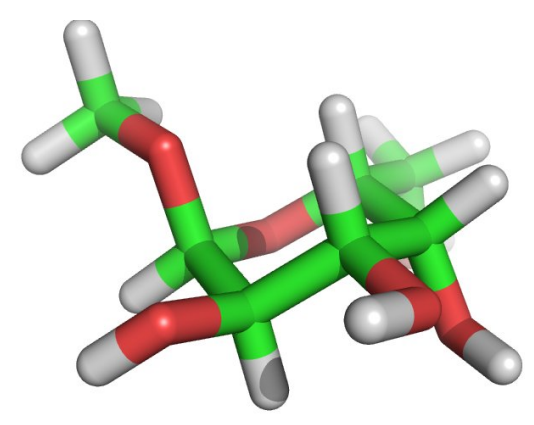

(a) $\alpha$-metil-D-galactose - $\mathrm{C}_{7} \mathrm{H}_{14} \mathrm{O}_{6}$

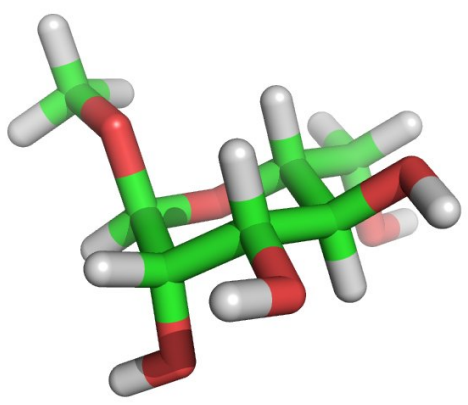

(c) O1-metil-D-manose - $\mathrm{C}_{7} \mathrm{H}_{14} \mathrm{O}_{6}$

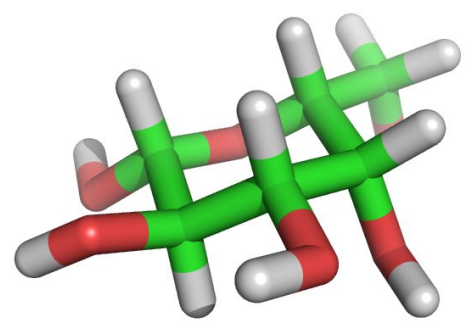

(b) $\beta$-D-galactose - $\mathrm{C}_{6} \mathrm{H}_{12} \mathrm{O}_{6}$

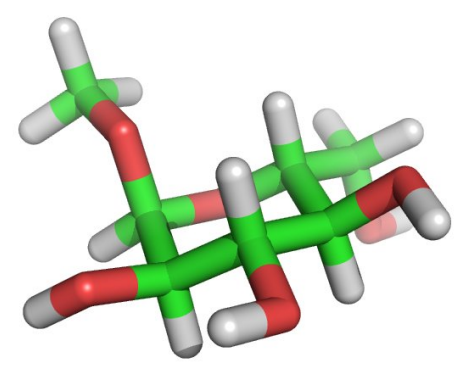

(d) $\alpha$-metil-D-glucopiranose $\mathrm{C}_{7} \mathrm{H}_{14} \mathrm{O}_{6}$

Figura 1.4: Ilustração dos 4 carboidratos selecionados para os estudos das propriedades eletrônicas e estruturais no presente trabalho. Os átomos de carbono, hidrogênio e oxigênio são representados pelas cores verde, branca e vermelha respectivamente. 


\section{Capítulo 2}

\section{Metodologia}

Há mais de 30 anos, a DFT têm sido o formalismo de mecânica quântica predominante para a descrição de sistemas periódicos entre a comunidade dos Físicos, e mais recentemente, têm sido também adotada pela comunidade de química quântica para tratar sistemas moleculares. Neste trabalho, utilizaremos a DFT aliada a métodos semi-empíricos, dinâmica molecular e docking molecular para investigar a estrutura eletrônica do sítio ativo da proteína e a sua interação com carboidratos.

O código computacional que utilizamos neste trabalho é o Car Parrinello - Projector Augmented Waves (CP-PAW), baseado no método PAW, desenvolvido em 1994 por Peter E. Bloechl [22] que é um método de mecânica quântica ab initio dentro da DFT. Este código propõem uma forma distinta para tratar a função de onda dentro do DFT combinando a dinâmica molecular quântica de Car e Parrinello [23]. Descreveremos neste capítulo de forma mais detalhada esta parte da metodologia.

O formalismo DFT apresentado neste capítulo obedece à separação de BornOppenheimer (BO), que trata separadamente os elétrons e os núcleos. Esta aproximação é baseada na diferença de massa entre os núcleos e os elétrons, considerando que os elétrons se movem muito mais rápido que os núcleos, onde uma aproximação bastante razoável é tratar os núcleos parados e analisar a configuração eletrônica de uma dada estrutura espacial atômica. Sendo assim, a função de onda é separada em dois componentes: eletrônica e nuclear. 


\subsection{Teoria do Funcional da Densidade}

Muitos métodos para resolver a equação de Shcroedinger têm sido desenvolvidos, visando sempre tentar resolver da melhor forma possível o problema de muitos corpos encontrado ao se juntar átomos para formar um dado sistema. Inicialmente a DFT foi desenvolvida por Hohenberg e Kohn [24], que propõem um mapeamento do problema de muitos corpos através da densidade de carga eletrônica. Seguiremos as referências [25, 26] para a descrição da DFT.

A DFT é uma das formulações mais populares e eficientes para o estudo da estrutura da matéria através de mecânica quântica. Atualmente esta teoria é confiável para calcular diversas grandezas e as aplicações, inicialmente apenas na Física, começaram a aparecer em outras áreas importantes como a Química e a Biologia.

Esta seção tem por objetivo apresentar a DFT na formalização do chamado esquema de Kohn e Sham (KS) [27], que vem sendo constantemente utilizada computacionalmente para investigar problemas de estrutura eletrônica. Podemos escrever na formulação proposta por KS o funcional da energia em função da densidade eletrônica $n(\vec{r})$ (por simplicidade, não consideramos aqui a polarização de spin e oimitiremos a dependência em $\vec{r}$ na notação) como a soma de três termos: energia cinética $T[n]$, interação com um potencial externo $V_{\text {ext }}[n]$ (em geral ocasionado pelos núcleos atômicos) e a interação elétron-elétron $V_{e e}[n]$

$$
E[n]=T[n]+V_{e x t}[n]+V_{e e}[n]
$$

Aqui a interação $V_{e x t}[n]$ tem a seguinte forma:

$$
V_{e x t}[n]=\int V_{e x t} n(\vec{r}) d \vec{r}
$$

Em 1965, Kohn e Sham propuseram o esquema de KS que transforma o complicado e insolúvel problema de muitos corpos em vários problemas de um corpo [27]. A ideia consiste em introduzir um sistema fictício de N elétrons não interagentes descritos por N funções de onda ( usualmente denotados por "orbitais") $\phi_{i}$. Neste sistema a energia cinética é dada por 


$$
T_{K S}[n]=-\frac{1}{2} \sum_{i}^{N}\left\langle\phi_{i}\left|\nabla^{2}\right| \phi_{i}\right\rangle
$$

O Sufixo "KS" enfatiza que esta não é a energia cinética real, mas é a energia correspondente de um sistema de elétrons não interagentes. A densidade eletrônica $n(\vec{r})$ dos orbitais é:

$$
n(\vec{r})=\sum_{i}^{N}\left|\phi_{i}\right|^{2}
$$

e a interação elétron-elétron é dada pela interação clássica de Coulomb (energia de Hartree no formalismo Hartree-Fock):

$$
V_{H}[n]=\frac{1}{2} \int \frac{n\left(\overrightarrow{r_{1}}\right) n\left(\overrightarrow{r_{1}}\right)}{\left|\overrightarrow{r_{1}}-\overrightarrow{r_{2}}\right|} d \overrightarrow{r_{1}} \overrightarrow{r_{2}}
$$

Utilizando as equações 2.3, 2.4 e 2.5 podemos reescrever o funcional da energia (2.1) da seguinte forma:

$$
E[n]=T_{K S}[n]+V_{e x t}[n]+V_{H}[n]+E_{x c}[n]
$$

Aqui introduzimos a energia de troca e correlação

$$
E_{x c}[n]=\left(T[n]-T_{K S}[n]\right)+\left(V_{e e}[n]-V_{H}[n]\right)
$$

para corrigir e levar em conta todos os efeitos de muitos corpos.

Escrevendo o funcional 2.6 explicitamente a partir da densidade eletrônica 2.4 e aplicando o teorema variacional [25] é possível encontrar os orbitais que minimizam a energia, que são os que satisfazem as equações:

$$
\left[-\frac{1}{2} \nabla^{2}+V_{e x t}(\vec{r})+\int \frac{n\left(\overrightarrow{r^{\prime}}\right)}{\left|\vec{r}-\overrightarrow{r^{\prime}}\right|} d \overrightarrow{r^{\prime}}+V_{x c}(\vec{r})\right] \phi_{i}(\vec{r})=\epsilon_{i} \phi_{i}(\vec{r})
$$

e 


$$
v_{x c}=\frac{\delta E_{x c}[n]}{\delta n}
$$

Onde introduzimos o potencial de troca e correlação $v_{x c}(\vec{r})$, que é a derivada da energia de troca e correlação com relação a densidade. Este conjunto de equações é conhecido como as equações de KS. Para o funcional de energia exato, e portanto o potencial exato, os "orbitais" produzem o estado fundamental exato da densidade através da equação 2.4 e o estado fundamental exato da energia através da equação 2.6 .

As equações KS possuem a mesma estrutura das equações de Hartree-Fock, ou de equações de Schrödinger para uma única partícula onde os efeitos de muitos corpos estão no potencial de troca e correlação $V_{x c}$. O esquema de KS para o DFT reduz o problema de $\mathrm{N}$ partículas interagentes para um sistema de $\mathrm{N}$ partículas não interagentes com um potencial de interação que pode ser obtido de forma auto consistente.

\subsubsection{Fundamentos para o tratamento da função de onda}

As equações de KS apresentadas neste capítulo representam um grande avanço para o tratamento ab initio de sistemas eletrônicos com muitos corpos. Entretanto, as soluções destas equações ainda apresentam uma série de dificuldade numéricas:

- A energia cinética dos elétrons é muito grande na região perto do núcleo atômico, resultando em oscilações rápidas da função de onda que exigem, por exemplo, numa usual expansão um grande número de ondas planas para uma descrição precisa desta região. Por outro lado, um pequeno conjunto de funções de onda compostas por combinações lineares de orbitais atômicos é suficiente para representar esta mesma região.

- Na região intersticial do átomo, onde ocorre a ligação química, a situação é completamente oposta. A energia cinética dos elétrons é pequena e a função de onda varia suavemente, entretanto, responde fortemente a qualquer alteração em sua vizinhança. Este tipo de ambiente requer um grande conjunto de combinações lineares de orbitais atômicos para ser satisfatoriamente descrito. 
Estas dificuldades apresentadas são abordadas por diversas estratégias, apresentando assim diferentes implementações do esquema de KS para o DFT de acordo com os diferentes tipos de expansões da função de onda. Diferentes tipos de tratamento são mais adequados aos diferentes sistemas e propriedades a serem estudadas, por exemplo: interações intermoleculares, parâmetros hiperfinos, magnetismo, caminhos de reação, interação entre cristal e moléculas, etc. Uma breve ideia das principais estratégias para tratamento da função de onda são apresentadas a seguir.

Uma estratégia comumente adotada pela comunidade de química quântica consiste em utilizar conjuntos de funções de base dados por combinações lineares de orbitais "tipo" atômicos (dados pelo produto de uma parte radial e uma parte angular). Estes conjuntos de bases exploram a boa descrição das regiões nucleares. A técnica mais comum para criação deste tipo de função de onda consiste em desenvolver conjunto de bases numericamente convenientes, como as funções Gaussianas, onde os erros apresentados na região intersticial são compensados ao aumentar o conjunto de funções de base.

A família de métodos dos "pseudopotenciais" de ondas planas truncam a função de onda nas proximidades do núcleo, onde a função de onda oscila abruptamente. A grande desvantagem desta metodologia é a perda de toda informação sobre a densidade de carga e a função de onda nas regiões próximas do núcleo.

A família de métodos "augmented waves" (ondas expandidas) utilizam uma base mista, composta por funções de onda orbitais "tipo" atômicos na região do núcleo e ondas planas, na região de ligação. Este tipo de tratamento gera soluções parciais, que são separadas de acordo com regiões centradas nos átomos, definindo as regiões atômicas e intersticiais. Após obter as soluções parciais nas diferentes regiões é necessário garantir as condições de continuidade da função de onda e de suas derivadas.

O método "Projector Augmented Waves" (PAW) combina métodos de ondas expandidas e métodos dos pseudopotenciais de ondas planas em um único método para tratamento da estrutura eletrônica. 


\subsection{Base de Ondas Planas}

Uma expansão de ondas planas para as funções de onda de KS é muito eficiente para calcular a energia total de sólidos e ainda possui a vantagem de ser periódica, reproduzindo assim um cristal. Para sistemas finitos, como átomos isolados, moléculas ou interfaces superfície/molécula expansão em ondas planas também podem ser utilizadas na aproximação de "super células" ou células unitárias aumentadas (LUC) ${ }^{1}$, utilizado no CP-PAW e que permite o estudo de sistemas moleculares carregados. No método das "super células", um sistema finito é colocado em uma célula unitária de um cristal, construída de forma grande o suficiente para que as imagens periódicas não interajam. As equações de KS são resolvidas no espaço recíproco, utilizando transformadas de Fourier. Adotaremos o padrão de unidade atômicas de Hartree para o desenvolvimento das equações $\left(\hbar=m_{e}=e=1\right)$. O Hamiltoniano de KS no espaço recíproco pode ser escrito como:

$$
\mathcal{H}_{\vec{G}, \vec{G}^{\prime}}(\vec{k})=\frac{1}{2}|\vec{k}+\vec{G}|^{2}+V_{H}\left(\vec{G}-\vec{G}^{\prime}\right)+V_{e x t}+V_{x c}\left(\vec{G}-\vec{G}^{\prime}\right)
$$

onde: $\vec{k}$

é o vetor da rede recíproca na $1^{a}$ zona de Brillouin; $\vec{G}$ e $\vec{G}^{\prime}$ são vetores de translação na rede reciproca; $\frac{1}{2}|\vec{k}+\vec{G}|^{2}$ é a energia cinética; $V_{H}\left(\vec{G}-\vec{G}^{\prime}\right)$ é o potencial de Hartree; $V_{\text {ext }}$ é potencial externo; $V_{x c}\left(\vec{G}-\vec{G}^{\prime}\right)$ é potencial de troca e correlação. Nesta descrição de base que adotamos, os orbitais de KS são descritos através de expansões de ondas planas:

$$
\phi_{k, n}(\vec{r})=e^{i \vec{k} \cdot \vec{r}} \sum_{G} c_{k, n}(\vec{G}) e^{i \vec{G} \cdot \vec{r}}
$$

onde: $n$ é o índice de bandas e $c_{k, n}$ são coeficientes de Fourier. A densidade de carga, no espaço real, utilizando as ondas planas é:

A utilização de LUC para sistemas moleculares se aplica, em princípio, apenas para sistemas de carga neutra, devido a interação de logo alcance existente entre moléculas carregadas nas imagens periódicas vizinhas. Algumas técnicas podem ser utilizadas para superar esta dificuldade, como o desacoplamento das imagens periódicas [22]. 


$$
n(\vec{r})=\sum_{\vec{k}, n} \sum_{\vec{G}, \vec{G}^{\prime}} f_{n} c_{\vec{k}, n}^{*} c_{\vec{k}, n} e^{i\left(\vec{G}-\vec{G}^{\prime}\right) \cdot \vec{r}}
$$

onde $f_{n}$ denota os números de ocupação eletrônica. A transformada de Fourier da densidade é

$$
n(\vec{G})=\sum_{\vec{k}, n} \sum_{\vec{G}^{\prime}} f_{n} c_{\vec{k}, n}^{*}\left(\vec{G}^{\prime}-\vec{G}\right) c_{\vec{k}, n}\left(\vec{G}^{\prime}\right)
$$

\subsection{Projector Augmented Wave}

\subsubsection{Transformação da função de onda}

O método PAW realiza uma transformação que mapeia as funções de onda de uma partícula no esquema de KS, com sua estrutura completa, em funções de onda auxiliares numericamente convenientes, buscando funções de ondas suaves que rapidamente convergem em uma expansão. Todas as seções referentes à metodologia PAW são baseadas nas referências $[22,28]$. Usaremos a notação $\left|\Psi_{n}\right\rangle$ para as funções de onda de uma partícula, e $\left|\tilde{\Psi}_{n}\right\rangle$ as funções de onda auxiliares (o símbolo $\sim$ será sempre aqui utilizado para denotar a base e operadores expressos na base auxiliar). O índice $n$ indexa todas as informações a respeito da função de onda, ponto- $k$, índice de banda e índice de spin. Em alguns momentos, trataremos a função de onda no espaço contínuo, nestes caso temos que $\left\langle\vec{r} \mid \Psi_{i}\right\rangle=\Psi_{i}(\vec{r})$, este formalismo será útil quando estivermos tratando regiões específicas dentro do conjunto de estados da base. Considere um operador $\mathcal{T}$ que transforma a função de onda real em uma função de onda que trata elétrons de valência:

$$
\left|\Psi_{n}\right\rangle=\mathcal{T}\left|\tilde{\Psi}_{n}\right\rangle
$$

A correspondente equação de Schrödinger de uma partícula fica:

$$
\mathcal{T}^{\dagger} \mathcal{H} \mathcal{T}\left|\tilde{\Psi}_{n}\right\rangle=\epsilon_{n} \mathcal{T}^{\dagger} \mathcal{T}\left|\tilde{\Psi}_{n}\right\rangle
$$


O operador Hamiltoniano agora é dado por, $\tilde{\mathcal{H}}=\mathcal{T}^{\dagger} \mathcal{H} \mathcal{T}$ e o operador de superposição por, $\tilde{\mathcal{O}}=\mathcal{T}^{\dagger} \mathcal{T}$. O valor esperado de qualquer operador $\mathcal{A}$ pode ser então escrito em termo das funções de onda originais ou das funções de onda auxiliares:

$$
\langle\mathcal{A}\rangle=\sum_{n} f_{n}\left\langle\Psi_{n}|\mathcal{A}| \Psi_{n}\right\rangle=\sum_{n} f_{n}\left\langle\tilde{\Psi}_{n}\left|\mathcal{T}^{\dagger} \mathcal{A} \mathcal{T}\right| \tilde{\Psi}_{n}\right\rangle
$$

Vamos agora definir o operador de transformação $\mathcal{T}$ que irá transformar a função de onda real em uma função de onda conveniente numericamente no método PAW. O operador irá dividir as funções de onda em duas: uma região próxima ao núcleo atômico (também chamada de região de "augmentation"), que definiremos como região atômica; outra região será chamada de valência. O raio de corte $r_{c, R}$ será responsável por separar estas regiões. Seja $\mathcal{T}$ um operador que descreva a função de onda suave na região atômica, resultando uma função de onda que expresse corretamente as características desta região. Para isso, adicionaremos um termo $\mathcal{S}_{R}$ que será responsável por corrigir as contribuições da região atômica:

$$
\mathcal{T}=1+\sum_{R} \mathcal{S}_{R}
$$

O índice $R$ representa uma dada região atômica.

Para todos os átomos presentes no sistema, $\mathcal{S}_{R}$ adiciona as diferenças entre a função de onda verdadeira e auxiliar. Para os termos presentes na região atômica, $\mathcal{S}_{R}$ é definido em termos da solução $\left|\phi_{i}\right\rangle$ da equação de Schrödinger para os respectivos átomos isolados. A função de onda na região atômica é representada por combinações lineares do conjunto de soluções apresentadas anteriormente:

$$
\Psi(\vec{r})=\sum_{i \in R} \phi_{i}(\vec{r}) c_{i} \quad \text { para } \quad|\vec{r}-\vec{R}|<r_{c, R}
$$

O coeficiente $c_{i}$ deve ser definido. O vetor $\vec{R}$ indica a posição do núcleo e o índice $i$ representa a posição $R$, o momento angular $(l, m)$ e também um índice que o diferencia das outras funções de onda parciais auxiliares. Dentro de $i \epsilon R$, indicaremos esta onda parcial pertencente ao sítio $R$. Aplicando o operador $\mathcal{T}$ para o conjunto de ondas auxiliares $\left|\phi_{i}\right\rangle$ temos: 


$$
\begin{aligned}
\left|\phi_{i}\right\rangle & =\left(1+\mathcal{S}_{R}\right)\left|\tilde{\phi}_{i}\right\rangle \quad \text { para } \quad \mathrm{i} \epsilon R \\
\mathcal{S}_{R}\left|\tilde{\phi}_{i}\right\rangle & =\left|\phi_{i}\right\rangle-\left|\tilde{\phi}_{i}\right\rangle
\end{aligned}
$$

A partir da equação 2.19, definimos a contribuição local de $\mathcal{S}_{R}$. Como o operador $\mathcal{T}$ age localmente apenas em uma região definida $r_{c, R}$, a função auxiliar $\left|\phi_{i}\right\rangle$ e a sua correspondente $\left|\tilde{\phi}_{i}\right\rangle$ devem se anular após a região local. Sendo assim, temos:

$$
\phi_{i}(\vec{r})=\tilde{\phi}_{i}(\vec{r}) \quad \text { para } \quad|\vec{r}-\vec{R}|>r_{c, R}
$$

Uma vez que o operador de transformação $\mathcal{T}$ deve ser linear, podemos definir então o coeficiente $c_{i}$ como um produto escalar:

$$
c_{i}=\left\langle\tilde{p}_{i} \mid \tilde{\Psi}\right\rangle
$$

Onde $\left\langle\tilde{p}_{i}\right|$ é definida como função projetora. Como não existe superposição entre as esferas das funções de onda auxiliares, a expansão de uma função de onda eletrônica auxiliar deve ser reduzida a ela mesma dentro da região definida por $r_{c, R}$, isto é:

$$
\left|\tilde{\Psi}_{i}\right\rangle=\sum_{i}\left|\tilde{\phi}_{i}\right\rangle\left\langle\tilde{p}_{i} \mid \tilde{\Psi}_{i}\right\rangle \quad \text { para } \quad|\vec{r}-\vec{R}|<r_{c, R}
$$

Portanto as funções projetoras e a função auxiliar devem satisfazer as relações:

$$
\sum_{i}\left|\tilde{\phi}_{i}\right\rangle\left\langle\tilde{p}_{i}\right|=1
$$

e

$$
\left\langle\tilde{p}_{i} \mid \tilde{\phi}_{j}\right\rangle=\delta_{i, j} \quad \text { para } \quad i, j \in R
$$

A função projetora deve ser ortonormal a função de onda auxiliar na região definida 
próxima ao núcleo. A forma mais geral da função projetora pode ser definida como

$$
\left\langle\tilde{p}_{i}\right|=\sum_{j}\left(\left\{\left\langle f_{k} \mid \tilde{\phi}_{i}\right\rangle\right\}\right)_{i, j}^{-1}\left\langle f_{j}\right|
$$

$\left|f_{j}\right\rangle$ é um conjunto de funções arbitrárias e linearmente independentes. Aplicando $\mathcal{S}_{R}$ em 2.23 temos:

$$
\mathcal{S}_{R}|\tilde{\Psi}\rangle=\sum_{i \in R} \mathcal{S}_{R}\left|\tilde{\phi}_{i}\right\rangle\left\langle\tilde{p}_{i} \mid \tilde{\Psi}\right\rangle=\sum_{i \in R}\left(\left|\phi_{i}\right\rangle-\left|\tilde{\phi}_{i}\right\rangle\right)\left\langle\tilde{p}_{i} \mid \tilde{\Psi}\right\rangle
$$

substituindo os resultados de 2.27 em 2.17, temos a forma final do operador de transformação $\mathcal{T}$ :

$$
\mathcal{T}=1+\sum_{i \in R}\left(\left|\phi_{i}\right\rangle-\left|\tilde{\phi}_{i}\right\rangle\right)\left\langle\tilde{p}_{i}\right|
$$

As funções de onda all electron de KS são:

$$
|\Psi\rangle=|\tilde{\Psi}\rangle+\sum_{i \in R}\left(\left|\phi_{i}\right\rangle-\left|\tilde{\phi}_{i}\right\rangle\right)\left\langle\tilde{p}_{i} \mid \tilde{\Psi}\right\rangle
$$

Esta função pode ser convenientemente escrita na forma:

$$
|\Psi\rangle=|\tilde{\Psi}\rangle+\sum_{i \in R}\left|\Psi_{R}^{1}\right\rangle-\left|\tilde{\Psi}_{R}^{1}\right\rangle
$$

onde

$$
\left|\Psi_{R}^{1}\right\rangle=\sum_{i \in R}\left|\phi_{i}\right\rangle\left\langle\tilde{p}_{i} \mid \tilde{\Psi}\right\rangle
$$

$\mathrm{e}$

$$
\left|\tilde{\Psi}_{R}^{1}\right\rangle=\sum_{i \in R}\left|\tilde{\phi}_{i}\right\rangle\left\langle\tilde{p}_{i} \mid \tilde{\Psi}\right\rangle
$$

A função de onda obtida tem por objetivo tratar todas as dificuldades da função de onda KS original, possuindo um comportamento compatível com as rápidas os- 
cilações nas regiões próximas do núcleo atômico e um comportamento suave na região intersticial. Ao decompor a equação 2.30, separamos a função de onda em funções de onda auxiliares que são suaves em qualquer região do espaço e uma parcela de contribuições que contém rápidas oscilações, entretanto, contribuem em uma pequena parte do espaço.

Em termos práticos, vamos definir conceitualmente o comportamento da função de onda 2.30:

- Quando $|\vec{r}-\vec{R}|>r_{c, R}$ a função de onda auxiliar é idêntica a função original, isto é, $\Psi(\vec{r})=\tilde{\Psi}(\vec{r})$

- Quando $|\vec{r}-\vec{R}|<r_{c, R}$ a função de onda auxiliar é idêntica a função de onda auxiliar de um centro, isto é: $\tilde{\Psi}(\vec{r})=\tilde{\Psi}_{R}^{1}(\vec{r})$. Então a função de onda real, $\Psi(\vec{r})$ é representada por $\Psi_{R}^{1}(\vec{r})$, formada por ondas parciais que descrevem corretamente as rápidas oscilações da função de onda próxima ao núcleo.

\subsubsection{Valores Esperados}

O valor esperado, equação 2.16, para um dado observável $\mathcal{A}$ dentro da chamda "aproximação de caroço congelado" é dado por:

$$
\langle\mathcal{A}\rangle=\sum_{n}^{\mathrm{N}_{\text {val }}} f_{n}\left\langle\Psi_{n}|\mathcal{A}| \Psi_{n}\right\rangle+\sum_{n}^{\mathrm{N}_{\text {core }}}\left\langle\phi_{n}^{c}|\mathcal{A}| \phi_{n}^{c}\right\rangle
$$

A função de onda foi dividida para representar os elétrons de valência $\left(\left|\Psi_{n}\right\rangle\right)$ obtidos após a solução da equação de Schrödinger para o sistema completo, e os elétrons de caroço $\left(\left|\phi_{n}^{c}\right\rangle\right)$ obtidos através de soluções para os átomos isolados.

Desenvolvendo $\langle\Psi|\mathcal{A}| \Psi\rangle$ encontramos a equação:

$$
\begin{aligned}
\langle\Psi|\mathcal{A}| \Psi\rangle & =\left\langle\tilde{\Psi}\left|\mathcal{T}^{\dagger} \mathcal{A} \mathcal{T}\right| \tilde{\Psi}\right\rangle \\
& =\left\langle\tilde{\Psi}+\sum_{R}\left(\Psi_{R}^{1}-\tilde{\Psi}_{R}^{1}\right)|\mathcal{A}| \tilde{\Psi}+\sum_{R^{\prime}}\left(\Psi_{R^{\prime}}^{1}-\tilde{\Psi}_{R^{\prime}}^{1}\right)\right\rangle \\
& =\left\{\langle\tilde{\Psi}|\mathcal{A}| \tilde{\Psi}\rangle+\sum_{R^{\prime}}\left\langle\tilde{\Psi}|\mathcal{A}|\left(\Psi_{R^{\prime}}^{1}-\tilde{\Psi}_{R^{\prime}}^{1}\right)\right\rangle+\sum_{R}\left\langle\left(\Psi_{R}^{1}-\tilde{\Psi}_{R}^{1}\right)|\mathcal{A}| \tilde{\Psi}\right\rangle\right.
\end{aligned}
$$




$$
\begin{aligned}
& \left.+\sum_{R, R^{\prime}}\left\langle\left(\Psi_{R}^{1}-\tilde{\Psi}_{R}^{1}\right)|\mathcal{A}|\left(\Psi_{R^{\prime}}^{1}-\tilde{\Psi}_{R^{\prime}}^{1}\right)\right\rangle\right\} \\
& =\left\{\langle\tilde{\Psi}|\mathcal{A}| \tilde{\Psi}\rangle+\sum_{R}\left(\left\langle\Psi_{R}^{1}|\mathcal{A}| \Psi_{R}^{1}\right\rangle-\left\langle\tilde{\Psi}_{R}^{1}|\mathcal{A}| \tilde{\Psi}_{R}^{1}\right\rangle\right)\right. \\
& +\sum_{R}\left(\left\langle\Psi_{R}^{1}-\tilde{\Psi}_{R}^{1}|\mathcal{A}| \tilde{\Psi}-\tilde{\Psi}_{R}^{1}\right\rangle+\left\langle\tilde{\Psi}^{-} \tilde{\Psi}_{R}^{1}|\mathcal{A}| \Psi_{R}^{1}-\tilde{\Psi}_{R}^{1}\right\rangle\right) \\
& \left.+\sum_{R \neq R^{\prime}}\left\langle\left(\Psi_{R}^{1}-\tilde{\Psi}_{R}^{1}\right)|\mathcal{A}|\left(\Psi_{R^{\prime}}^{1}-\tilde{\Psi}_{R^{\prime}}^{1}\right)\right\rangle\right\}
\end{aligned}
$$

A expressão 2.34 pode ser simplificada devido a ausência de contribuição para o caso de operadores locais. $\left|\Psi_{R}^{1}-\tilde{\Psi}_{R}^{1}\right\rangle$ é não nula quando $|\vec{r}-\vec{R}|<r_{c, R}$, enquanto $\mid \tilde{\Psi}-$ $\left.\tilde{\Psi}_{R}^{1}\right\rangle$ é não nula apenas quando $|\vec{r}-\vec{R}|>r_{c, R}$. O último termo da expressão corresponde a uma superposição entre 2 sítios diferentes, sendo automaticamente anulados pelo método PAW, onde não existe superposição das regiões de caroço.

A partir de 2.31, 2.32 e 2.34, podemos reescrever 2.33:

$$
\begin{aligned}
\langle\mathcal{A}\rangle & =\sum_{n}^{\mathrm{N}_{\text {val }}} f_{n}\left(\left\langle\tilde{\Psi}_{n}|\mathcal{A}| \tilde{\Psi}_{n}\right\rangle+\left\langle\Psi_{n}^{1}|\mathcal{A}| \Psi_{n}^{1}\right\rangle-\left\langle\tilde{\Psi}_{n}^{1}|\mathcal{A}| \tilde{\Psi}_{n}^{1}\right\rangle\right)+\sum_{n}^{\mathrm{N}_{\text {core }}}\left\langle\phi_{n}^{c}|\mathcal{A}| \phi_{n}^{c}\right\rangle \\
& =\left\{\sum_{n}^{\mathrm{N}_{\text {val }}} f_{n}\left\langle\tilde{\Psi}_{n}|\mathcal{A}| \tilde{\Psi}_{n}\right\rangle+\sum_{n}^{\mathrm{N}_{\text {core }}}\left\langle\tilde{\phi}_{n}^{c}|\mathcal{A}| \tilde{\phi}_{n}^{c}\right\rangle\right. \\
& +\sum_{R}\left(\sum_{i, j \in R} D_{i, j}\left\langle\phi_{j}|\mathcal{A}| \phi_{i}\right\rangle+\sum_{n \in R}^{\mathrm{N}_{\text {core }}, R}\left\langle\phi_{n}^{c}|\mathcal{A}| \phi_{n}^{c}\right\rangle\right) \\
& \left.-\sum_{R}\left(\sum_{i, j \in R} D_{i, j}\left\langle\tilde{\phi}_{j}|\mathcal{A}| \tilde{\phi}_{i}\right\rangle+\sum_{n \in R}^{\mathrm{N}_{\text {core }}, R}\left\langle\tilde{\phi}_{n}^{c}|\mathcal{A}| \tilde{\phi}_{n}^{c}\right\rangle\right)\right\}
\end{aligned}
$$

Onde introduzimos o operador $D_{i, j}$ :

$$
D_{i, j}=\sum_{n} f_{n}\left\langle\tilde{\Psi}_{n} \mid \tilde{p}_{j}\right\rangle\left\langle\tilde{p}_{i} \mid \tilde{\Psi}_{n}\right\rangle
$$

À partir das equações obtidas, podemos definir o operador superposição $\tilde{\mathcal{O}}$, ou o operador identidade, pode ser escrito como: 


$$
\tilde{\mathcal{O}}=\mathcal{T}^{\dagger} \mathcal{T}=1+\sum_{i, j}\left|\tilde{p}_{i}\right\rangle\left[\left\langle\phi_{i} \mid \phi_{j}\right\rangle-\left\langle\tilde{\phi}_{i} \mid \tilde{\phi}_{j}\right\rangle\right]\left\langle\tilde{p}_{j}\right|
$$

Para que a condição da normalização seja garantida é necessário impor $\left\langle\tilde{\phi}_{i} \mid \tilde{\phi}_{j}\right\rangle=$ $\left\langle\phi_{i} \mid \phi_{j}\right\rangle$.Os elementos de matriz de um operador com as funções de onda auxiliares $\left|\Psi_{N}^{1}\right\rangle$ e $\left|\tilde{\Psi}_{N}^{1}\right\rangle$ podem convergir lentamente. Este inconveniente pode ser diminuído utilizando um operador identidade $\mathcal{B}$ puramente localizado dentro da região atômica:

$$
\mathcal{B}-\sum_{i, j}\left|\tilde{p}_{i}\right\rangle\left\langle\tilde{\phi}_{i}|\mathcal{B}| \tilde{\phi}_{j}\right\rangle\left\langle\tilde{p}_{j}\right|=0
$$

É fácil mostrar que o valor esperado desde termo é zero para as função de onda $|\tilde{\Psi}\rangle$, desde que $|\tilde{\Psi}\rangle=\sum_{i}\left|\tilde{\phi}_{i}\right\rangle\left\langle\tilde{p}_{i} \mid \tilde{\Psi}\right\rangle$ dentro da região compreendida por $r_{c, R}$.

\subsubsection{Densidade de Carga}

Por definição, a densidade de carga eletrônica em um sistema é dado por:

$$
n(\vec{r})=\sum_{n} f_{n}\left\langle\Psi_{n} \mid \vec{r}\right\rangle\left\langle\vec{r} \mid \Psi_{n}\right\rangle=\sum_{n} f_{n}\left|\Psi_{n}(\vec{r})\right|^{2}
$$

Utilizando a relação 2.35, temos que a expressão para densidade de carga:

$$
\begin{aligned}
n(\vec{r}) & =\tilde{n}(\vec{r})+\sum_{R}\left(n_{R}^{1}(\vec{r})-\tilde{n}_{R}^{1}(\vec{r})\right) \\
n_{R}^{1}(\vec{r}) & =\sum_{n} f_{n} \tilde{\Psi}_{n}^{*}(\vec{r}) \tilde{\Psi}_{n}(\vec{r})+\tilde{n}_{c} \\
n_{R}^{1}(\vec{r}) & =\sum_{i, j \in R} D_{i, j} \phi_{j}^{*}(\vec{r}) \phi_{i}(\vec{r})+n_{c, R} \\
\tilde{n}_{R}^{1}(\vec{r}) & =\sum_{i, j \in R} D_{i, j} \tilde{\phi}_{j}^{*}(\vec{r}) \tilde{\phi}_{i}(\vec{r})+\tilde{n}_{c, R}
\end{aligned}
$$




\subsubsection{Energia Total}

Assim comos os valores esperados e a densidade de carga, a energia total pode ser escrita como:

$$
E[n]=\tilde{E}+\sum_{R}\left(E_{R}^{1}-\tilde{E}_{R}^{1}\right)
$$

Onde:

$$
\begin{aligned}
& \tilde{E}=\sum_{n}\left\langle\tilde{\Psi}_{n}\left|-\frac{\nabla^{2}}{2}\right| \tilde{\Psi}_{n}\right\rangle \\
& +\frac{1}{2} \iint \frac{[\tilde{n}(\vec{r})+\tilde{Z}(\vec{r})]\left[\tilde{n}\left(\overrightarrow{r^{\prime}}\right)+\tilde{Z}\left(\overrightarrow{r^{\prime}}\right)\right]}{\left|\vec{r}-\overrightarrow{r^{\prime}}\right|} d^{3} \vec{r} d^{3} \overrightarrow{r^{\prime}} \\
& +\int \bar{v}(\vec{r}) \tilde{n}(\vec{r}) d^{3} \vec{r}+E_{x c}[\tilde{n}(\vec{r})] \\
& E_{R}^{1}=\sum_{i, j \in R} D_{i, j}\left\langle\phi_{j}\left|-\frac{\nabla^{2}}{2}\right| \phi_{i}\right\rangle+\sum_{n \in R}^{\mathrm{N}_{\text {core }, R}}\left\langle\phi_{n}^{c}\left|-\frac{\nabla^{2}}{2}\right| \phi_{n}^{c}\right\rangle \\
& +\frac{1}{2} \iint \frac{\left[n^{1}(\vec{r})+Z(\vec{r})\right]\left[n^{1}\left(\overrightarrow{r^{\prime}}\right)+Z\left(\overrightarrow{r^{\prime}}\right)\right]}{\left|\vec{r}-\overrightarrow{r^{\prime}}\right|} d^{3} \vec{r} d^{3} \overrightarrow{r^{\prime}} \\
& +E_{x c}\left[\tilde{n}^{1}(\vec{r})\right] \\
& \tilde{E}_{R}^{1}=\sum_{i, j \in R} D_{i, j}\left\langle\tilde{\phi}_{j}\left|-\frac{\nabla^{2}}{2}\right| \tilde{\phi}_{i}\right\rangle \\
& +\frac{1}{2} \iint \frac{\left[\tilde{n}^{1}(\vec{r})+\tilde{Z}(\vec{r})\right]\left[\tilde{n}^{1}\left(\overrightarrow{r^{\prime}}\right)+\tilde{Z}\left(\overrightarrow{r^{\prime}}\right)\right]}{\left|\vec{r}-\overrightarrow{r^{\prime}}\right|} d^{3} \vec{r} d^{3} \overrightarrow{r^{\prime}} \\
& +\int \bar{v}(\vec{r}) \tilde{n}^{1}(\vec{r}) d^{3} \vec{r}+E_{x c}\left[\tilde{n}^{1}(\vec{r})\right]
\end{aligned}
$$

$Z(\vec{r})$ representa as cargas atômicas dos núcleos, enquanto $\tilde{Z}(\vec{r})$ representa uma compensação na densidade de carga, onde $\tilde{Z}(\vec{r})=\sum_{R} \tilde{Z}_{R}(\vec{r})$ é dada por uma função gaussiana e as respectivas contribuições do momento angular. 


\subsubsection{O operador Hamiltoniano}

O operador Hamiltoniano pode ser escrito como a primeira derivada da energia total em função do operador densidade $\rho=\sum_{n} f_{n}\left|\Psi_{n}\right\rangle\left\langle\Psi_{n}\right|$, onde $f_{n}$ denota a ocupação dos estados e $\left|\Psi_{n}\right\rangle$ as autofunções ortogonais do operador densidade. Como $\langle\mathcal{A}\rangle=\operatorname{Tr}[\rho \mathcal{A}]$, podemos calcular a primeira derivada:

$$
\begin{aligned}
\frac{\partial E}{\partial \rho} & =\frac{\partial \operatorname{Tr}\left[-\frac{1}{2} \nabla^{2} \rho\right]}{\partial \rho}+\int \frac{\partial E}{\partial n(r)} \frac{\partial \operatorname{Tr}[|r\rangle\langle r| \rho]}{\partial \rho} d r \\
& =-\frac{1}{2} \nabla^{2}+v
\end{aligned}
$$

Onde o potencial é $v(r)=|r\rangle \frac{\partial E}{\partial n(r)}\langle r|$. Dentro da metodologia PAW é necessário estender o operador de densidade, $\tilde{\rho}=\sum_{n} f_{n}\left|\tilde{\Psi}_{n}\right\rangle\left\langle\tilde{\Psi}_{n}\right|$, para as funções de auxiliares. A energia total PAW será estendida em função das densidades $\tilde{n}_{R}, n_{R}^{1}$ e $\tilde{n}_{R}^{1}$ e os momentos de multipolo $Q_{R L}$ para compensar as densidades de carga, sendo elas próprias funções de um centro:

$$
\begin{aligned}
\frac{\partial E}{\partial \tilde{\rho}} & =\frac{\partial \operatorname{Tr}[\tilde{\rho} \tilde{T}]}{\partial \tilde{\rho}}+\int \frac{\partial E}{\partial \tilde{n}} \frac{\partial \tilde{n}}{\partial \tilde{\rho}} d r \\
& +\int\left(\frac{\partial E}{\partial n^{1}}+\sum_{R, L} \frac{\partial E}{\partial Q_{R L}} \frac{\partial Q_{R L}}{\partial n^{1}}\right) \frac{\partial n^{1}}{\partial \tilde{\rho}} d r \\
& +\int\left(\frac{\partial E}{\partial \tilde{n}^{1}}+\sum_{R, L} \frac{\partial E}{\partial Q_{R L}} \frac{\partial Q_{R L}}{\partial \tilde{n}^{1}}\right) \frac{\partial \tilde{n}^{1}}{\partial \tilde{\rho}}
\end{aligned}
$$

Onde o símbolo $\tilde{T}$ indexa todas as informações a respeito do termo de energia cinética da energia total PAW:

$$
\tilde{T}=-\frac{1}{2} \nabla^{2}+\sum_{i, j}\left|\tilde{p}_{i}\right\rangle\left(\left\langle\phi_{i}\left|-\frac{1}{2} \nabla^{2}\right| \phi_{j}\right\rangle-\left\langle\tilde{\phi}_{i}\left|-\frac{1}{2} \nabla^{2}\right| \tilde{\phi}_{j}\right\rangle\right)\left\langle\tilde{p}_{j}\right|
$$

A expressão final para o operador Hamiltoniano, a partir da qual as forças serão obtidas para os cálculos de dinâmica molecular de primeiros princípios, é: 


$$
\tilde{\mathcal{H}}=-\frac{1}{2} \nabla^{2}+\tilde{v}+\sum_{i, j}\left|\tilde{p}_{i}\right\rangle\left(\left\langle\phi_{i}\left|-\frac{1}{2} \nabla^{2}+v^{1}\right| \phi_{j}\right\rangle-\left\langle\tilde{\phi}_{i}\left|-\frac{1}{2} \nabla^{2}+\tilde{v}^{1}\right| \tilde{\phi}_{j}\right\rangle\right)\left\langle\tilde{p}_{j}\right|
$$

onde as componentes dos potencial total, analogamente às outras expressões, podem ser descompostas em $v(r)=\tilde{v}(r)+v^{1}(r)-\tilde{v}^{1}(r)$, e são:

$$
\begin{aligned}
\tilde{v}(r) & =\int \frac{\tilde{n}\left(r^{\prime}\right)+\tilde{Z}^{\prime}\left(r^{\prime}\right)}{\left|r-r^{\prime}\right|} d r+\hat{v}(r)+\bar{v}(r)+\mu_{x c}[\tilde{n}(r)] \\
\hat{v}(r) & =\int \frac{\tilde{Z}\left(r^{\prime}\right)-\tilde{Z}^{\prime}\left(r^{\prime}\right)}{\left|r-r^{\prime}\right|} d r \\
v_{R}^{1}(r) & =\int_{R} \frac{n_{R}^{1}\left(r^{\prime}\right)+Z_{R}\left(r^{\prime}\right)}{\left|r-r^{\prime}\right|} d r^{\prime}+\mu_{x c}\left[n_{R}^{1}(r)\right]+v_{R}^{0} \\
\tilde{v}_{R}^{1}(r) & =\int_{R} \frac{\tilde{n}_{R}^{1}\left(r^{\prime}\right)+\tilde{Z}_{R}\left(r^{\prime}\right)}{\left|r-r^{\prime}\right|} d r^{\prime}+\mu_{x c}\left[\tilde{n}_{R}^{1}(r)\right]+v_{R}^{0} \\
v_{R}^{0}(r) & =\sum_{L}(r-R)^{l} Y_{L}(|r-R|) \frac{\partial E}{\partial Q_{R L}}
\end{aligned}
$$

com

$$
\tilde{Z}_{R}(\vec{r})=\sum_{L} Q_{R L} C_{l}|\vec{r}-\vec{R}|^{l} Y_{L}(\vec{r}-\vec{R}) e^{-\left(|\vec{r}-\vec{R}| / r_{c}\right)^{2}}
$$

O momento de multipolo $Q_{R L}$ é dado por:

$$
Q_{R L}=\int|\vec{r}-\vec{R}|^{l}\left[n_{R}^{1}(\vec{r})+Z(\vec{r})-\tilde{n}_{R}^{1}(\vec{r})\right] \mathrm{Y}_{L}^{*}(\vec{r}-\vec{R}) d \vec{r}
$$

Onde o índice $L=(l, m)$ representa os números quânticos do momento angular e do momento magnético na expansão dos harmônicos esféricos $\mathrm{Y}_{L}$.

\subsubsection{Aproximações Práticas Para a Metodologia PAW}

Todo o formalismo apresentado é, em princípio exato, porém computacionalmente é necessário realizar algumas aproximações para viabilizar seu uso. As ondas planas 
são truncadas de acordo com a energia cinética, tal que, $T_{s}=\frac{G^{2}}{2}$. Um corte na energia cinética no valor de 30 Ry se mostrou suficiente para estudar a estrutura eletrônica dos sistemas considerados no presente trabalho. Outra aproximação é a escolha do momento angular máximo para as funções projetoras, tipicamente $l=$ $1,2,3$. A variação nos projetores em geral é proporcional à complexidade do átomo alvo utilizado: quanto maior for o número de elétrons presentes, maior o número de projetores.

\subsection{Dinâmica Molecular de Primeiros Princípios}

A dinâmica molecular clássica utiliza potenciais pré-definidos baseados em resultados empíricos ou cálculos de estrutura eletrônica. É uma ferramenta bem estabelecida e poderosa para investigar sistemas de muitos corpos na matéria condensada. O caminho tradicional da dinâmica molecular consiste em determinar seus respectivos potenciais, dividindo-as em diversas contribuições distintas.

A dinâmica molecular e métodos de estrutura eletrônica vem sendo utilizadas em conjunto por uma família de técnicas conhecida por dinâmica molecular ab initio, ou dinâmica molecular de primeiros princípios. O código computacional CP-PAW utiliza a metodologia proposta por Car e Parrinello para a encontrar a função de onda de KS que minimiza a energia do sistema. Notamos que não utilizamos este método para otimizar a geometria dos núcleos, nem realizar simulações de temperatura no presente trabalho.

\subsubsection{Dinâmica Molecular de Car e Parrinello}

O fundamento para a DMCP [23] está na separação adiabática de mecânica quântica por escala de tempo entre o rápido movimento eletrônico e o lento movimento nuclear. A ideia inovadora da DMCP é utilizar as funções de onda eletrônicas como coordenadas generalizadas para juntamente com as coordenadas nucleares $\left(R_{i}\right)$, escrever a Lagrangeana do sistema.A energia eletrônica $\left\langle\Psi_{0}|\mathcal{H}| \Psi_{0}\right\rangle$ é calculada a partir de uma função de onda $\Psi_{0}$, que depende das funções das posições nucleares $\left\{R_{i}\right\}$ num dado sistema. 
Aqui descreveremos as equações básicas da DMCP obedecendo o formalismo PAW descrito nas seções anteriores. A Lagrangeana $\mathcal{L}_{C P}$ fica:

$$
\mathcal{L}_{C P}=\underbrace{\sum_{n} m_{\Psi} f_{n}\left\langle\tilde{\Psi}_{n} \mid \tilde{\Psi}_{n}\right\rangle}_{T_{c} \text { eletrônico }}+\underbrace{\sum_{R} \frac{M_{R}}{2} \dot{R}_{R}^{2}}_{T_{c} \text { nuclear }}-\underbrace{\left\langle\tilde{\Psi}_{n, R}|\mathcal{H}| \tilde{\Psi}_{n, R}\right\rangle}_{\text {V eletrônico }}+\underbrace{\sum_{i j} \wedge_{n, m}\left(\left\langle\tilde{\Psi}_{n}|\tilde{\mathcal{O}}| \tilde{\Psi}_{m}\right\rangle-\delta_{n m}\right)}_{\text {Vínculo de ortogonalidade }}
$$

Aqui $m_{\Psi}$ é uma massa fictícia atribuída às funções de onda eletrônicas que deve ser muito menor que $M_{R}$ para satisfazer a aproximação de Born-Oppenheimer; $f_{n}$ são as ocupações dos orbitais, $\wedge_{n, m}$ são os multiplicadores de Lagrange que fornecem as condições de vínculo para as funções de onda.

As equações de Eüler-Lagrange para as coordenadas generalizadas $\left|\tilde{\Psi}_{n}\right\rangle$ e $R_{R}$ são:

$$
\begin{aligned}
\frac{d}{d t}\left(\frac{\partial \mathcal{L}_{C P}}{\partial \dot{\mathbf{R}}_{R}}\right) & =\frac{\partial \mathcal{L}_{C P}}{\partial \mathbf{R}_{R}} \\
\frac{d}{d t}\left(\frac{\partial \mathcal{L}_{C P}}{\partial\left\langle\dot{\tilde{\Psi}}_{n}\right|}\right) & =\frac{\partial \mathcal{L}_{C P}}{\partial\left\langle\tilde{\Psi}_{n}\right|}
\end{aligned}
$$

Como na mecânica clássica, estas equações podem ser integradas resultando nas equações de movimento de Newton:

$$
M_{R} \ddot{\mathbf{R}}=F_{R}
$$

$\mathrm{e}$

$$
m_{\Psi}\left|\ddot{\tilde{\Psi}}_{n}\right\rangle=-\tilde{\mathcal{H}}\left|\tilde{\Psi}_{n}\right\rangle+\sum_{m} \tilde{\mathcal{O}}\left|\tilde{\Psi}_{m}\right\rangle \wedge_{n, m} \frac{1}{f_{n}}
$$

A Força $F_{R}$ é dada por: 


$$
\begin{aligned}
F_{R}= & -\sum_{n} f_{n}\left\langle\tilde{\Psi}_{n}\left|\nabla_{R} \tilde{\mathcal{H}}\right| \tilde{\Psi}_{n}\right\rangle+\sum_{n, m} \frac{f_{n}+f_{m}}{2}\left\langle\tilde{\Psi}_{m}\left|\nabla_{R} \tilde{\mathcal{O}}\right| \tilde{\Psi}_{n}\right\rangle\left\langle\tilde{\Psi}_{n}|\tilde{\mathcal{H}}| \tilde{\Psi}_{m}\right\rangle \\
& +\sum_{n, m} \frac{f_{n}-f_{m}}{2} \mathcal{B}_{n, m}\left\langle\tilde{\Psi}_{n}|\tilde{\mathcal{H}}| \tilde{\Psi}_{m}\right\rangle
\end{aligned}
$$

e pode ser obtida, dentro do formalismo PAW, através de:

$$
\begin{aligned}
\nabla_{R}\left|\tilde{\Psi}_{n}\right\rangle= & -\frac{1}{2} \sum_{m}\left|\tilde{\Psi}_{m}\right\rangle\left[\left\langle\tilde{\Psi}_{m}\left|\nabla_{R}\right| \tilde{\mathcal{O}} \mid \tilde{\Psi}_{n}\right\rangle+\mathcal{B}_{m, n}\right] \\
& \left.\frac{\partial E[\tilde{\Psi}, R]}{\partial R}\right|_{\left|\tilde{\Psi}_{n}\right\rangle}=\sum_{n} f_{n}\left\langle\tilde{\Psi}_{n}\left|\nabla_{R} \tilde{\mathcal{H}}\right| \tilde{\Psi}_{n}\right\rangle
\end{aligned}
$$

A interessante proposta de Car e Parrinello é que as funções de onda que minimizam a energia potencial eletrônica e iônica coincidam com os autovalores de KS para este potencial. Na prática os movimentos nucleares e eletrônicos são separados desde que movimento eletrônico seja suficientemente rápido para seguir adiabaticamente o lento movimento dos núcleos atômicos. Isto é possível se os espectros vibracionais decorrentes da dinâmica dos sistemas não se superpõem substancialmente.

\subsubsection{O controle da Adiabaticidade}

Uma análise do espectro harmônico de frequências pode ser obtida através de um campo clássico próximo do mínimo de energia que nos leva ao estado fundamental:

$$
\omega_{i j}=\left(\frac{2\left(\epsilon_{j}-\epsilon_{i}\right)}{m_{\Psi}}\right)^{\frac{1}{2}}
$$

onde $\epsilon_{i}$ e $\epsilon_{j}$ representam os orbitais ocupados e o orbitais desocupados respectivamente. Logo, uma estimativa para uma frequência mínima, $\omega_{\min }$ que respeite a adiabaticidade pode ser escrita como: 


$$
\omega_{\min } \propto\left(\frac{E_{g a p}}{m_{\Psi}}\right)^{\frac{1}{2}}
$$

onde $E_{\text {gap }}$ é definido pela diferença de energia entre o orbital KS de maior energia ocupado (HOMO) e o orbital KS de menor energia desocupado (LUMO) num sistema molecular.

A frequência máxima $\omega_{\max }$ é escrita partir da energia cinética máxima adotada no sistema, $E_{c u t}$, de forma que:

$$
\omega_{\max } \propto\left(\frac{E_{c u t}}{m_{\Psi}}\right)^{\frac{1}{2}}
$$

Para garantir a separação adiabática as frequências máxima $\omega_{\max }$, e mínima $\omega_{\text {min }}$ devem possuir uma grande separação, para que não haja interferências entre o sistema nuclear e o sistema eletrônico. Entretanto, o único parâmetro do sistema é a massa fictícia. A frequência máxima, $\omega_{\max }$, é inversamente proporcional ao intervalo de passos máximos, $\Delta t_{\max }$ da dinâmica molecular, de forma que $\Delta t_{\max } \propto 1 / \omega_{\max }$.

Um problema da DMCP é que o princípio da conservação da adiabaticidade que falha completamente quando $E_{\text {gap }} \rightarrow 0$.

\subsubsection{Otimização da Função de Onda Através da Dinâmica Molecular Car-Parrinello}

Se mantivermos os núcleos parados num dado instante, é possível iniciar o procedimento de otimização da função de onda a partir de uma função de onda aleatória, que não possui a energia eletrônica minimizada. Neste caso, a energia cinética fictícia dos elétrons é alta. Entretanto, esta energia pode ser sistematicamente retirada do sistema, resfriando os elétrons para temperaturas mais baixas. Isto pode ser feito na DMCP através de um termo não conservativo que pode ser adicionado na equação de movimento dos elétrons

$$
m_{\Psi}\left|\ddot{\tilde{\Psi}}_{n}\right\rangle=-\tilde{\mathcal{H}}\left|\tilde{\Psi}_{n}\right\rangle+\sum_{m} \tilde{\mathcal{O}}\left|\tilde{\Psi}_{m}\right\rangle \wedge_{n, m} \frac{1}{f_{n}}-m_{\Psi} \gamma\left|\dot{\tilde{\Psi}}_{n}\right\rangle
$$


Aqui $\gamma>0$ é uma constante de fricção responsável pela dissipação da energia cinética. Com este procedimento é possível realizar a chamada "otimização" do sistema eletrônico, isto é, encontrar as funções de onda e coordenadas generalizadas que coincidem com os autovalores de KS no mínimo de energia. A otimização global do sistema pode ser feita introduzindo para os núcleos uma constante fricção análoga.

Uma revisão do algoritmo computacional utilizado para realizar a dinâmica molecular pode ser encontrado no apêndice B.

\subsection{Funcional de Troca e Correlação}

Não existe uma forma exata para o funcional $E_{x c}[\rho]$, entretanto, existem muitos estudos nesta área para desenvolver e aprimorar os funcionais de troca e correlação.

O primeiro funcional a ser desenvolvido se baseava na aproximação da densidade local (LDA - local density approximation). Utilizaremos neste trabalho o funcional de troca e correlação GGA, baseado na densidade eletrônica local e no gradiente da densidade eletrônica.

Na tentativa de aprimorar o funcional LDA foi desenvolvido a família de funcionais GGA, que dependem também do gradiente da densidade eletrônica $\nabla n(\vec{r})$ :

$$
E_{x c}^{G G A}[n(\vec{r})]=\int \epsilon_{x c}^{G G A}(n, \nabla n) n(\vec{r}) d \vec{r}
$$

Este tipo de tratamento reproduz melhor a densidade eletrônica observada numa molécula, pois sua densidade varia rapidamente em função das diferentes geometrias e dos diferentes tipos atômicos. A função $\epsilon_{x c}^{G G A}$ não é unicamente definida, de forma que existem diversas aproximações GGA que podem ser encontradas na literatura, e neste trabalho escolhemos utilizar o funcional de Perdew-Burke-Ernzerhof (PBE) [29] dado por:

$$
E_{x c}^{P B E}[n]=\int n \epsilon_{e}^{h o m}(n) F_{x}^{P B E}(n, \nabla n) d^{3} \vec{r}+\int n \epsilon_{c}^{P B E}(n, \nabla n) d^{3} d \vec{r}
$$

onde $F_{x}^{P B E}$ é 


$$
F_{x}^{P B E}(n, \nabla n)=1+k-\frac{k}{1+\mu s^{2} / k}
$$

e

$$
s=\frac{|\nabla n|}{2\left(3 \pi^{2}\right)^{1 / 3} n^{4 / 3}}
$$

Aqui $s$ é definido como o gradiente da densidade de densidade adimensional e as constantes $\mu$ (coeficiente do gradiente efetivo para a $F_{x}$ ) e $k$ (vetor de onda de Thomas-Fermi) são constantes.

Para uma molécula, o funcional GGA-PBE usualmente superestima as distâncias de ligação em até 5\%, melhora as energias de atomização e fornece curvas de ligação compatíveis para dímeros de gases nobres. Em estado sólido, o GGA-PBE aprimora a descrição de propriedades magnéticas para diversos metais de transição e pressões de transição de fase e algumas vezes melhora o parâmetro de rede dos sólidos.

\subsection{Outros Códigos Computacionais Utilizados}

A principal contribuição nesta dissertação é o estudo e a modelagem da interação lectina-carboidrato através da mecânica quântica. Até aqui descrevemos as ferramentas para o estudo ab initio, entretanto, a modelagem do sistema só é possível com a utilização de outras metodologias, tanto teórica como experimental, o que foi realizada através de colaborações com outros grupos de pesquisas ou utilizando resultados já publicados na literatura.

Além do código computacional CP-PAW, também utilizamos cálculos HartreeFock (HF) semi-empíricos com parametrização proposta por Zerner, usualmente chamada de ZINDO (Zerner Intermediate Neglect Diferential Overlap), contida no pacote VAMP presente no código computacional comercial Materials Studio 4.0. O método HF é anterior a DFT e a sua aproximação para a equação de Schrödinger consiste em tratar um campo médio para um sistema eletrônico. Quando tratada de forma semi-empírica, a equação HF tem alguns termos não diagonais de sua matriz parametrizados (ou ignorados) a partir de resultados experimentais, aumentando grandemente o tempo 
computacional em detrimento da precisão de alguns resultados. Desta forma, Zerner criou uma metodologia semi-emipírica capaz de reproduzir o espectro ótico com resultados bastante satisfatórios e com um custo computacional bastante reduzido. Como a DFT usualmente apresenta problemas para reproduzir o espectro ótico, decidimos estudar as propriedades óticas através da metodologia ZINDO. Uma descrição mais detalhada a respeito da metodologia ZINDO pode ser encontrada na referência [30].

De forma resumida, os códigos computacionais utilizados foram:

- CP-PAW [22]: baseado em DFT no esquema de KS com funções de base PAW.

- Materials Studio 4.0/ZINDO [31]: baseado em Hartree-Fock semi-empírico, ajustado para as propriedades óticas, como absorção UV/Vis.

- GOLD [32]: docking molecular baseado em resultados de algoritmo genético. Este código foi testado e validado para mais de 305 diferentes estruturas proteicas complexos ligantes encontrados no PDB, onde $72 \%$ dos seus resultados de melhor ranking descreveram o resultado experimental. O rank é um termo empírico criado para classificar as conformações obtidas através de docking.

- SYBYL [33]: baseado em dinâmica molecular clássica, utiliza o campo de força Tripos, parametrizado especificamente para proteínas e sistemas biológicos. 



\section{Capítulo 3}

\section{Resultados e Discussão}

\subsection{Procedimento}

Descrevemos inicialmente aqui, de forma geral, todo o procedimento adotado para simular a interação proteína-carboidrato combinando técnicas clássicas e quânticas dentro de uma metodologia multiescala desenvolvida nesta dissertação.

Seis estruturas cristalográficas para a Jacalina depositadas no banco de dados de proteínas (Protein Data Bank - PDB) foram selecionadas para o presente estudo. Notamos que estes modelos foram depositados pelo mesmo grupo, em datas, resoluções de raios-X e utilizando ligantes distintos. Analisamos o grau de mobilidade dos diferentes modelos, nos concentrando majoritariamente sobre o sítio ativo, que é o principal objeto de investigação deste trabalho. A superposição de todos os sítios ativos nos permite considerar que a proteína apresenta um comportamento rígido na região dos sítios ativos. Escolhemos o modelo 1WS4 como sítio ativo padrão para o estudo. De acordo com a disponibilidade de resultados experimentais de microcalorimetria, selecionamos quatro carboidratos distintos para a modelagem. Apesar de possuirmos os dados cristalográficos de todos os carboidratos que estamos utilizando nas proteínas do PDB, não tínhamos estes dados para todos dentro do sítio ativo do modelo 1WS4 que adotamos para a simulação. Após selecionar a proteína modelo e os carboidratos, utilizamos a técnica de docking molecular para inserir os monossacarídeos no sítio ativo da proteína 1WS4. O procedimento de docking molecular gerou 50 configurações 
distintas para cada monossacarídeo. As configurações selecionadas para utilização em nosso modelo foram as que mais apresentaram repetições na posição espacial. $O$ docking molecular foi validado a partir das superposições espaciais e comparações de desvios, onde escolhemos os valores mais próximos dos resultados experimentais de difração de Raios-X. Uma vez selecionada a estrutura mais provável para cada sistema lectina-carboidrato, iniciamos o procedimento de otimização de geometria através da técnica de mecânica molecular, simulando todas as condições físico-químicas do ambiente. O modelo proposto para o estudo quântico da interação proteína-carboidrato é baseado nas posições espaciais geradas após esta otimização de geometria. A partir do carboidrato no sítio ativo, definimos uma região considerando todos os aminoácidos internos e testamos três diferentes modelos. Estes modelos foram avaliados utilizando duas metodologias distintas, segundo as propriedades óticas e eletrônicas.

O conjunto de resultados obtidos servem para validar o modelo proposto e a metodologia, possibilitando a investigação dos mecanismos de interação proteínacarboidrato. Detalharemos nas próximas seções todo o procedimento aqui descrito.

\subsection{Estudo dos modelos cristalográficos}

O PDB [34] é um banco de dados de livre acesso que disponibiliza o Raio-X de proteínas de onde obtivemos as seguintes estruturas cristalográficas diferentes para a Jacalina: 1JAC [35], 1TOQ e 1TP8 [36], 1UGW [37] e 1WS4 e 1WS5 [38]. Utilizamos o programa Ppymol [39] para sobrepor os monômeros de cada uma das proteínas selecionadas e analisamos os RMSD entre suas estruturas cristalográficas. Todos os monômeros da Jacalina são idênticos entre si pois esta é uma proteína tetramérica, portanto, não houve a necessidade de realizar nenhuma superposição. A Figura 1.2 apresenta uma ilustração da estrutura cristalográfica da Jacalina e a Tabela 3.1 apresenta os dados em detalhe de cada modelo de Raio-X.

O RMSD obtido para as distâncias interatômicas dos átomos nos monômeros é aproximadamente $0,22 \AA$. A partir deste resultado e das diferentes fontes de informação a respeito da estrutura cristalográfica (publicadas em anos e por pesquisadores diferentes), vamos considerar o seu sítio ativo sendo rígido. A Figura 3.1 exemplifica a sobreposição dos sítios ativos das estruturas 1JAC, 1TP8, 1UGW e 1WS4. 


\begin{tabular}{ccc}
\hline código PDB & $\begin{array}{c}\text { resolução } \\
\text { Raio-X }\end{array}$ & $\begin{array}{c}\text { ano da } \\
\text { publicação }\end{array}$ \\
\hline 1JAC [35] & $2,43 \AA$ & 1996 \\
1UGW [37] & $1,70 \AA$ & 2003 \\
1TOQ [36] & $2,50 \AA$ & 2004 \\
1TP8 [36] & $3,00 \AA$ & 2004 \\
1WS4 [38] & $1,90 \AA$ & 2005 \\
1WS5 [38] & $1,90 \AA$ & 2005 \\
\hline
\end{tabular}

Tabela 3.1: Referência para resolução obtida e data de publicação

\subsection{Inserção dos Carboidratos na Proteína}

Após a análise dos dados cristalográficos da proteína é necessário avaliar como simular a inserção do carboidrato dentro da mesma. Para realizar esta etapa do estudo da interação do sítio ativo e os carboidratos, adotamos dois procedimentos computacionais em colaboração com o grupo da Profa. Dra. Antônia Tavares do Amaral, professora do Instituto de Química da Universidade de São Paulo (IQUSP). Inicialmente utilizamos docking molecular para inserir o carboidrato na proteína e avaliamos os resultados através de comparação estrutural com os resultados de raios-X. Após esta etapa, realizamos uma otimização de geometria utilizando mecânica molecular clássica, uma vez que o procedimento de docking considerava todas as estruturas rígidas.

\subsubsection{Docking Molecular}

O processo de docking molecular é estocástico, isto é, para cada simulação é gerada uma nova configuração do ligante dentro do espaço conformacional do sítio ativo selecionado. Também como parte do procedimento, tanto a proteína quanto o ligante foram considerados rígidos. As simulações são validadas a partir de alguns fatores importantes: sua repetição para uma geometria espacial obtida dentro de um desvio quadrático médio mínimo e a comparação dos cálculos com as medidas de Raio-X, caso elas existam e por último, o valor do rank para a configuração. O valor do rank é uma fórmula empírica implementada no código computacional GOLD que, com base na literatura, não é um argumento válido se considerado isolado. O procedimento adotado seleciona exatamente a estrutura de maior rank após os outros testes citados. 


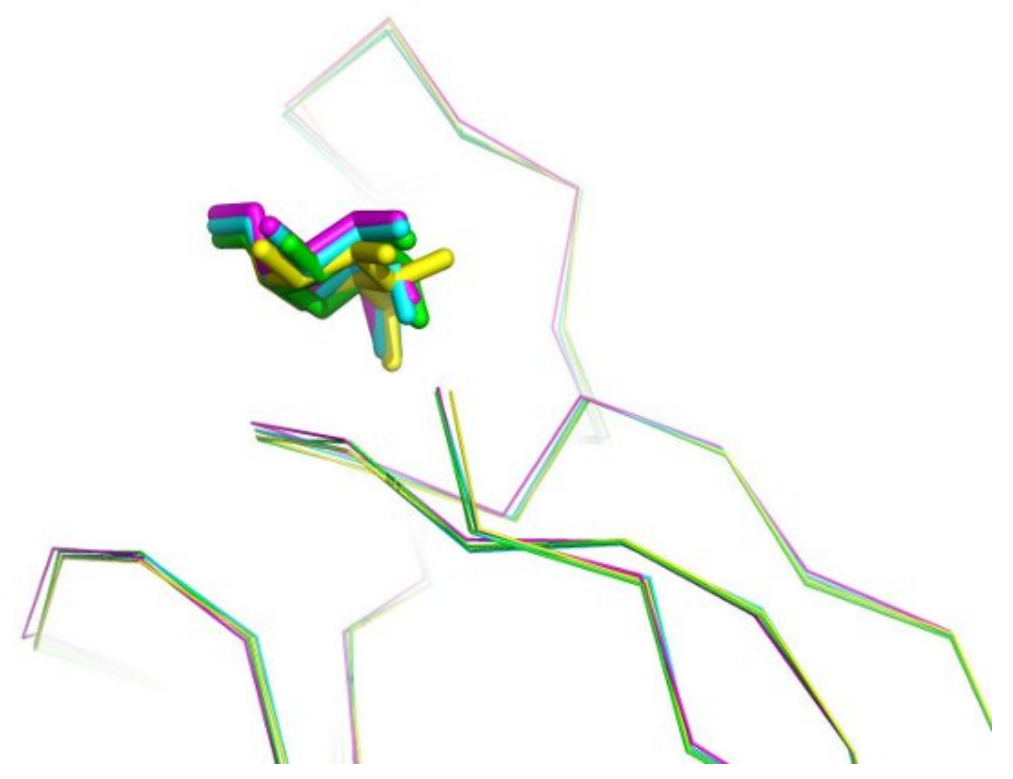

(a)

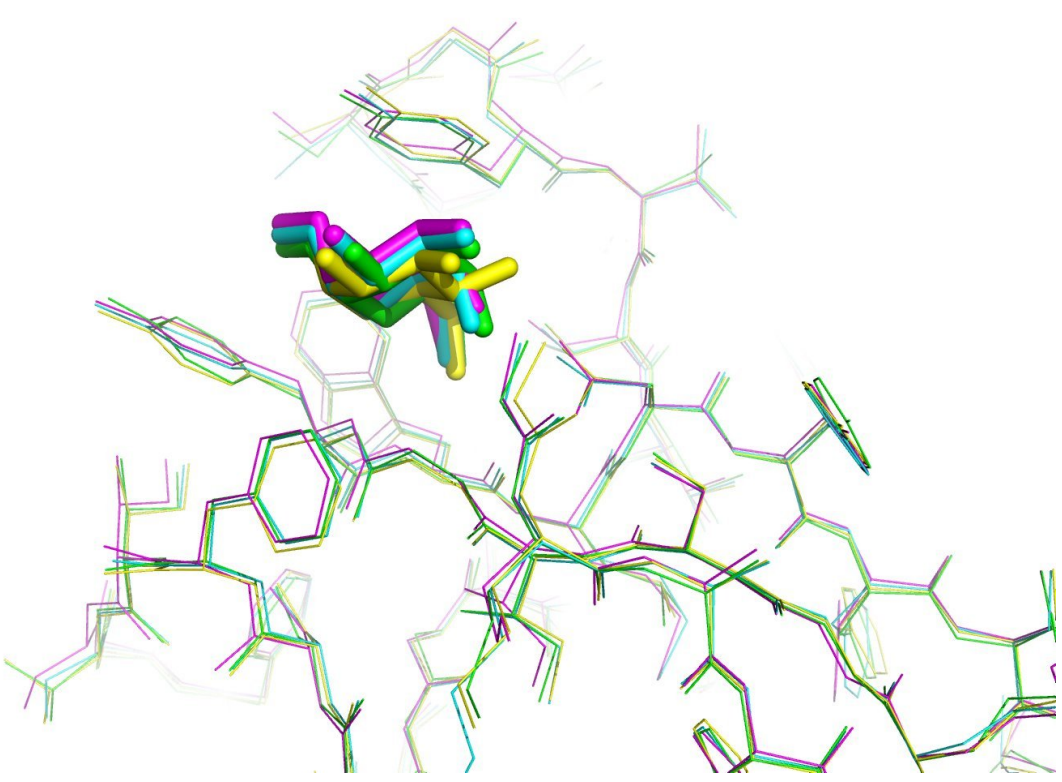

(b)

Figura 3.1: Superposição cristalográfica das estruturas 1JAC, 1TP8,1UGW e 1WS4. As cores distintas representam as diferentes estruturas obtidas segundo a literatura. (a) Representação dos monômeros cristalográficos considerando apenas os carbonos $\alpha$.(b)Representação dos monômeros considerando a estrutura completa. 
Selecionamos a estrutura 1WS4 para realizar o estudo de docking molecular, uma vez que este modelo apresenta a mais atual medida de Raio-X da proteína para a Jacalina.

Simulamos 50 conformações distintas para cada carboidrato utilizando o código computacional GOLD [32]. Os resultados obtidos foram então comparados entre si e agrupados. O critério para formação dos grupos é possuir um RSMD inferior a 0,25 A entre cada conformação do grupo. Selecionamos o grupo que mais apresentou repetições, pois, uma vez que o método é estocástico e empírico, o maior número de repetições indica uma maior probabilidade da estrutura ser a correta. Finalmente, escolhemos a conformação de maior rank do grupo que mais apresentou repetições. Para validar os resultados de docking para os quatro carboidratos, comparamos a conformação escolhida, inserida na proteína 1WS4, com os resultados de raios-X dos outros modelos que possuíam o mesmo carboidrato e adotamos um RMSD inferior a $0,25 \AA$.

\subsubsection{Mecânica Molecular}

Com os resultados obtidos a partir dos critérios selecionados na seção anterior, iniciamos o procedimento de otimização de geometria do sistema proteína + carboidrato utilizando mecânica molecular clássica, onde consideramos configuração obtida pelo docking.

Utilizamos o método do "gradiente conjugado" para a otimização de geometria, utilizando um parâmetro de convergência de $0,05 \mathrm{kcal} / \mathrm{mol}$ para as diferenças nas superfícies de energia geradas classicamente. De forma a simular as condições experimentais da proteína, incluímos algumas moléculas de água do Raio-X, ajustamos os hidrogênios para simular o fator PH 7,0 e consideramos a constante dielétrica da água como $\epsilon=78$. Na otimização de geometria, permitimos graus de liberdade para movimentação nos átomos contidos numa região de $15 \AA$ a partir do carboidrato e o restante da proteína esteve presente na simulação mais foi considerado rígido e os efeitos de temperatura não foram simulados. O campo de força "Tripos" foi adotado para as simulações, sendo um este um campo de força de segunda geração parametrizado para interações em proteínas e biomoléculas, disponível no código computacional SYBYL [33]. Após a otimização de geometria, onde nenhum sistema apresentou um valor superior a 0,20 A para o RMSD. As Figuras 3.2 (a-d) apresentam os resultados visuais do sistema 
antes e após a otimização de geometria onde apenas os carbonos- $\alpha$ dos aminoácidos foram ilustrados uma vez que estes são os átomos que apresentam o maior grau de liberdade conformacional.

Notamos um total de 5 ligações de hidrogênio formadas entre os sistemas proteínacarboidrato. Tais ligações são as mesmas em todos os carboidratos, sendo formada pelos aminoácidos Gly1, Tyr122 e Trp123 (estamos adotando nomenclatura utilizada dentro do código PDB para identificar estes aminoácidos na estrutura). Os resultados apresentam um aumento sistemático das distâncias de ligações de Hidrogênio após a otimização de geometria. Apresentamos na Tabela 3.2 as distâncias das ligações de hidrogênio formadas entre o carboidrato e o sítio ativo da proteína e também o RMSD após sobrepor a região em que foi efetuada a otimização de geometria. As distâncias de ligações de hidrogênio sistematicamente aumentam após a otimização de geometria, entretanto, este desvio é superior a $0,5 \AA$ em somente um caso.

\subsection{Recorte do Sítio Ativo}

Devido à grande quantidade de átomos presentes, torna-se necessário (para viabilizar a abordagem computacional utilizada) recortar a proteína para estudar apenas a região próxima ao carboidrato, que é a região de interesse aqui. Esta etapa de construção do modelo a ser utilizado no cálculo é bastante importante, pois, por um lado, é necessário manter as propriedades relevantes e por outro lado minimizar o números de átomos que serão tratados dentro de um formalismo quântico ab initio. O processo de "recorte" é formado unicamente pela seleção dos átomos em uma região específica. Visando desenvolver uma metodologia que descrevesse a interações do sítio, propusemos 3 modelos distintos. Estes modelos são baseados em recortes de um raio variável de 4 Â 5 $\AA$, ao redor do carboidrato, considerando inteiro qualquer aminoácido presente nesta região. Mesmo que apenas um único átomo do aminoácido fosse selecionado, este será incluído inteiro. Também introduzimos algumas modificações ad hoc buscando descrever corretamente as interações presentes.

Denotaremos nesta seção as seguintes definições para as figuras: As cores verde, vermelha, branca e azul representam os átomos de carbono $\mathbf{C}$, oxigênio $\mathbf{O}$, hidrogênio $\mathbf{H}$ e nitrogênio $\mathbf{N}$, respectivamente. A imagem a azul clara no centro da Figura 


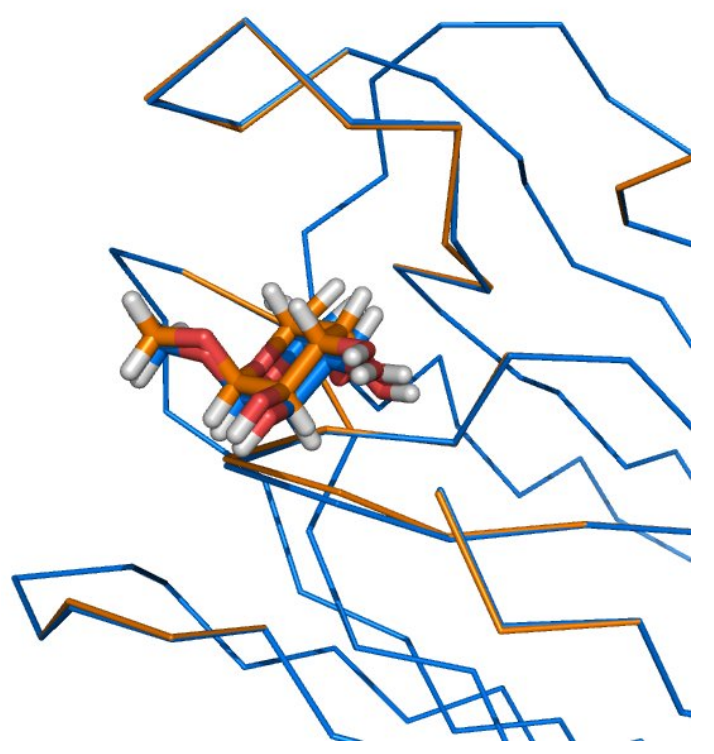

(a) $\alpha$-metil-D-galactose

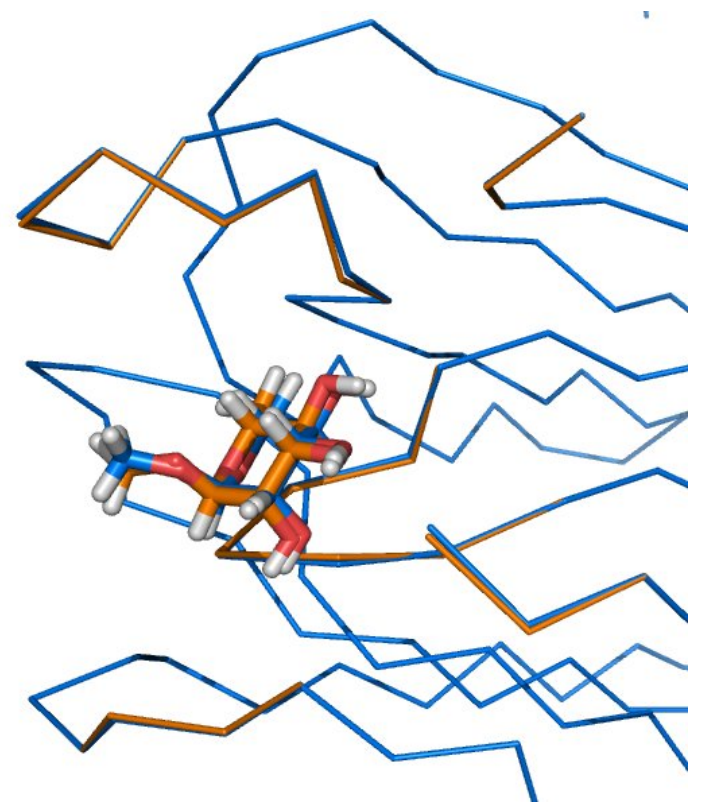

(c) O1-metil-D-manose

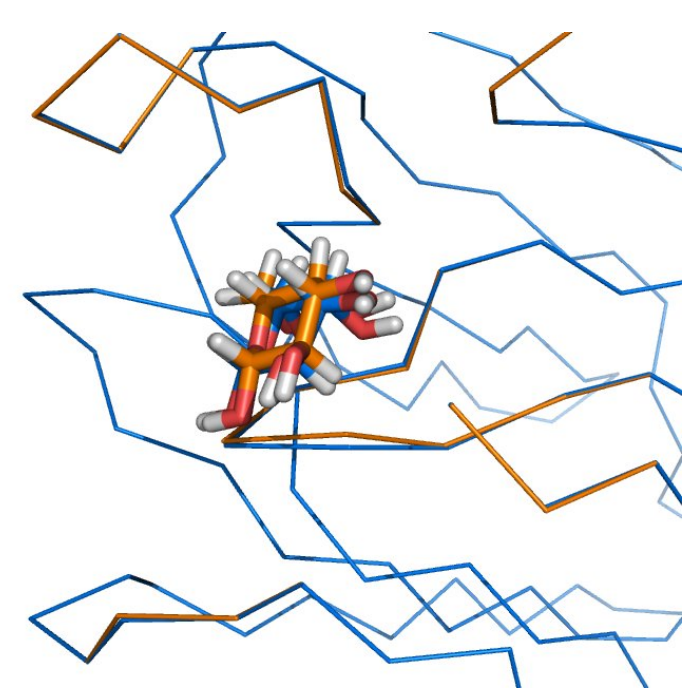

(b) $\beta$-D-galactose

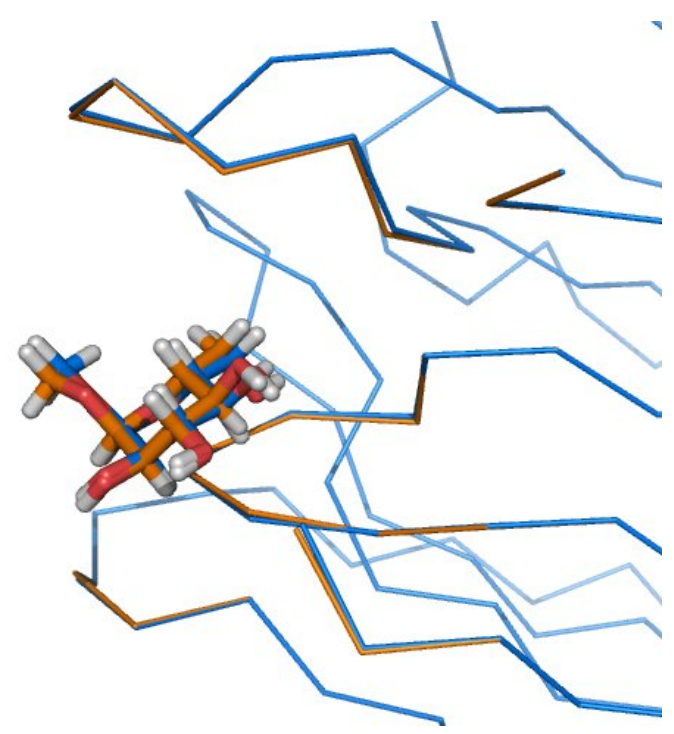

(d) $\alpha$-metil-D-glucopiranose

Figura 3.2: Posições atômicas da proteína antes e após a otimização de geometria para os diferentes carboidratos. Os traços azuis representam os carbonos, e suas ligações, antes da otimização de geometria e os traços em laranja representam os carbonos, e suas ligações, após a otimização de geometria. Os átomos de hidrogênio e oxigênio são representados pelas cores branca e vermelha respectivamente. 


\begin{tabular}{|c|c|c|c|c|}
\hline \multirow[t]{2}{*}{ Carboidrato } & \multirow[t]{2}{*}{$\operatorname{RMSD}(\AA)$} & \multicolumn{2}{|c|}{ Ligação de Hidrogênio $(\AA)$} & \multirow[t]{2}{*}{$\Delta(\AA)$} \\
\hline & & antes da otimização & após a otimização & \\
\hline \multirow[t]{5}{*}{ AMG } & 0,169 & 2,167 & 2,468 & 0,301 \\
\hline & & 1,922 & 2,255 & 0,333 \\
\hline & & 1,974 & 2,225 & 0,251 \\
\hline & & 2,451 & 2,479 & 0,028 \\
\hline & & 2,029 & 2,316 & 0,287 \\
\hline \multirow[t]{5}{*}{ GAL } & 0,118 & 2,230 & 2,523 & 0,293 \\
\hline & & 1,934 & 2,257 & 0,323 \\
\hline & & 2,057 & 2,184 & 0,127 \\
\hline & & 2,340 & 2,353 & 0,013 \\
\hline & & 2,038 & 2,287 & 0,249 \\
\hline \multirow[t]{5}{*}{ MMA } & 0,184 & 2,164 & 2,688 & 0,524 \\
\hline & & 2,111 & 2,244 & 0,133 \\
\hline & & 2,328 & 2,445 & 0,117 \\
\hline & & 1,966 & 2,245 & 0,279 \\
\hline & & 2,332 & 2,785 & 0,453 \\
\hline \multirow[t]{5}{*}{ GYP } & 0,167 & 2,244 & 2,608 & 0,364 \\
\hline & & 2,099 & 2,172 & 0,073 \\
\hline & & 2,434 & 2,568 & 0,134 \\
\hline & & 1,949 & 2,273 & 0,324 \\
\hline & & 2,452 & 2,844 & 0,392 \\
\hline
\end{tabular}

Tabela 3.2: RMSD para as posições atômicas da proteína antes e após a otimização de geometria e as distâncias das ligações de hidrogênio formadas entre os carboidratos e a proteína. A terceira coluna apresenta as diferenças nas ligações de Hidrogênio.

exemplifica um carboidrato que está ligado ao sítio ativo. Todas as figuras desta seção fornecem apenas um exemplo visual do modelo.

\section{Modelo 1}

A Figura 3.3 apresenta o modelo construído a partir do recorte do sítio ativo da proteína utilizando $4 \AA$ de raio, onde estão presentes um total de 146 átomos sem considerar os átomos do carboidrato. Notamos que diferentes carboidratos serão utilizados para estudar as propriedades eletrônicas do sítio ativo. Este recorte contém 8 aminoácidos, sendo eles: GFYVGYWD (obedecendo a nomenclatura apresentada na Figura 1.1). 


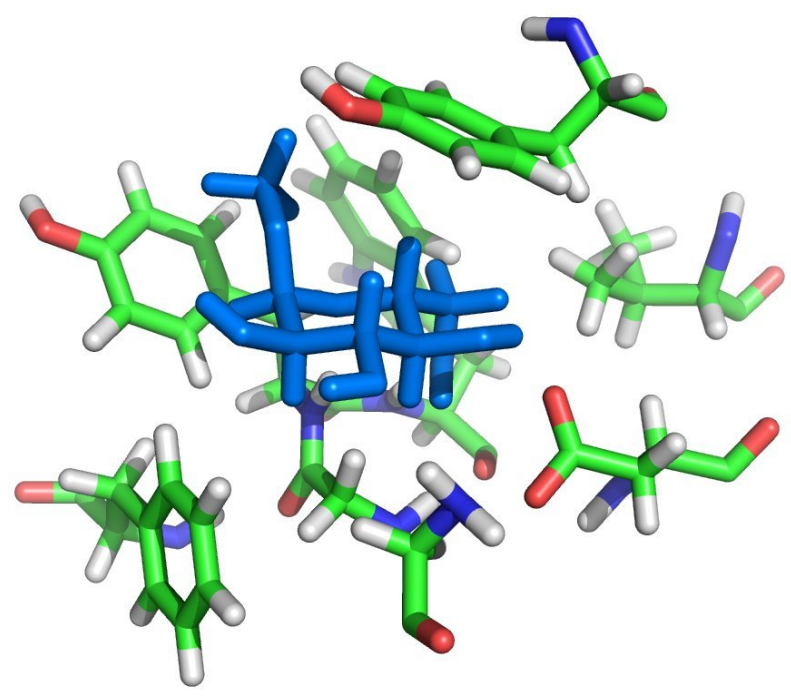

(a)

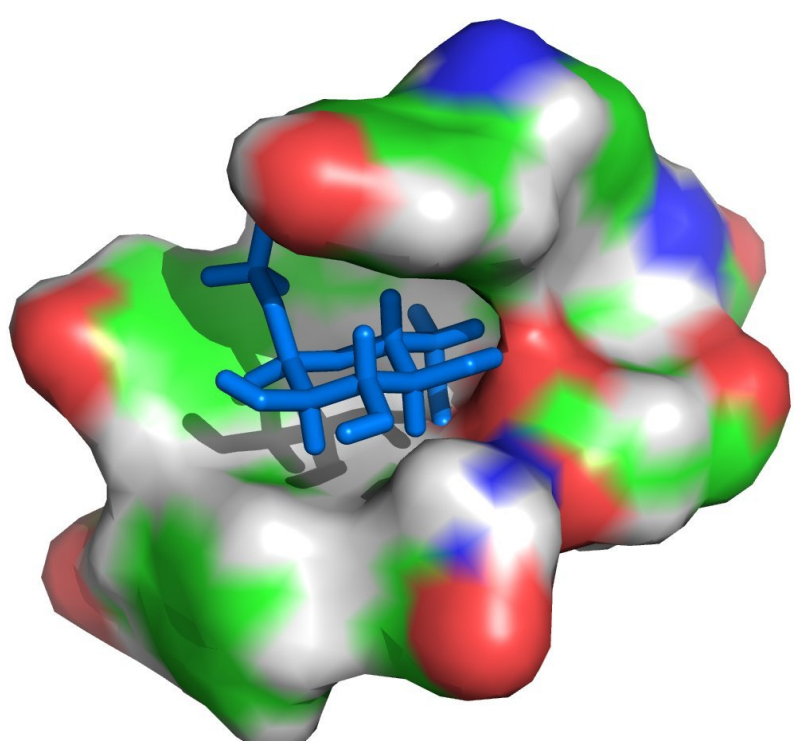

(b)

Figura 3.3: Modelo 1 em duas representações distintas: (a) no formato de traços representando ligações químicas e (b) no formato de esferas atômicas evidenciando o sítio ativo. 


\section{Modelo 2}

A Figura 3.4 apresenta o modelo construído a partir do recorte do sítio ativo da proteína utilizando $4 \AA$ de raio. Este modelo possui algumas diferenças quando comparado ao modelo 1. Os átomos $\mathbf{N}$ e $\mathbf{O}$ mais externos, que anteriormente formavam ligações peptídicas, foram substituídos por átomos de hidrogênio, de forma a simular mais adequadamente o estado real da proteína. Estão presentes um total de 137 átomos sem considerar os átomos do carboidrato. Notamos que diferentes carboidratos serão utilizados para estudar as propriedades eletrônicas do sítio ativo. Este recorte contém 8 aminoácidos, sendo eles: GFYVGYWD (obedecendo a nomenclatura proposta na Figura 1.1).

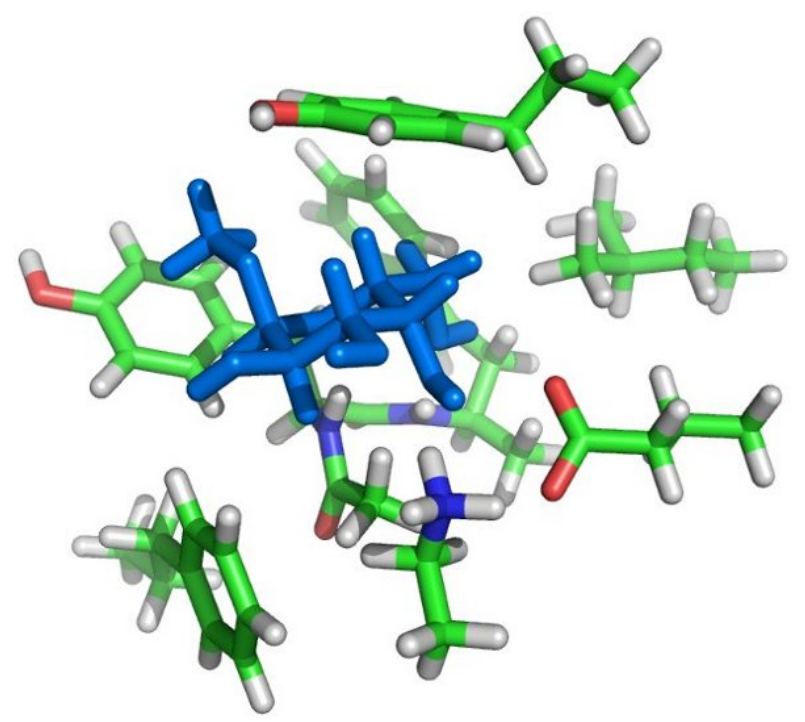

Figura 3.4: Modelo 2 no formato de traços representando ligações químicas.

\section{Modelo 3}

A Figura 3.5 apresenta o modelo construído a partir do recorte do sítio ativo da proteína utilizando $5 \AA$ de raio e a mesma metodologia adotada no modelo 2. Estão presentes um total de 170 átomos sem considerar os átomos do carboidrato, contendo 10 aminoácidos, sendo eles: GFYVVGYWLD (obedecendo a nomenclatura proposta na Figura 1.1). 


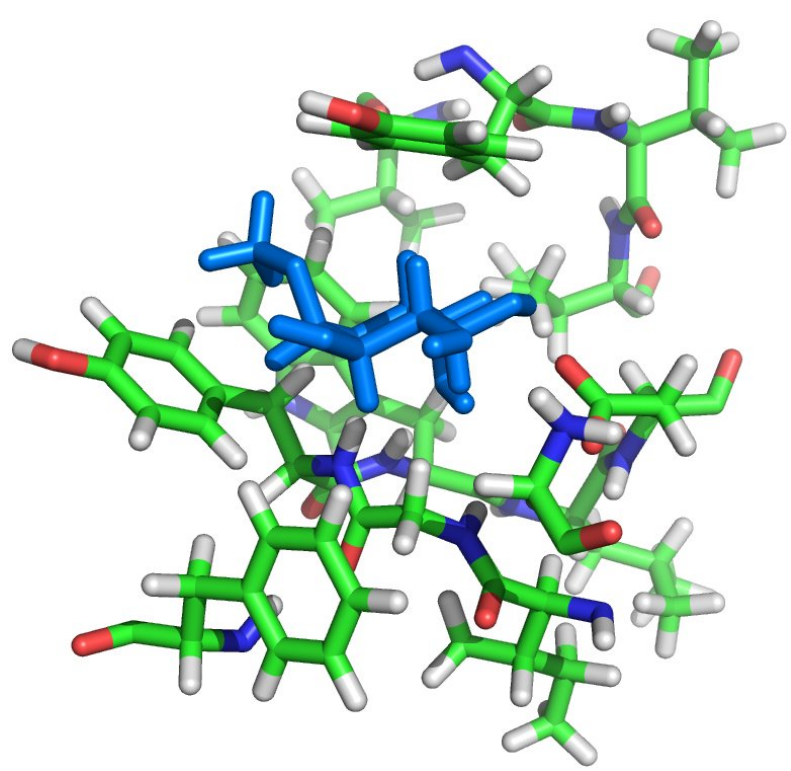

(a)

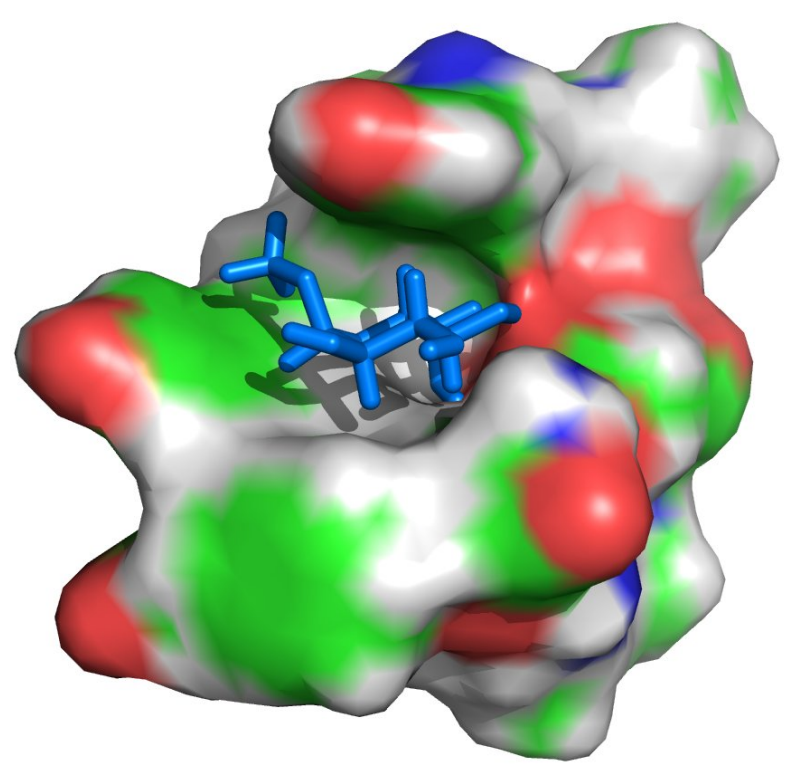

(b)

Figura 3.5: Modelo 3 em duas representações distintas: (a) no formato de traços representando ligações químicas e (b) no formato de esferas atômicas evidenciando o sítio ativo. 


\subsection{Estrutura Eletrônica}

O estudo da estrutura eletrônica será avaliado para os diferentes modelos propostos de forma a estudar a interação proteína-carboidrato.

Nesta etapa não será realizada nenhuma otimização de geometria para o modelo, pois, o modelo é baseado no resultado otimizado pela mecânica molecular clássica. Segundo a literatura, a teoria do funcional da densidade não descreve bem as interações não ligadas, como por exemplo, as interações Van der Waals (VDW). Optamos então por considerar apenas a geometria final após a mecânica molecular, uma vez que a mesma considera, por meio de parametrizações, todas as interações presentes no sistema e possui um custo computacional inferior se comparado ao custo computacional de um código quântico para otimização de geometria. O modelo é uma imagem efetiva do sítio ativo após passar por um tratamento clássico considerando toda a proteína e todas as condições físico-químicas do meio, portanto, a otimização de geometria do mesmo pode perder interações importantes.

Abordaremos algumas propriedades, como a energia de ligação, absorção UV/Vis e testes sistemáticos a respeito dos três modelos propostos para selecionar um modelo e garantir sua validade. Finalmente, poderemos investigar os mecanismos da interação proteína-carboidrato.

\subsection{Absorção UV/Vis}

A DFT é uma teoria de estado fundamental e pode não descrever corretamente estados excitados de um sistema. Para estudar o espectro ótico de um sistema é necessário uma boa descrição dos estados excitados, principalmente as excitações que envolvem transições entre o nível de energia mais alto ocupado (Highest Occupied Molecular Orbital - HOMO) e o nível de mais baixa energia desocupado (Lowest Unoccupied Molecular Orbital - LUMO) e níveis próximos ao HOMO e LUMO. Diante desta dificuldade, escolhemos estudar as propriedades óticas utilizando um método semi-empírico dentro do formalismo Hartree-Fock (HF), chamado ZINDO, ( Zerner's Intermediate Neglect of Differential Overlap). Este é um método especialmente parametrizado para calcular as propriedades óticas [30] em sistemas selecionados. Os resultados experimentais 
da proteína, que apresentaremos a seguir, foram obtidos apenas no caso da interação com o carboidrato GAL, utilizando o espectrômetro Hitachi U2800, pelo grupo do Prof. Valtencir Zucolotto do Instituto de Física de São Carlos, na Universidade de São Paulo [21]. Utilizamos um total de 80 excitações no espectro de energia dos modelos.

A Figura 3.6 apresenta o espectro UV experimental e teórico para todos os modelos. Notamos inicialmente que os espectros experimentais obtidos com ou sem o carboidrato GAL são bastante semelhantes. O mesmo é observado nos espectros teóricos utilizando todos os três modelos, embora o máximo de absorção apresente diferentes deslocamentos com relação aos resultados experimentais. Como já se sabe, a literatura atribui majoritariamente o efeito de absorção no UV ao triptofano em sistemas proteicos, sendo um aminoácido encontrado no sítio ativo da proteína [13].

O limiar de absorção (primeira excitação ativa) ocorreu no comprimento de onda de 334,5 nm, com uma força de oscilador (FO) de 0,0019 e o máximo de absorção ocorreu em 295,4 nm e com um FO de 0,0752 para o modelo 1. Para o modelo 2, o limiar de absorção aparece em $305 \mathrm{~nm}$ com uma FO de 0,0108 e o máximo de absorção em 278,9 nm com uma FO de 0,14585. O modelo 3 apresenta um limiar de absorção em 304,2 nm com uma FO de 0,0122 e o máximo de absorção ocorreu em 295,3 nm com uma FO de 0,0741. Diferentemente dos outros modelos, somente o modelo 2 apresentou um primeiro pico que acompanha o comportamento experimental ${ }^{1}$, isto se torna ainda mais intrigante quando observamos que o modelo 3 não reproduz este mesmo resultado embora tenha sido construído de forma semelhante ao modelo 2. Notamos que a substituição de $\mathbf{O}$ e $\mathbf{N}$ por $\mathbf{H}$ reduz o número de estados eletrônicos, tornando as excitações internas mais acessíveis. Acreditamos que o problema pode ser uma limitação computacional. Apesar de ser uma característica interessante, não possui grande importância, pois o pico está localizado no limite experimental onde não é possível observar transições eletrônicas.

\footnotetext{
${ }^{1}$ Este pico não foi apresentado na figura por motivos de clareza, mas pode ser encontrado no apêndice $\mathrm{C}$.
} 


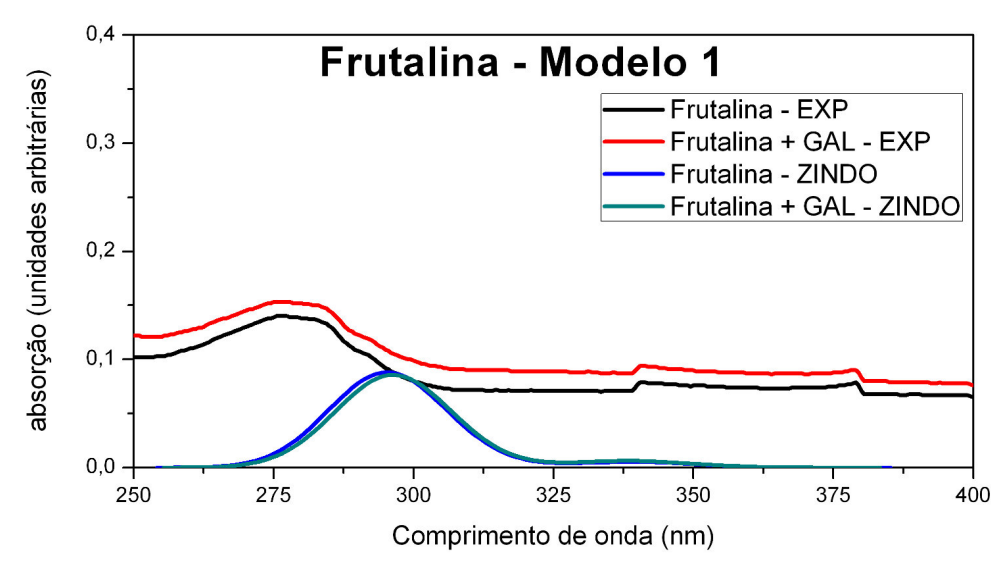

(a)

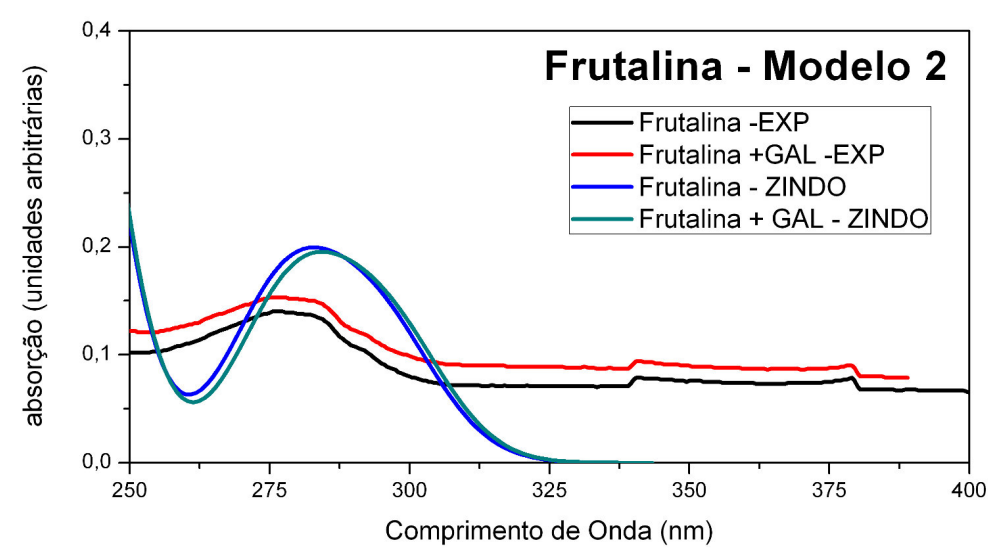

(c)

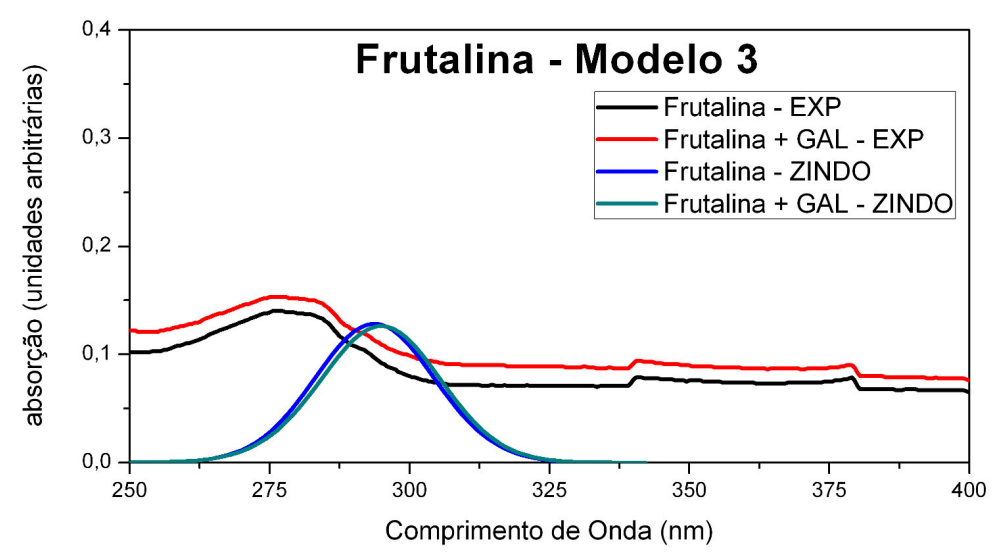

(e)

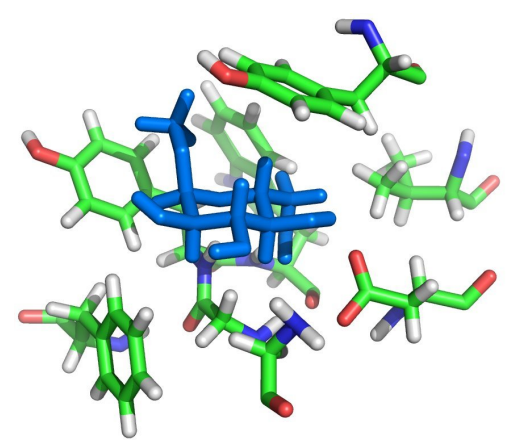

(b)

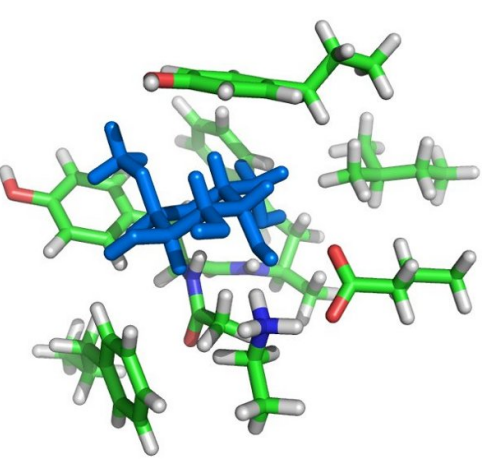

(d)

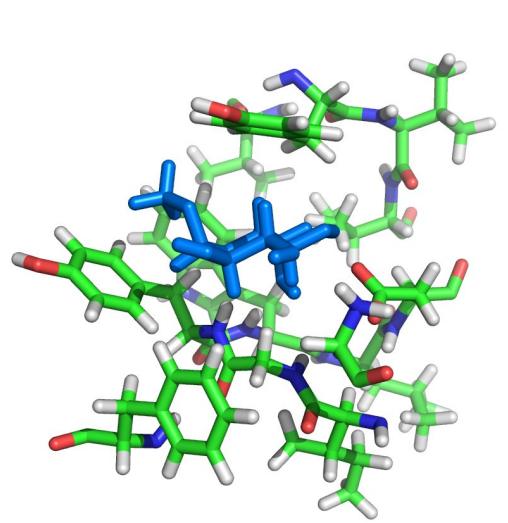

(f)

Figura 3.6: Resultados obtidos para absorção UV e exemplo visual respectivamente para: (a) e (b) Modelo 1; (c) e (d) Modelo 2; (e) e (f) Modelo 3. Repetimos os resultados experimentais em todos os gráficos por motivos de clareza. 


\subsection{Energias de Ligação}

Um dos objetivos deste trabalho é propor um modelo quântico que, mesmo apresentando certas limitações, deve servir como uma primeira aproximação para o cálculo de $\Delta H$ utilizando uma descrição $a b$ initio. A variação de entalpia pode ser obtida durante um experimento de microcalorimetria, sendo umas das grandezas responsáveis por caracterizar a interação sistema - ligante. Para o caso da Jacalina, estas medidas podem ser encontradas na referência [38]. As energias de ligação podem ser obtidas a partir dos cálculos de primeiros princípios através das diferenças de energias totais:

$$
E_{\text {ligação }}=E_{\text {sitio ativo }+ \text { carboidrato }}-E_{\text {sítio ativo isolado }}-E_{\text {carboidrato isolado }}
$$

Os termos da equação 3.1 representam: $E_{\text {sítio ativo + carboidrato }}$ energia total do sistema completo; $E_{\text {sítio ativo isolado }}$ energia total do sítio ativo isolado; $E_{\text {carboidrato isolado }}$ energia total do carboidrato isolado. Portanto, para cada energia de ligação foram realizados 3 cálculos de energia total distintos. É importante notar que o modelo não descreve outras interações entre a proteína e o carboidrato como, por exemplo, efeitos de solvente, de temperatura, entrópicos, etc. Como foi mencionado na Introdução, a microcalorimetria ITC extrai diversos parâmetros termodiâmicos, dentre os quais estamos comparando apenas a variação de entalpia $\Delta H$

Como mencionamos na seção 2.3, o método PAW trata de formas diferentes os elétrons de valência e os elétrons de caroço e para realizarmos os cálculos, devemos selecionar um conjunto de funções projetoras (eq. 2.26) que serão responsáveis por unir as diferentes regiões. Baseado na literatura [22, 40, 41], escolhemos os seguintes conjuntos de funções projetoras para os átomos: 1 função tipo s para o $\mathbf{H} ; 2$ funções tipo s, 2 funções tipo $\mathbf{p}$ e 1 função tipo $\mathbf{d}$ para os átomos $\mathbf{C}, \mathbf{N}$ e $\mathbf{O}$.

Para isso, é necessário construir configurações que informam quais são os elétrons que serão tratados exatamente e quais serão tratados pela aproximação de caroço congelado. Outro fator importante é o número de funções projetoras selecionadas que responsáveis para descrever a ligação entre a região de caroço e valência do átomo. $\mathrm{O}$ número de funções projetoras (s,p,d) e número de elétrons de valência [número] para cada átomo é: $\mathrm{H}:(1,0,0)[1] ; \mathrm{C}:(2,2,1)[4] ; \mathrm{N}:(2,2,1)[5] ; \mathrm{O}:(2,2,1)[6]$. Estes projetores foram adotados com base na literatura [40-42]. Testes de convergência da base de 
ondas planas foram realizados e verificamos que um valores para o truncamento do "corte" de ondas planas de 40 Ry e uma correspondente para a densidade de carga de 160 Ry eram suficientes. As células unitárias utilizadas possuíam uma distância mínima de $6 \AA$ de vácuo entre os átomos mais próximos das imagens periódicas.

Estudamos oito tipos diferentes de sistemas para estudar a energia de ligação: a) modelo 2 para cada um dos quatro carboidratos (GAL, AMG,MMA e GYP); b) modelo 3 para o carboidrato GAL; c) modelo 1 para os carboidratos GAL e AMG; d) modelo 2 sem otimização de geometria para o carboidrato GAL. Apresentamos na Tabela 3.3 os dados dos átomos envolvidos em cada modelo, bem como a célula unitária utilizada. Admitimos que o modelo 2 deva ser o modelo que melhor descreve as interações do sistema com o menor custo computacional, por isso, efetuamos cálculos de energia de ligação para todos os carboidratos utilizando este modelo. Para o modelo 1, consideramos os carboidratos GAL e AMG. Apenas o carboidrato GAL foi utilizado nos cálculos dos modelos 3 e 2 sem otimização de geometria.

\begin{tabular}{lllccc}
\hline Modelo & Carboidrato & \multicolumn{3}{c}{ Número de Átomos } & Célula \\
& & Total & Sítio Ativo & Carboidrato & Unitária $(\AA)$ \\
\hline Modelo 1 & GAL & $C_{57} H_{81} N_{9} O_{18}$ & $C_{49} H_{69} N_{9} O_{12}$ & $C_{6} H_{12} O_{6}$ & $24 \times 20 \times 20$ \\
Modelo 1 & AMG & $C_{58} H_{83} N_{9} O_{18}$ & $C_{51} H_{69} N_{9} O_{12}$ & $C_{7} H_{14} O_{6}$ & $23 \times 23 \times 23$ \\
\hline Modelo 2 & GAL & $C_{57} H_{88} N_{4} O_{12}$ & $C_{49} H_{76} N_{4} O_{6}$ & $C_{6} H_{12} O_{6}$ & $24 \times 20 \times 20$ \\
Modelo 2 & AMG & $C_{58} H_{90} N_{4} O_{12}$ & $C_{51} H_{76} N_{4} O_{6}$ & $C_{7} H_{14} O_{6}$ & $20 \times 22 \times 23$ \\
Modelo 2 & MMA & $C_{58} H_{90} N_{4} O_{12}$ & $C_{51} H_{76} N_{4} O_{6}$ & $C_{7} H_{14} O_{6}$ & $20 \times 20 \times 24$ \\
Modelo 2 & GYP & $C_{57} H_{88} N_{4} O_{12}$ & $C_{49} H_{76} N_{4} O_{6}$ & $C_{7} H_{14} O_{6}$ & $23 \times 20 \times 21$ \\
Modelo 2 & GAL & $C_{57} H_{88} N_{4} O_{12}$ & $C_{49} H_{76} N_{4} O_{6}$ & $C_{6} H_{12} O_{6}$ & $24 \times 20 \times 20$ \\
\hline Modelo 3 & GAL & $C_{68} H_{102} N_{8} O_{16}$ & $C_{62} H_{90} N_{8} O_{10}$ & $C_{6} H_{12} O_{6}$ & $24 \times 20 \times 20$ \\
\hline
\end{tabular}

Tabela 3.3: Sistemas estudados e o valor das células cúbicas simples utilizadas para cada simulação.†indica a configuração para o modelo 2 sem a otimização de geometria.

Os valores que obtivemos para as energias de ligação, bem como a sua comparação com os resultados experimentais, são apresentados na Tabela 3.4. Vemos que os resultados obtidos utilizando o modelo 2 reproduzem a ordem de grandeza das energias de ligação experimentais, embora as pequenas diferenças observadas entre os diferentes carboidratos não foram reproduzidas. É importante notar que os cálculos experimentais possuem diversos parâmetros que não possuem um controle altamente preciso, como o efeito anomérico dos carboidratos e a pureza da solução utilizada [12, 21]. 
Os carboidratos GAL e AMG apresentam energias de ligação inferiores às energias experimentais, enquanto os carboidratos MMA e GYP apresentam valores superiores. O AMG é um caso de interesse na literatura [38], pois tem uma constante de ligação muito superior à constante de afinidade de ligação dos outros carboidratos.

Como mencionamos anteriormente na seção 1.2, os carboidratos não apresentam grandes diferenças entre si, possuindo geometrias relativamente semelhantes cuja grande diferença de conformação é a modificação dos átomos ligados ao anel. A principal diferença entre o carboidrato GAL e os outros é a ausência de um grupo metil, e vemos que este é o carboidrato que apresenta os resultados para energia de ligação mais próximos aos experimentais em todos os modelos. Estudamos as energias de ligação para o modelo 1 apenas com os carboidratos GAL e AMG. Estes carboidratos foram selecionados devido aos resultados experimentais bastante distintos e também ao interesse experimental, no caso do AMG. Os resultados não apresentam grandes diferenças se compararmos aos resultados obtidos com o modelo 2. Embora a energia de ligação obtida com o carboidrato GAL seja a mais próxima do resultado experimental, acreditamos que este é um resultado fortuito, uma vez que não observamos uma melhora correspondente nos resultados obtidos com a AMG. O funcional de troca e correlação PBE utilizado não possui nenhuma correção VDW [43]. Os sistemas AMG, MMA e GYP possuem grupos metil que são responsáveis por interações do tipo VDW no sítio ativo da proteína, o que pode ser o fator responsável pelo melhor resultado obtido com a GAL.

Vemos que o resultado obtido utilizando o modelo 3 não apresenta uma sistemática melhora na contribuição para o valor da energia de ligação no caso do carboidrato GAL. Devido ao maior custo computacional envolvido no cálculo com este modelo, escolhemos não prosseguir na investigação utilizando este modelo com os outros carboidratos.

É importante notar a ordem de grandeza das energias de ligações que estão sendo avaliadas: lembrando que 1 Hartree (ou 27,17 eV) equivale a 627,509 kcal/mol, as diferenças de energias obtidas nos cálculos aqui realizados são da ordem de $10^{-3}$ Hartree. Analisando sob o ponto de vista experimental, uma ligação de hidrogênio entre moléculas de água é tipicamente da ordem de $5 \mathrm{kcal} / \mathrm{mol}$ [44]. Sendo assim, as energias medidas nos casos aqui estudados são bastante pequenas. Chamamos atenção 
para o fato de que utilizamos somente as contribuições eletrostáticas para estimar as energias de ligação, não considerando assim de forma direta: condições termodinâmicas, interações não ligadas e efeitos de solvente. Além disto, segundo a literatura [1], não é possível verificar corretamente a energia de ligação da interação proteína-carboidrato apenas com uma conformação, e neste trabalho consideramos apenas uma imagem conformacional para cada carboidrato. Apesar destas aproximações, todos os nossos cálculos $a b$ initio reproduzem os resultados experimentais dentro de uma concordância usualmente aceitável na literatura para cálculos especificamente parametrizados.

\begin{tabular}{llcccc}
\hline Modelo & Carboidrato & $\begin{array}{c}\text { Corte de ondas } \\
\text { planas }(\mathrm{Ry})\end{array}$ & $\begin{array}{c}E_{\text {ligasão }} \\
(\mathrm{kcal} / \mathrm{mol})\end{array}$ & $\begin{array}{c}\Delta H \\
\text { Experimental } \\
(\mathrm{kcal} / \mathrm{mol})\end{array}$ & $\begin{array}{c}\left|\Delta E_{\text {ligasão }}\right| \\
(\mathrm{kcal} / \mathrm{mol})\end{array}$ \\
\hline Modelo 1 & GAL & 30 & $-5,88$ & & 0,34 \\
Modelo 1 & AMG & 40 & $-5,54$ & $-5,54 \pm 0,03$ & $9 \times 10^{-4}$ \\
Modelo 2 & GAL & 30 & $-4,82$ & $-10,83 \pm 0,03$ & 6,01 \\
& & 30 & $-4,47$ & & 1,06 \\
Modelo 2 & AMG & 40 & $-4,10$ & $-5,54 \pm 0,03$ & 1,43 \\
Modelo 2 & \multirow{2}{*}{ MMA } & 30 & $-4,84$ & & 5,99 \\
& & 40 & $-4,54$ & $-10,83 \pm 0,03$ & 6,29 \\
Modelo 2 & GYP & 30 & $-8,66$ & & 5,02 \\
& & 40 & $-8,32$ & $-3,64 \pm 0,03$ & 4,67 \\
Modelo 2 & \multirow{2}{*}{ GAL } & 30 & $-7,10$ & & 2,9913 \\
& & 40 & $-6,78$ & $-4,11 \pm 0,01$ & 2,67 \\
Modelo 3 & GAL & 30 & $-12,33$ & & 6,78 \\
& & 40 & $-12,89$ & $-5,54 \pm 0,03$ & 7,34 \\
& & 30 & $-4,65$ & & 0,89 \\
\hline
\end{tabular}

Tabela 3.4: Resultados aqui obtidos para as energias de ligação utilizando dois valores para a energia da base de corte de ondas planas do método PAW. †indica a configuração para o modelo 2 sem a otimização de geometria. Os valores experimentalmente obtidos são apresentados para comparação e a última coluna fornece a diferença entre os valores teóricos e experimentais. 


\subsection{Densidade Eletrônica}

Analisaremos nesta seção algumas isosuperfícies de densidades eletrônica para os sistemas estudados, de forma a investigar as interações eletrônicas responsáveis por formar a ligação entre o sítio ativo e os diferentes carboidratos. As isosuperfícies de densidade eletrônica são obtidas através das funções de onda de KS (seção 2.3.3).

Notamos que as Figuras desta seção possuem uma denotação diferente das Figuras anteriores: os átomos $\mathbf{C}, \mathbf{N}, \mathbf{O}$ e $\mathbf{H}$ são representados pelas cores cinza, verde, vermelha e branca respectivamente; as regiões azuis e amarelas representam uma isosuperfície dos orbitais; Foi traçado um plano azul claro para facilitar a visualização dos orbitais; os índices e nomenclaturas dos aminoácidos apresentados nas figuras seguem os códigos PDB.

A Figura 3.7 apresenta a densidade eletrônica nas regiões do HOMO e LUMO obtidas utilizando o modelo 2 e o carboidrato GAL. Observa-se que a densidade eletrônica do HOMO está concentrada no aminoácido Asp125 que apresenta uma grande reatividade, pois não possui átomos de $\mathbf{H}$ saturando as ligações ${ }^{2}$. Existe também uma pequena parcela de densidade eletrônica presente no $\mathbf{O}$ do carboidrato, próximo à Asp125. Notamos que não há formação de ligações de hidrogênio ${ }^{3}$ entre Asp125 e GAL. Isto indica que algum outro tipo de interação entre o carboidrato e o sítio ativo se realiza neste local. A densidade eletrônica na região do LUMO apresenta uma dispersão eletrônica no sítio ativo, majoritariamente concentrada sobre a Gly1, Asp125 e a GAL; as densidades eletrônicas no carboidrato estão concentradas sobre os $\mathbf{O}$ próximos ao sítio ativo com uma pequena contribuição num dos $\mathbf{C}$. A densidade eletrônica obtida na região do HOMO na AMG, é apresentada na Figura 3.8. Podemos ver um comportamento bastante semelhante observado no caso da GAL na região do HOMO. É possível notar densidades eletrônicas localizadas em dois $\mathbf{O}$ do carboidrato, o que ocorre devido à distinta geometria da AMG quando comparada à da GAL. A densidade eletrônica na região do LUMO apresenta um comportamento diferente, com orbitais dispersos em Gly1, Phe 47, Asp125 e AMG. De forma similar a região LUMO para GAL, a Asp125 apresenta uma densidade eletrônica apenas nos O. Nota-se que

\footnotetext{
${ }^{2}$ conformação usual do aminoácido Asp

${ }^{3}$ utilizamos aqui a definição clássica para ligação de $\mathbf{H}$ fornecida pelo código computacional $M a$ terials Studio $4.0[31]$
} 
a dispersão dos orbitais no sistema todo não se estende entre o carboidrato e a lectina como observado no sistema anterior(Figura 3.7). Na Figura 3.9 apresentamos as densidades eletrônicas obtidas com a MMA e na Figura 3.10 com a GYP. Podemos notar que as regiões de HOMO são bastante semelhantes às da Figura 3.7 e 3.8 para os da GAL e AMG. No entanto, ambas regiões de LUMO são semelhantes ao caso da GAL e todas são, portanto, ligeiramente diferentes ao caso da AMG. Comparando os resultados obtidos pelo modelo 1 apresentados na Figura 3.11, e o modelo 2 para GAL(Figura 3.7) não é possível notar diferenças na região do HOMO, entretanto, a região do LUMO apresenta um comportamento bastante diferente, onde os orbitais estão concentrados em uma região onde usualmente haveria uma ligação peptídica, o que não é razoável. Isto reforça a hipótese de que os resultados utilizando o modelo 2 representam melhor as interações que ocorrem no sistema.

Notamos que as ligações de hidrogênio (obtidas classicamente) estão localizadas sobre os aminoácidos Tyr122, Trp123 e Gly1. Vemos pelas Figuras 3.7 a 3.11 que em nenhum caso a densidade eletrônica se concentra sobre estes aminoácidos na região do HOMO. Chamamos a atenção para o fato de que é usual na literatura [1] atribuir às ligações de $\mathbf{H}$ a interação lectina-caroidrato. Entretanto, nossos resultados sugerem que a ligação feita entre o carboidrato e a proteína pode não ser realizada apenas pelas ligações de hidrogênio, mas sim, pelo aminoácido Asp125 que possui uma região de elétrons livres em sua conformação a pH 7,0. 


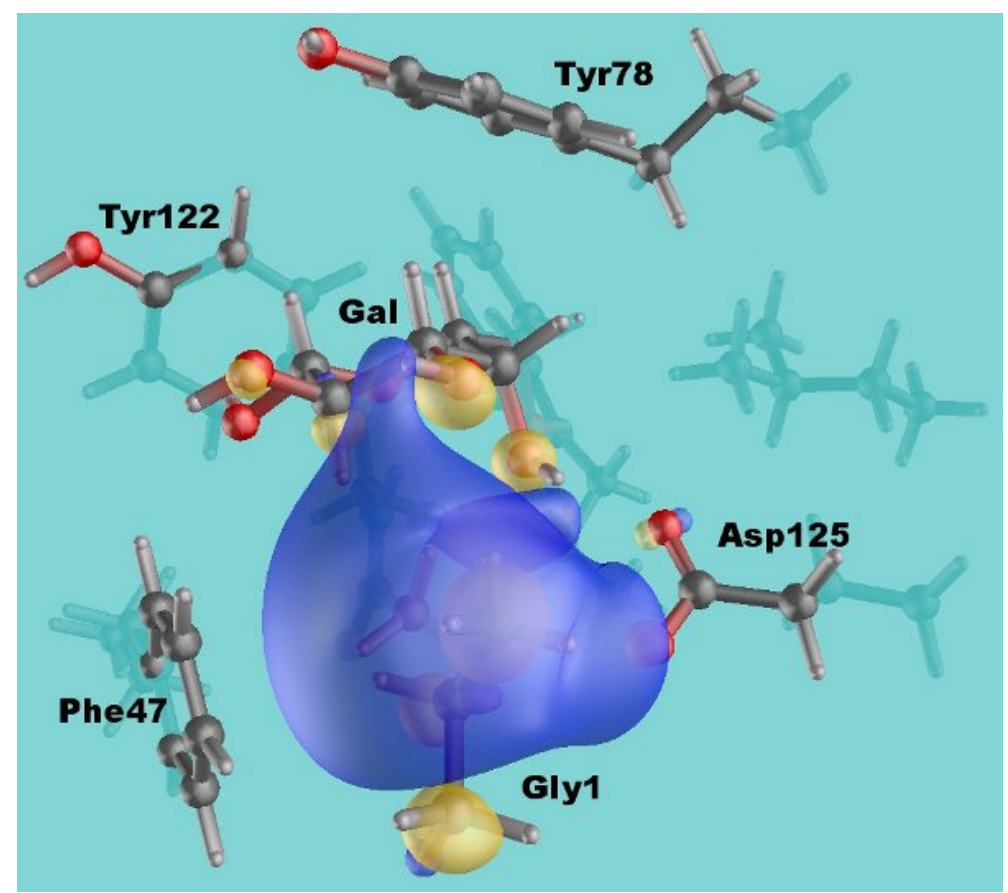

(a) LUMO

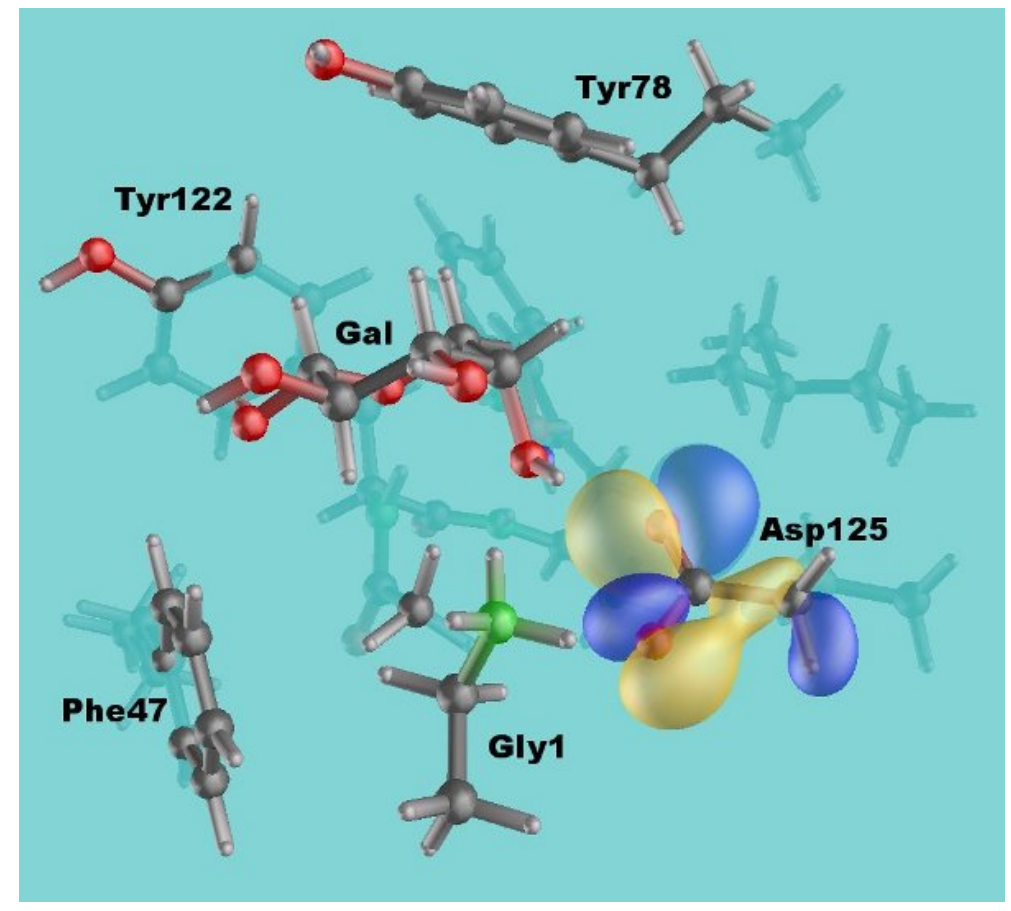

(b) HOMO

Figura 3.7: Isosuperfície de densidade eletrônica HOMO e LUMO do sítio ativo ligada à GAL obtida utilizando o modelo 2. 


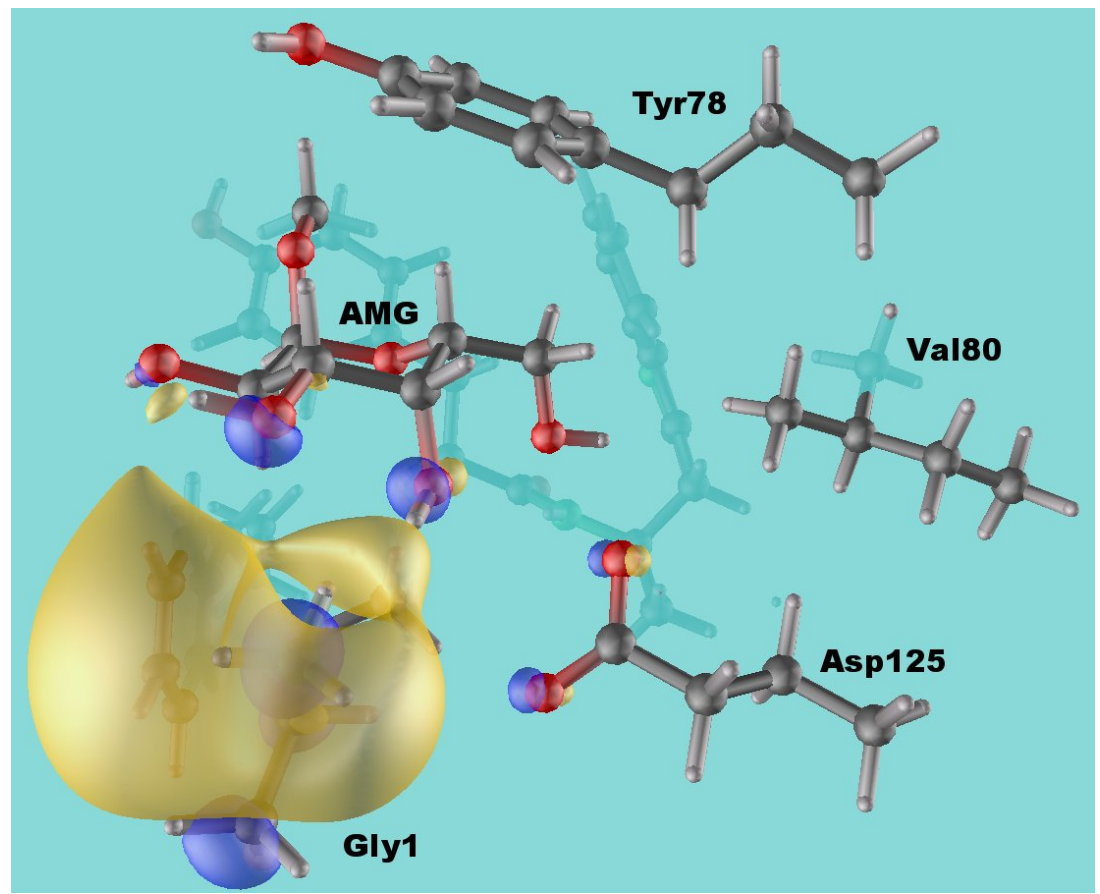

(a) LUMO

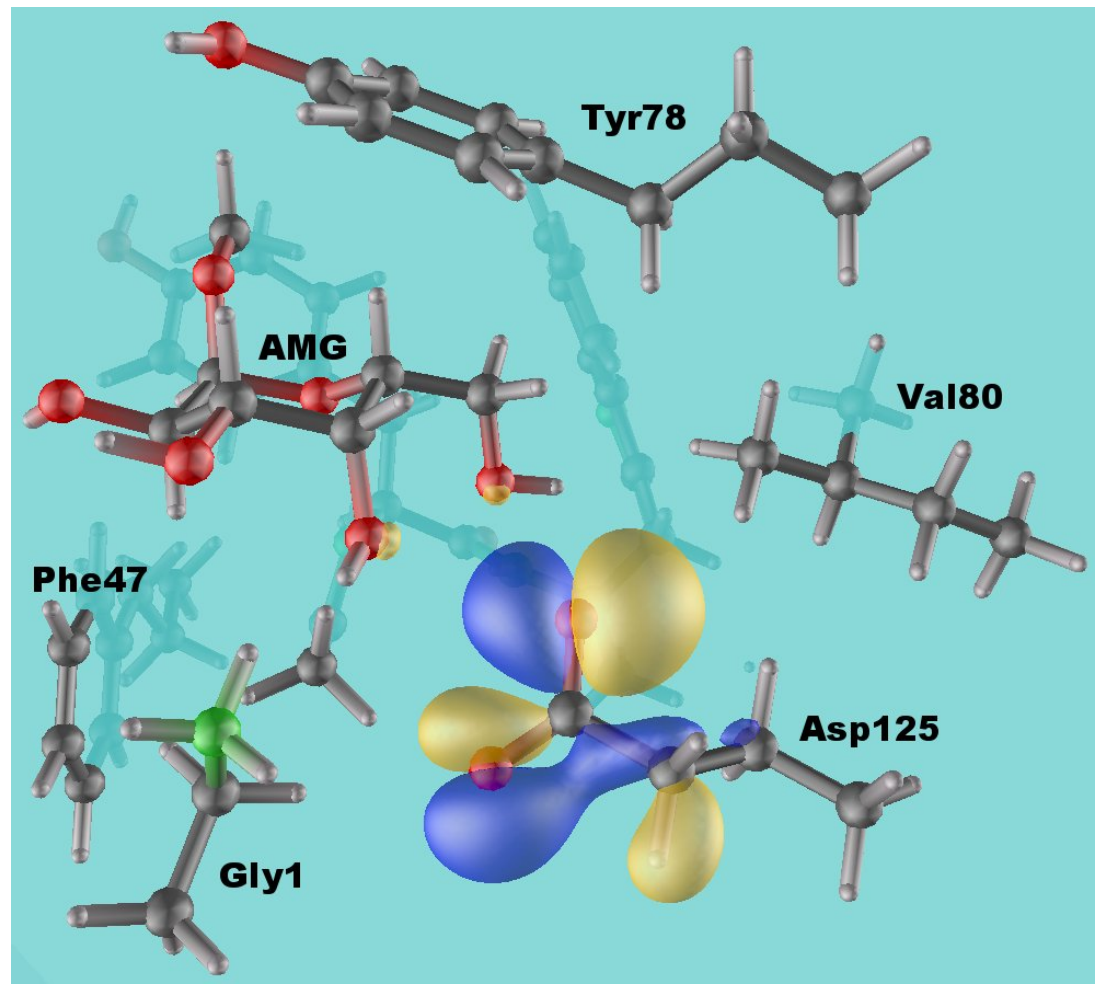

(b) HOMO

Figura 3.8: Isosuperfície de densidade eletrônica HOMO e LUMO do sítio ativo ligada à GAL obtida utilizando o modelo 2. 


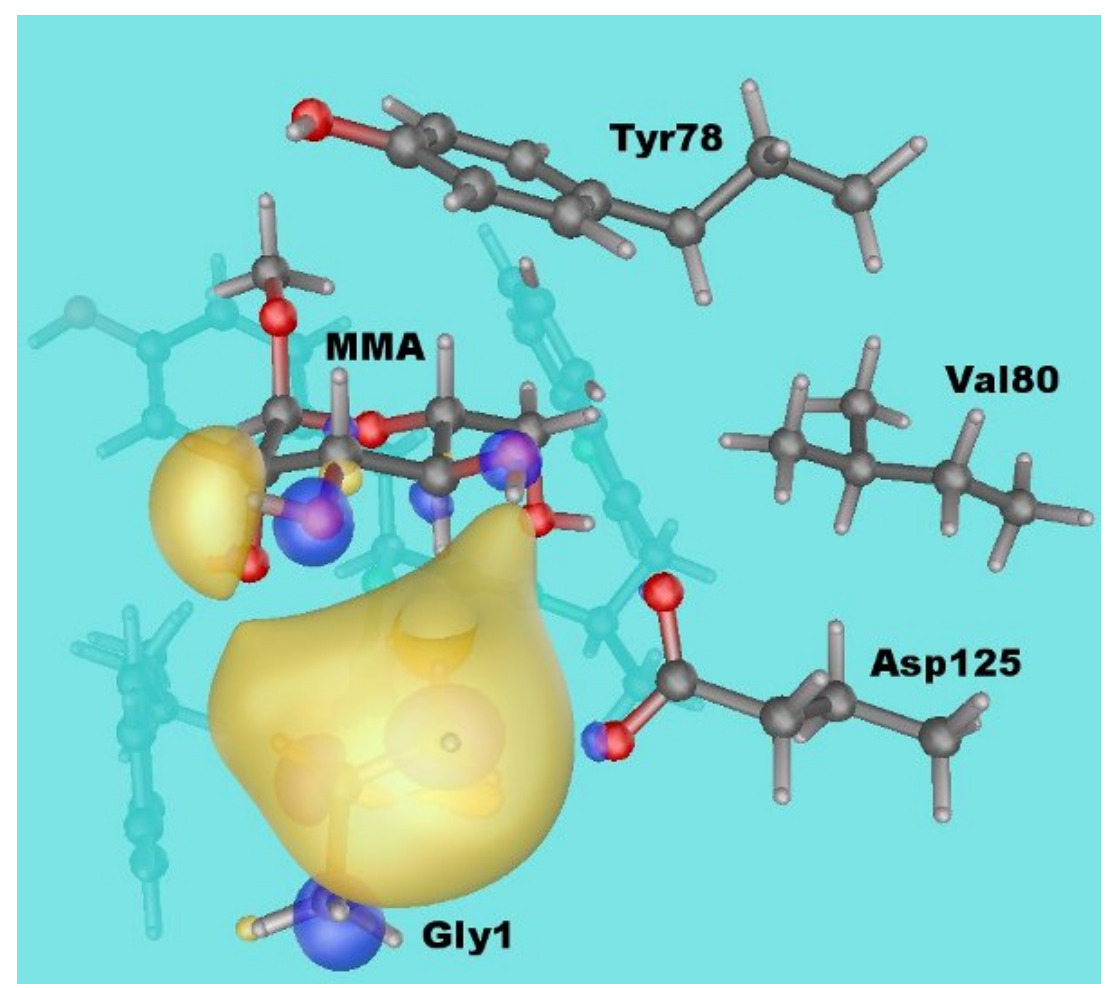

(a) LUMO

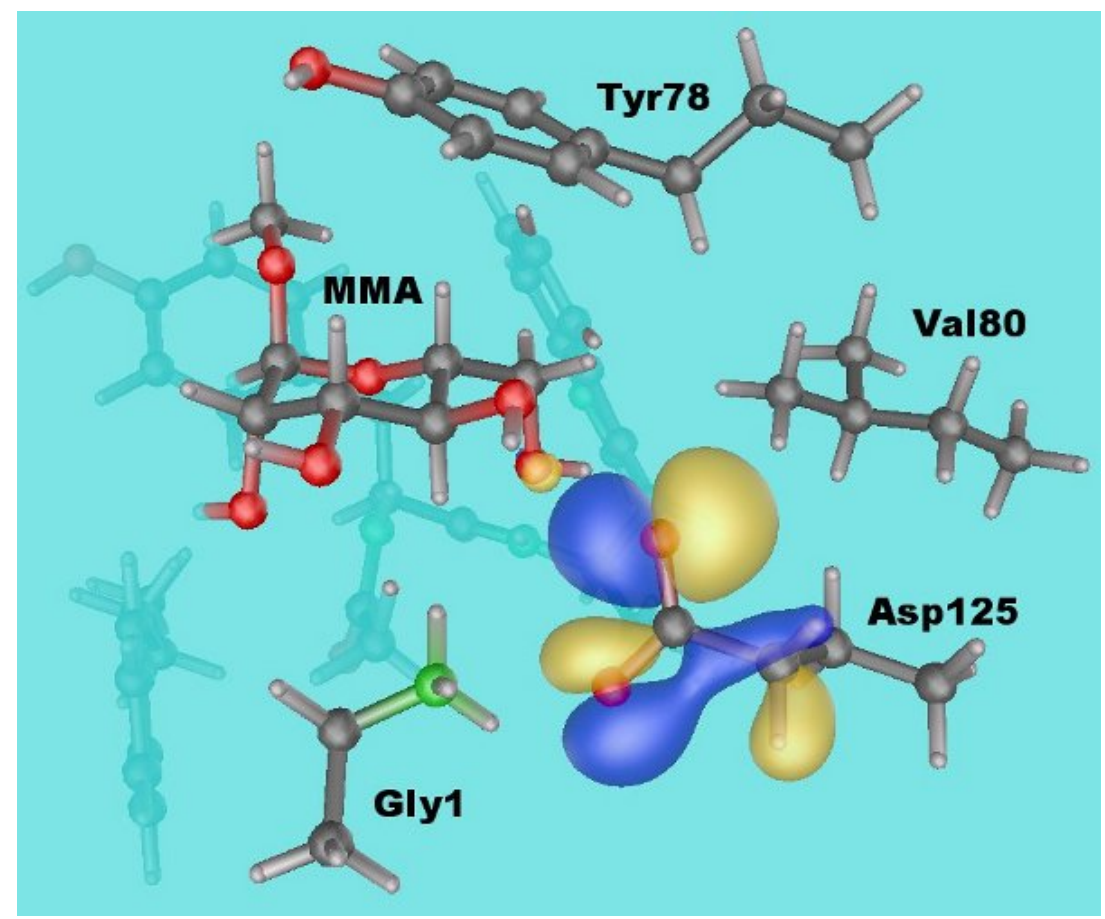

(b) HOMO

Figura 3.9: Isosuperfície de densidade eletrônica HOMO e LUMO do sítio ativo ligada à GAL obtida utilizando o modelo 2. 


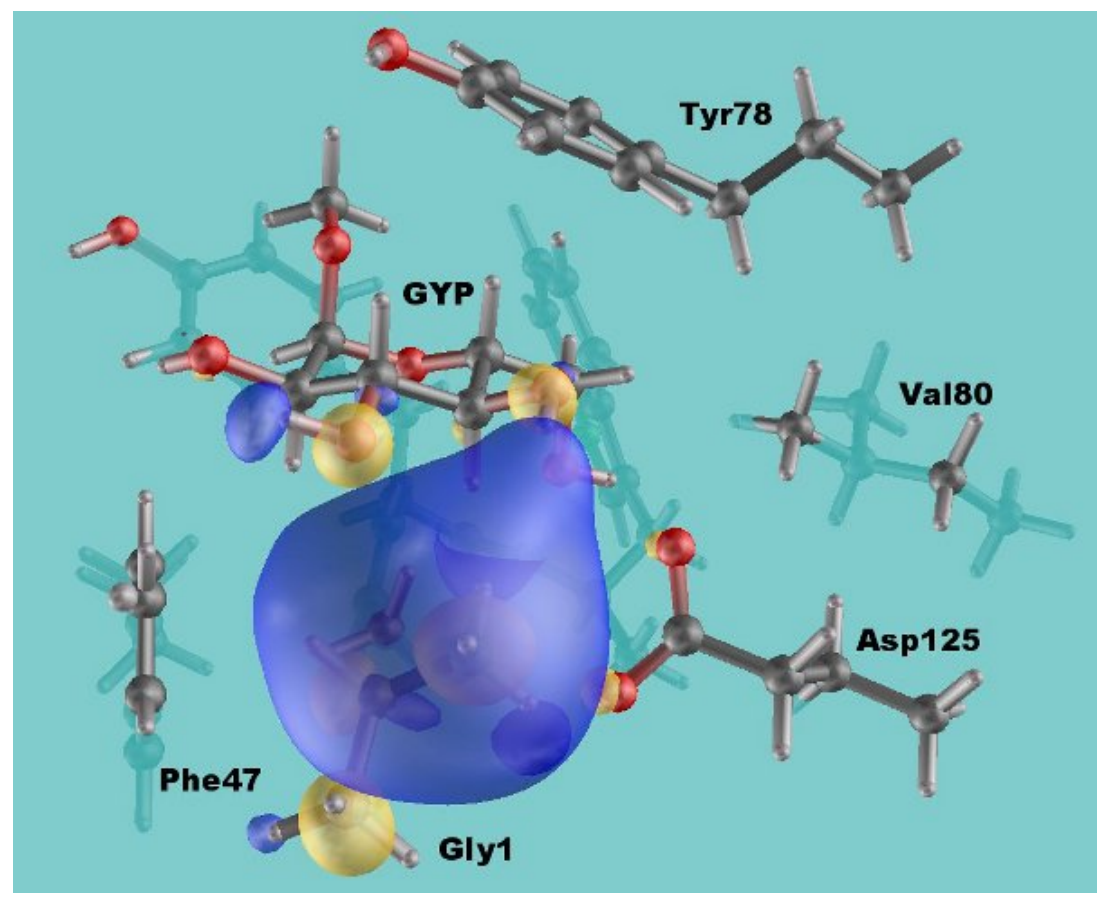

(a) LUMO

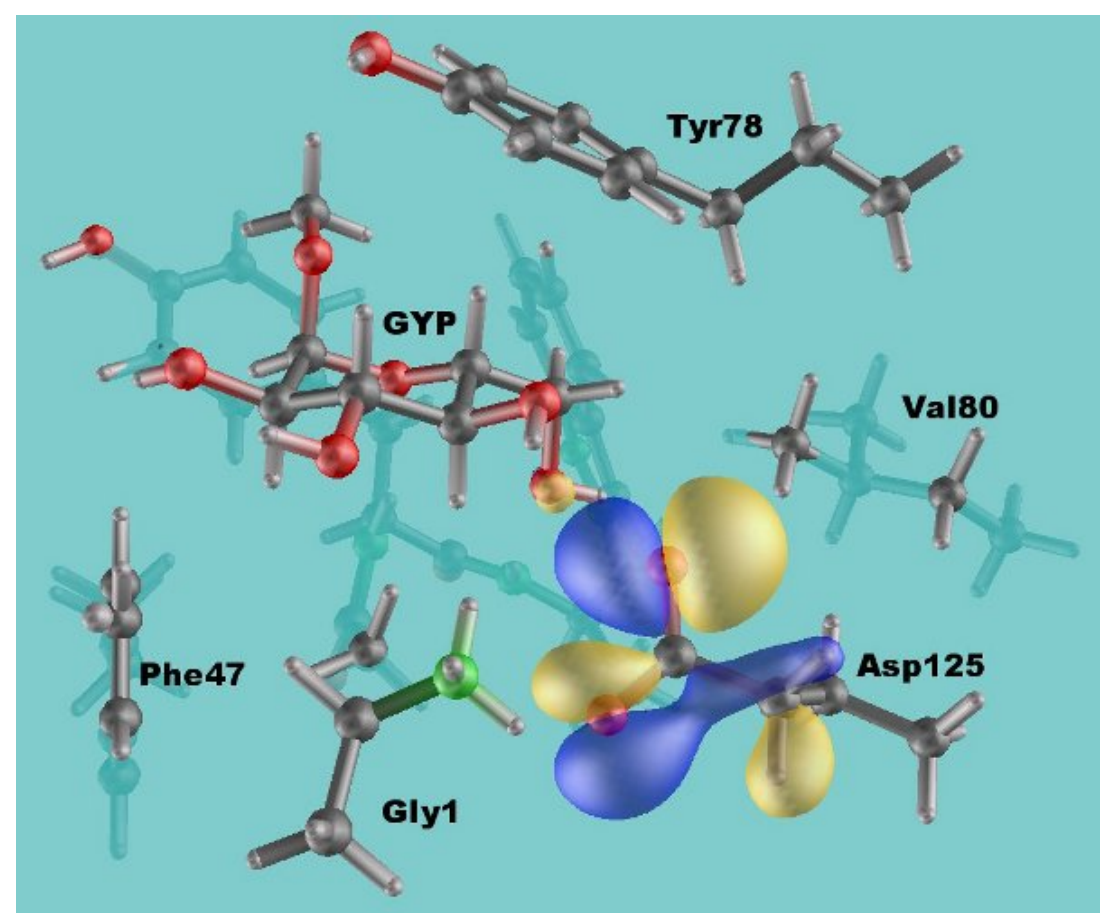

(b) HOMO

Figura 3.10: Isosuperfície de densidade eletrônica HOMO e LUMO do sítio ativo ligada à GAL obtida utilizando o modelo 2. 


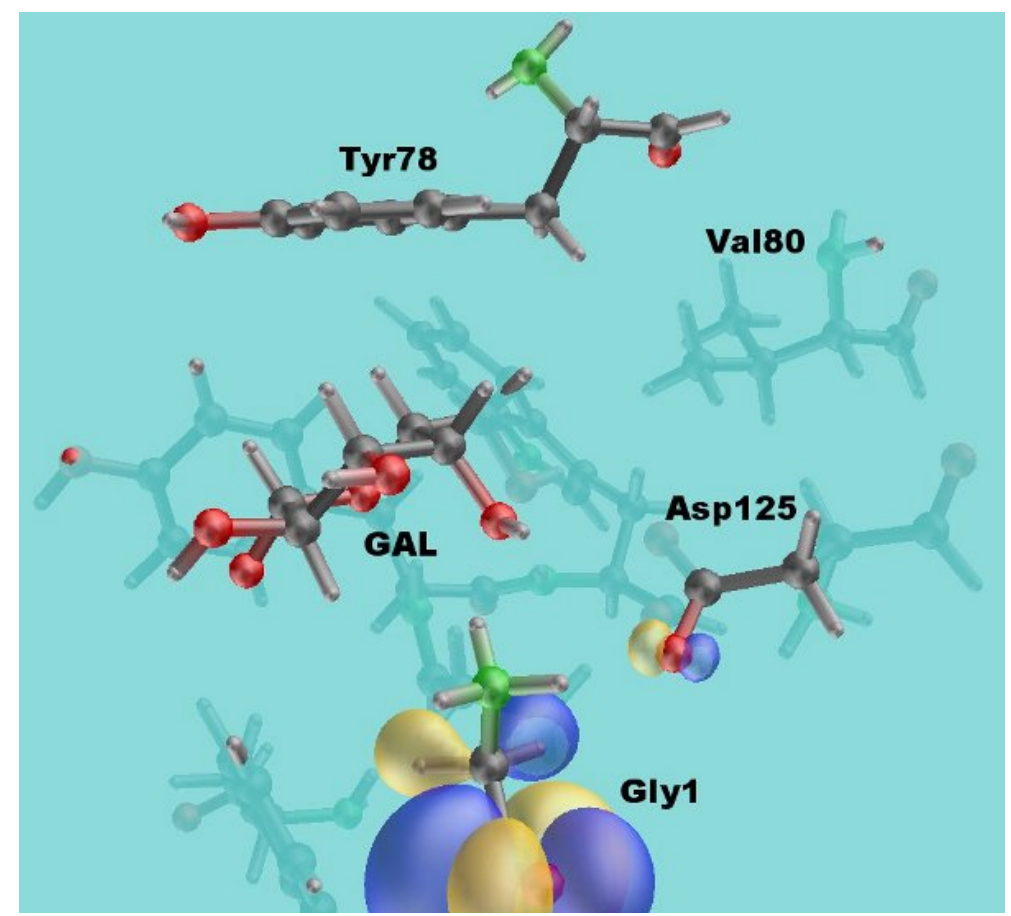

(a) LUMO

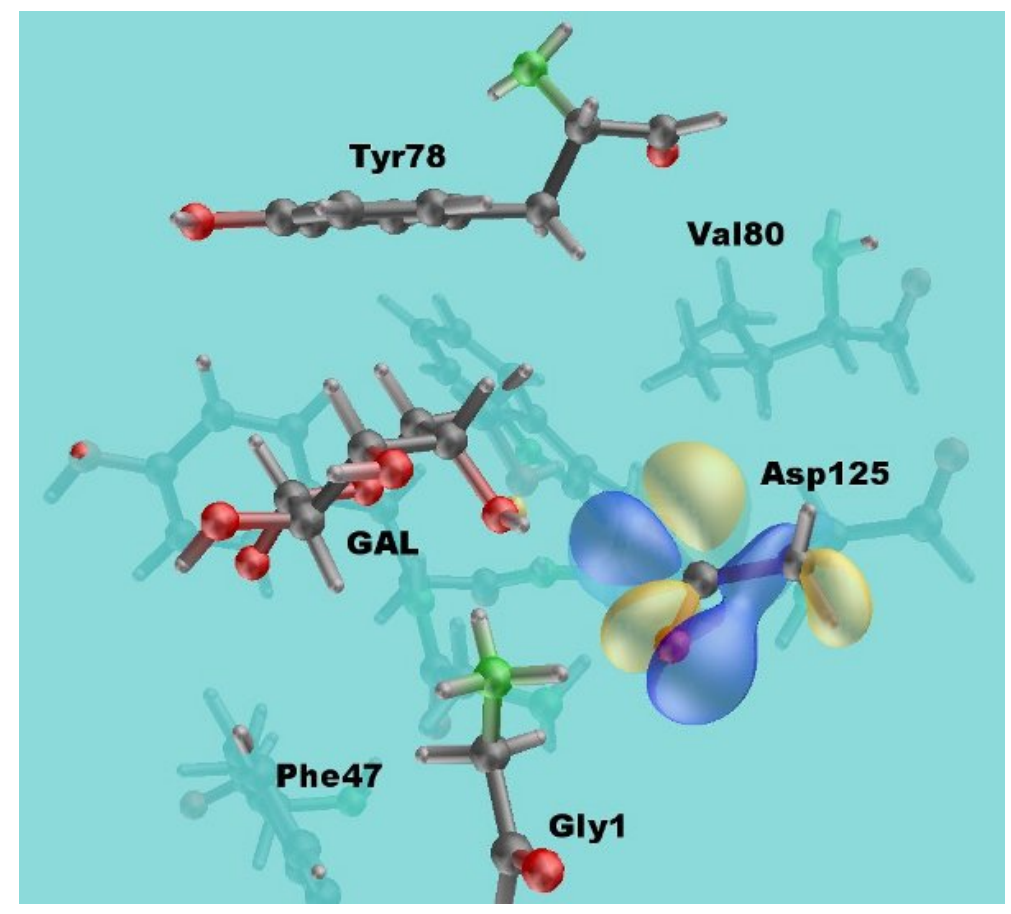

(b) HOMO

Figura 3.11: Isosuperfície de densidade eletrônica HOMO e LUMO do sítio ativo ligada à GAL obtida utilizando o modelo 1. 


\subsection{Densidade de Estados}

Apresentamos na Figura 3.12 as Densidade de Estados (DOS) totais e projetadas nos carboidratos obtidas utilizando o modelo 2. As diferenças de energia HOMOLUMO variam, sendo menor nos sistemas GAL e AMG e maior os sistemas MMA e GYP. Note-se que utilizamos, para melhor visualização, um alargamento dos níveis discretos de energia. Entretanto, os níveis de energia apresentam um comportamento quase contínuo. A contribuição dos carboidratos na região próxima ao HOMO é bem pequena. 


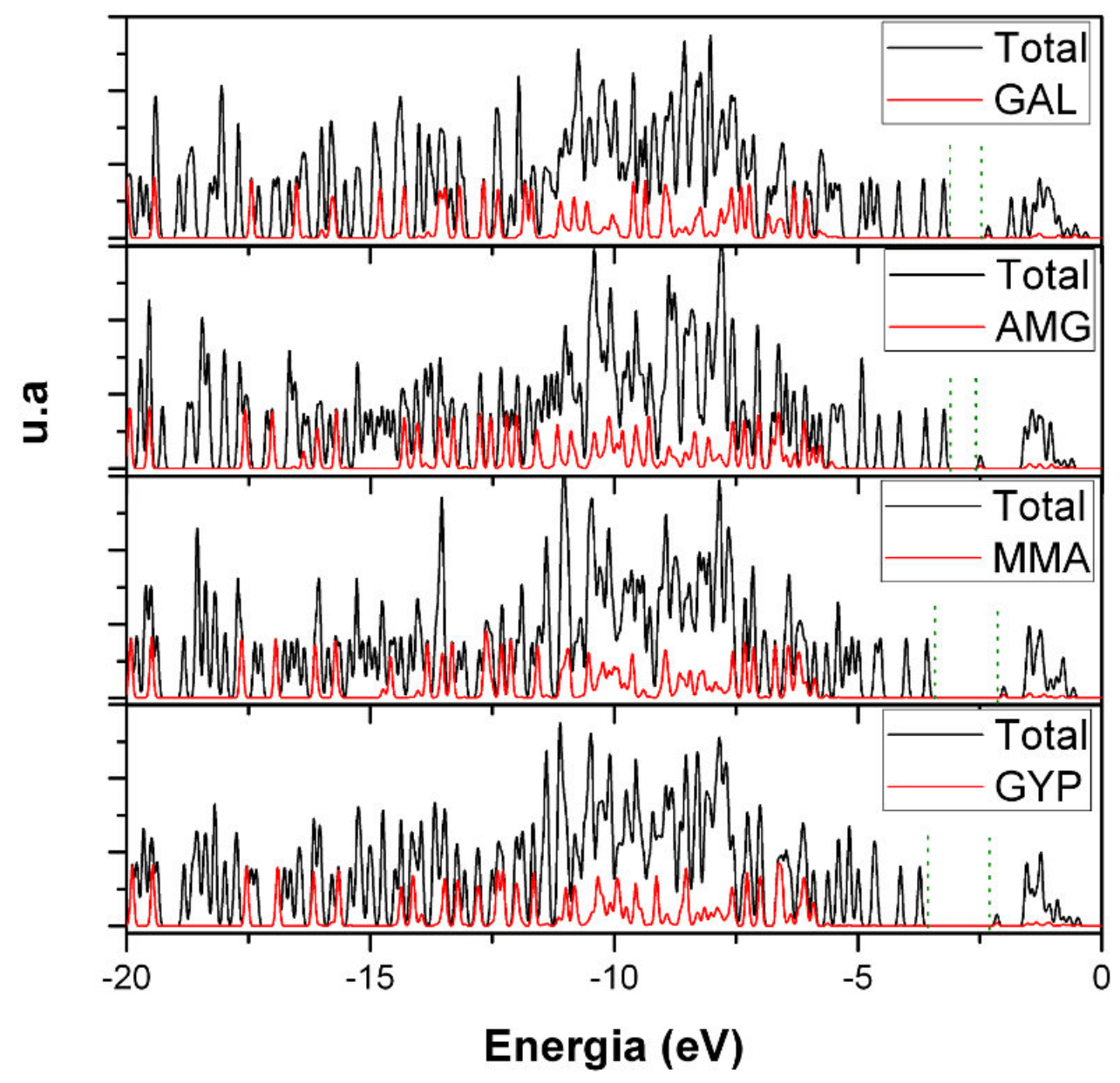

Figura 3.12: Densidades de estados para os sistemas GAL, AMG, MMA e GYP utilizando o modelo 2. Traços em vermelho representam a contribuição dos carboidratos e traços pretos representam as DOS totais. As energias HOMO e LUMO estão indicas por traços pontilhados em cada figura.

Analisaremos de forma mais profunda as interações presentes no sistema GAL, pois as DOS e as densidades eletrônicas nas regiões do HOMO e do LUMO apresentam comportamentos semelhantes em todos os sistemas aqui estudados. A Figura 3.13 apresenta os resultados da DOS total e projetada sobre os aminoácidos Asp125, Gly1, GAL e os aminoácidos restantes. O Asp125 é responsável pela contribuição dos níveis de energia próximos a região HOMO e também apresenta níveis de energia localizados sobre as regiões onde contribuem outros aminoácidos e o carboidrato. O aminoácido 
Gly1 apresenta um comportamento bem diferente, possuindo apenas um estado localizado nos níveis de energia interna e uma boa da parte contribuição na região LUMO. UMO. Notamos que há uma grande combinação dos estados dos aminoácidos e da GAL, onde apenas um pico (próximo a $-7,5 \mathrm{eV}$ ) apresenta uma pequena contribuição do sítio ativo se comparado com a GAL. Além da Gly1, também há uma pequena contribuição da GAL na região LUMO.

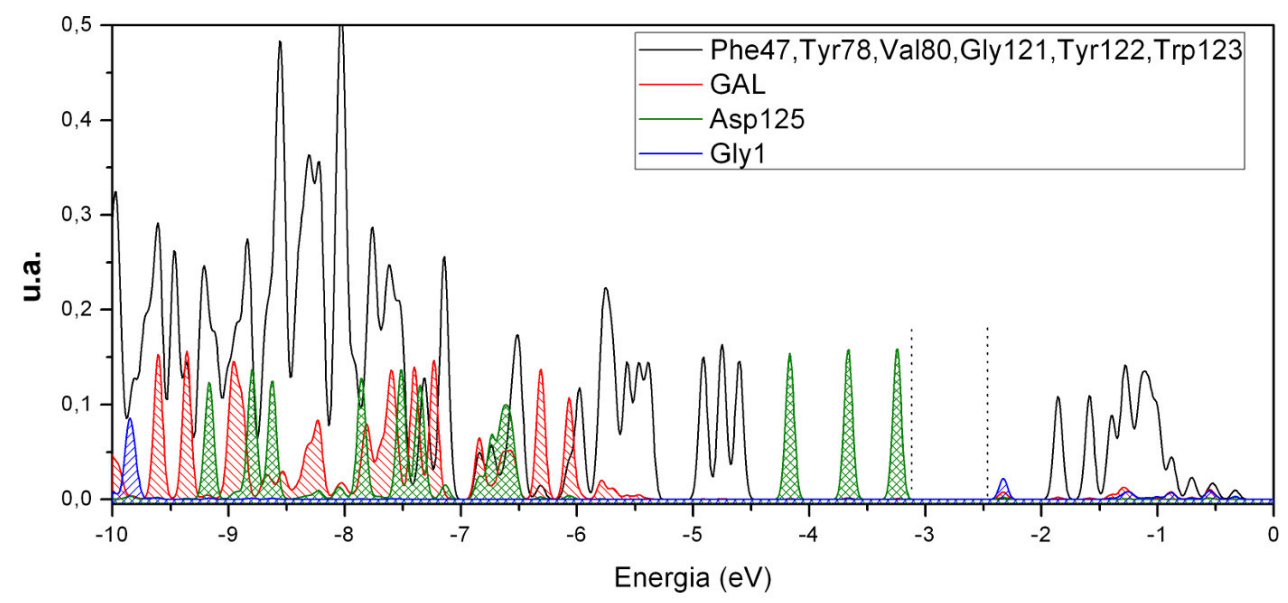

Figura 3.13: DOS projetadas sobre a GAL (traço vermelho), Asp125 (traço verde), Gly1 (traço azul) e os outros aminoácidos (traço preto) utilizando o modelo 2. As energias HOMO e LUMO estão indicas por traços pontilhados verticais.

É importante notar que todos o níveis de energia da DOS estão entre $-30 \mathrm{eV}$ e $0 \mathrm{eV}$, entretanto, estamos selecionando intervalos de energia menores, entre $-10 \mathrm{eV}$ e 0 $\mathrm{eV}$, para facilitar a visualização dos níveis de energia nas figuras aqui apresentadas.

Outras DOS projetadas para outros carboidratos usando o mesmo critério podem sem encontradas no Apêndice D.

\subsection{Propriedades Eletrônicas na Região de Energia Interna}

Apresentaremos nesta seção alguns resultados para a isosuperfície de densidade eletrônica do sistema Lectina-GAL em algumas energias escolhidas que estão denotadas na 
Figura 3.14 por números ${ }^{4}$. O sistema possui um total de 220 autovalores de KS no ponto $\gamma$, dos quais selecionamos os níveis: $131(-9.59 \mathrm{eV}), 172(-7.690 \mathrm{eV}), 179$ $(-7,35 \mathrm{eV}), 181(-7,23 \mathrm{eV}), 184(-6,84 \mathrm{eV}), 186(-6,64 \mathrm{eV}), 190(-4,75 \mathrm{eV}), 191(-6,07 \mathrm{eV})$ e $193(-5,79 \mathrm{eV})$. Apresentamos na Figura 3.15 as densidades eletrônicas para cada um dos níveis indicados na Figura 3.14.

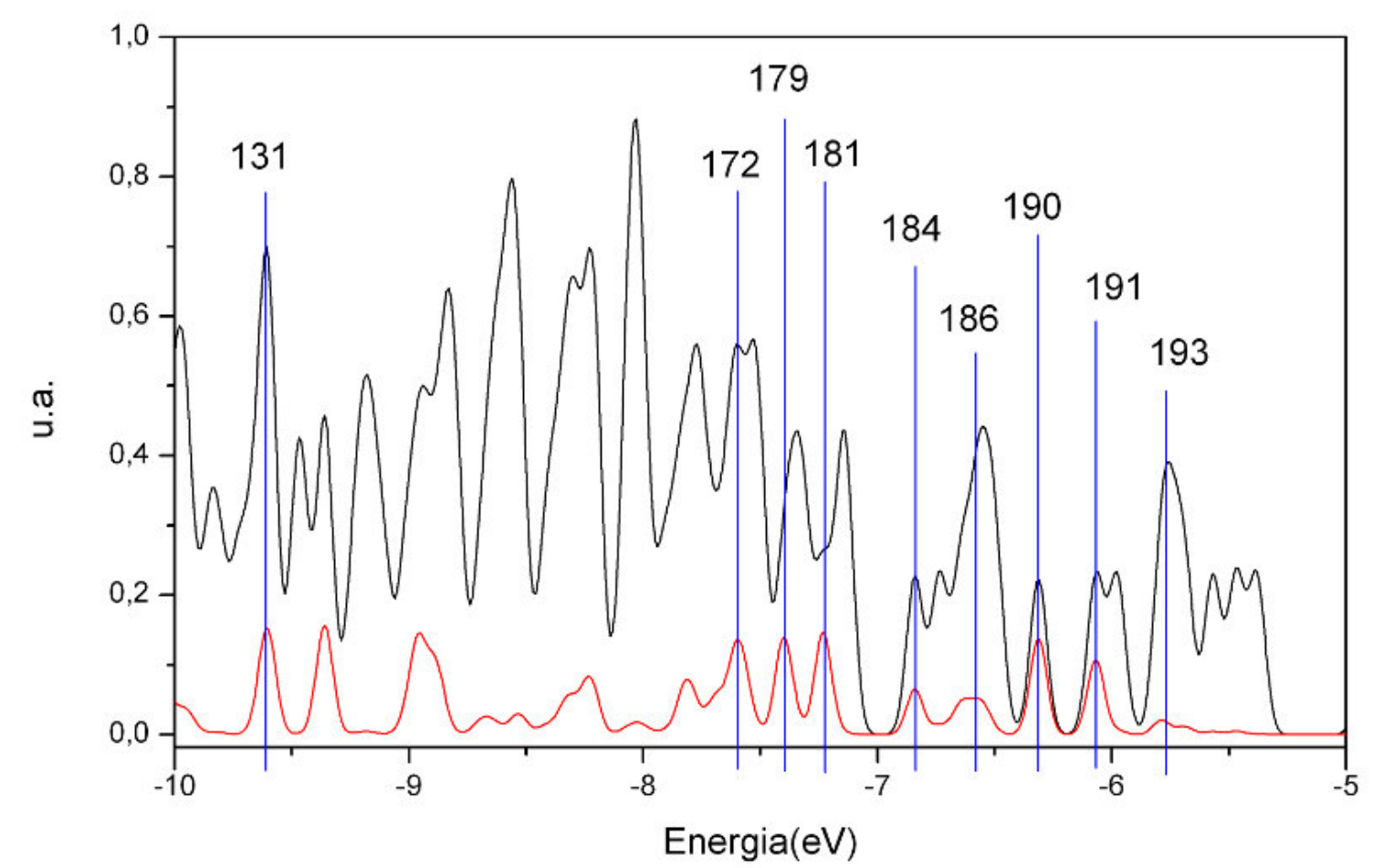

Figura 3.14: DOS projetada sobre a GAL utilizando o modelo 2. Os traços em preto e vermelho representam a contribuição total e projeção na GAL respectivamente. Os níveis de energia obtidos pelo CP-PAW estão indicados pelos traços azuis na figura.

\footnotetext{
${ }^{4}$ níveis de energia para os quais calculamos as densidades eletrônicas
} 


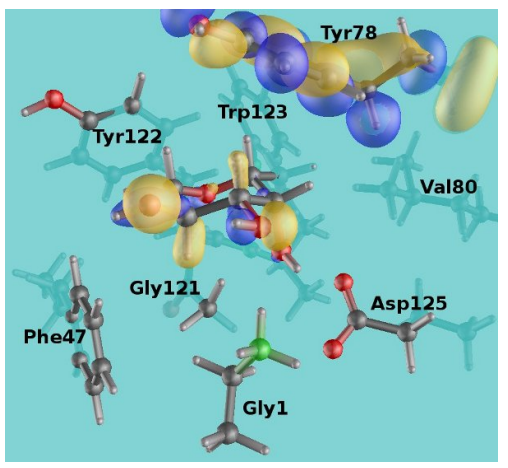

(a) CD 131

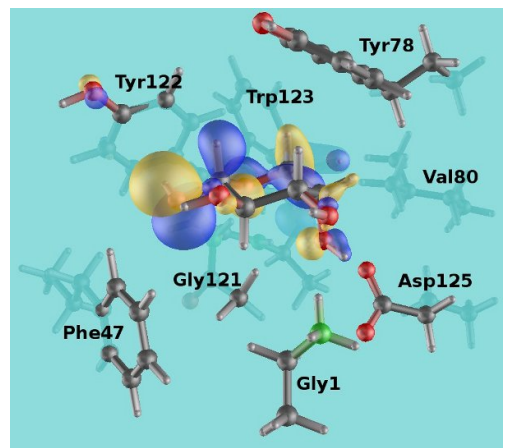

(d) CD 181

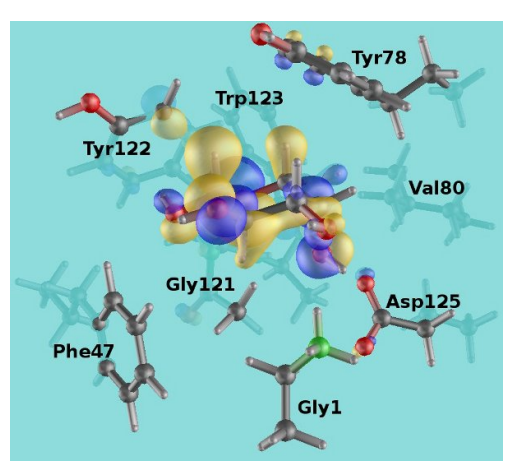

(g) CD 190

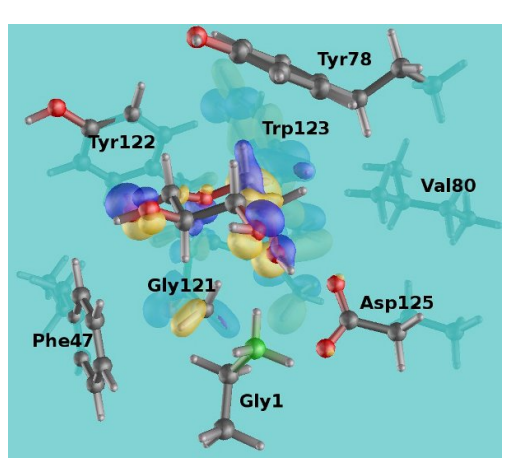

(b) CD 172

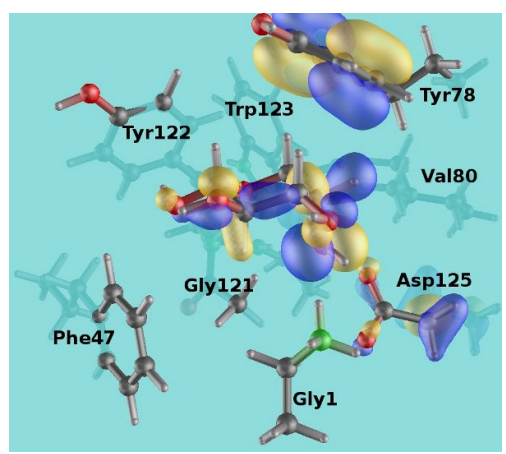

(e) CD 184

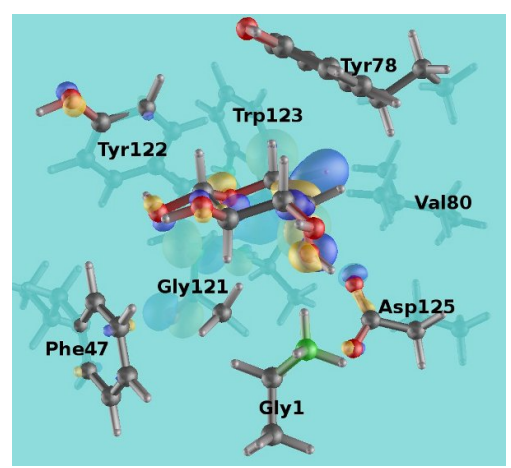

(h) CD 191

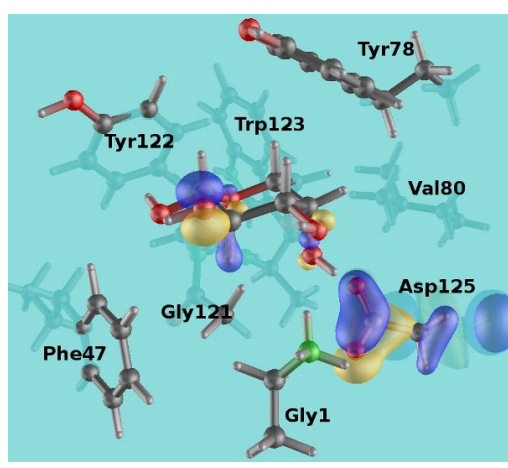

(c) CD 179

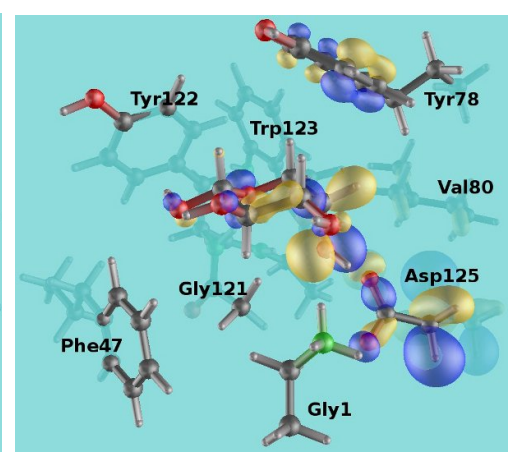

(f) CD 186

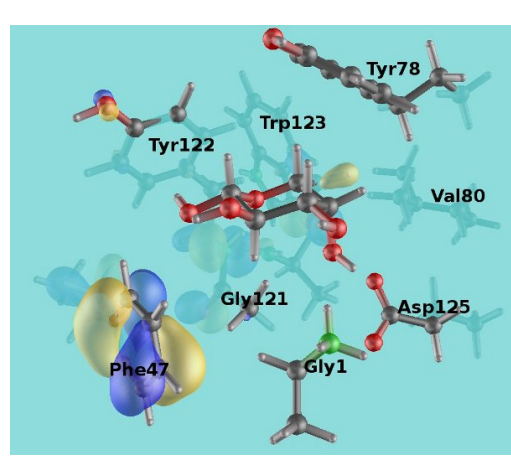

(i) CD 193

Figura 3.15: Densidade eletrônica do sítio ativo ligado com a GAL obtido utilizando o modelo 2. O índices das figuras são os autovalores de KS.

Iremos descrever os aspectos gerais de todas as densidades eletrônica, uma vez que é difícil visualizar os orbitais projetados apenas sob uma direção.

- CD 193: A maior parte das contribuições é dos aminoácidos Phe47, Gly121, 
Tyr122 e Trp123, que estão atrás do plano. A densidade eletrônica da GAL está bem localizada em sua região posterior.

- CD 191: A densidade eletrônica está localizada sobre os aminoácidos Phe47,Gly121,Tyr122 e Trp123. A GAL apresenta uma região bastante localizada e direcionada em sua região posterior.

- CD 190: Os orbitais estão bastante localizados sobre GAL, onde pequenas parcelas de orbitais estão espalhados sobre Tyr78, Tyr122 e Asp125.

- CD 186: Os orbitais se apresentam concentrados entre GAL, Tyr78 e Asp125.

- CD 184: Mesmo comportamento da densidade eletrônica 190 com um ligeiro aumento dos orbitais sobre Tyr78 e Asp125.

- CD 181: Os orbitais estão localizados na parte posterior da GAL e no Trp123.

- CD 179: Os orbitais estão localizados sobre a parte frontal da GAL e também sobre Asp125.

- CD 172: Os orbitais se posicionam entre GAL, Gly121,Tyr122 e Trp123.

- CD 131: Os orbtais estão bastante localizados na Tyr78 e GAL.

A maior parte das regiões acima mencionadas são as regiões onde ocorrem pequenas hibridizações dos orbitais de $\mathbf{O}$ da GAL e átomos de $\mathbf{O}$ ou $\mathbf{N}$ do sítio ativo. Sendo assim, podemos inferir que o principal mecanismo de ligação são os aminoácidos Asp125 e Gly1 e não as ligações de hidrogênio. Esta interessante observação pode explicar também por que não parece haver transferência eletrônica nas ligações de hidrogênio dos sistemas aqui estudados: estas ligações não fazem parte dos orbitais de fronteira do sistema.

Apresentamos na figura 3.16 uma DOS projetada apenas sobre os oxigênios e hidrogênios que formam ligações de hidrogênio no sistema. Notamos que as formações das ligações de hidrogênio estão localizadas nas regiões mais internas em energia à partir de $-8 \mathrm{eV}$, pois antes desta faixa de energia a população eletrônica é muito pequena. Observamos a superposição dos níveis de energia dos oxigênios e hidrogênios, o que nos permite inferir que as ligações de hidrogênio estão nestas regiões. As DOS projetadas para os outros sistemas estão no apêndice E 


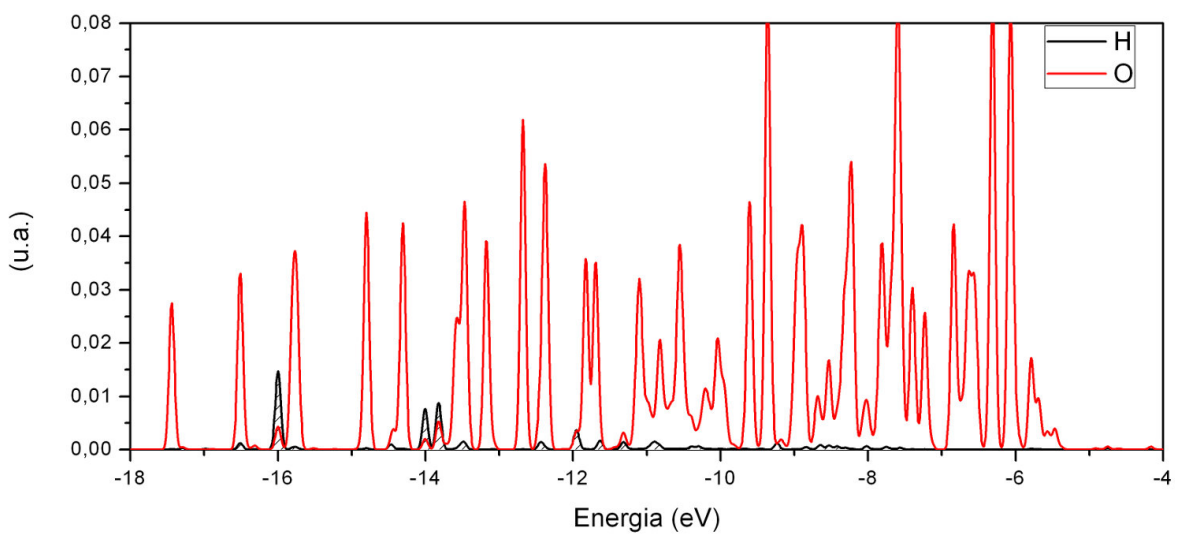

Figura 3.16: DOS projetadas sobre os $\mathbf{O}$ do carboidrato e sobre os $\mathbf{H}$ do sítio ativo que são responsáveis pela formação das ligações de hidrogênio no sistema GAL. 


\section{Capítulo 4}

\section{Conclusões}

Neste trabalho apresentamos e testamos um modelo para estudar a interação proteínacarboidrato que combina várias técnicas num estudo multiescala incluindo a análise através de cálculos de estrutura eletrônica ab initio. O conjunto de resultados aqui obtidos fornece um razoável banco de dados que ajuda a compreender as interações dos monossacarídeos $\alpha$-metil-galactose (AMG), $\beta$-D-galactose (GAL), O1-metil-D-manose (MMA) e $\alpha$-metil-D-glucopiranose (GYP) com as lectinas Jacalina e Frutalina.

A principal contribuição neste trabalho é apresentar resultados quânticos de um sistema que nunca tinha sido analisado sob esse aspecto. Estes resultados visam ajudar na compreensão dos mecanismos de interação proteína-carboidrato a partir das propriedades eletrônicas, permitindo novas propostas dentro da arquitetura de materiais com aplicações em nanobiotecnologia. Iniciamos assim a construção de um procedimento para estudar sítios ativos e ligantes que poderá ser aprimorado futuramente pela comunidade científica.

Os carboidratos aqui estudados apresentaram comportamentos semelhantes quanto à interação com a proteína. Através do método semi-empírico ZINDO, comparamos os resultados de absorbância UV/Vis teóricos e experimentais onde foi possível validar o modelo estrutural escolhido. Estimamos as energias de ligação considerando somente a contribuição eletrostática e obtivemos resultados com a mesma ordem de concordância com os resultados experimentais e dos resultados usuais de dinâmica molecular da literatura, o que são especificamente parametrizados para este fim. 
Notamos que a otimização de geometria é um fator essencial para obter a energia de ligação. A preparação da proteína e a simulação de mecânica molecular são também muito importantes para obter as posições do sistema. De forma surpreendente, a inclusão do efeito de solvente explícito parece não ser fundamental para o cálculo da energia de ligação, sendo suficiente utilizar uma geometria que considere este tipo de interação para corrigir as posições espaciais.

A partir dos resultados clássicos, notamos a existência de 5 ligações de hidrogênio em cada sistema que, segundo a literatura, seriam as ligações responsáveis pela interação proteína-carboidrato. Através da análise das densidades de carga, não observamos cargas localizadas nas regiões de HOMO sobre os átomos responsáveis por formar as ligações de hidrogênio no sítio ativo. Apenas o $\mathbf{O}$ do carboidrato apresenta algum tipo de concentração de carga e só conseguimos visualizar cargas que forneçam indícios da ligação de hidrogênio nos níveis de energia mais baixos (internos). Este resultado se apresenta bastante interessante, pois isso sugere um motivo pelo qual não há transferência eletrônica nas ligações de hidrogênio nos sistemas aqui estudados. Nossos resultados também sugerem fortemente que o principal mecanismo de interação proteína-carboidrato é o aminoácido Asp125 que é o responsável por quase toda a contribuição na região do $\mathrm{HOMO}$, como foi observado pela densidade de carga e densidade de estados.

Uma possível extensão do presente trabalho é, seguindo as sugestões da literatura, realizar testes para o cálculo da energia de ligação utilizando diferentes conformações para o mesmo carboidrato obtidas através do docking molecular e otimizadas por mecânica molecular. Novos campos de força também podem ser avaliados. Outra possível extensão é revisitar o sistema utilizando novos funcionais de troca e correlação testando também os funcionais que possuem correções VDW. 


\section{Apêndice A}

\section{Modelo Clássico para a Interação Lectina-Carboidrato}

A energia livre $\Delta G$ é usualmente decomposta em diversos termos que costumam variar entre os autores [1]. Aplicado ao caso estudado no presente trabalho, uma das formas mais usuais consiste em decompor a energia livre da ligação $\left(\Delta G_{\text {ligacão }}\right) \mathrm{em}$ :

$\Delta G_{\text {ligą̧ão }}=\Delta G_{\text {intermolecular }}+\Delta G_{\text {intramolecular,L }}+\Delta G_{\text {intramolecular, } \mathrm{A}}+\Delta G_{\text {solvatação,L }}+\Delta G_{\text {solvatação,A }}$

$\Delta G_{\text {intermolecular }}$ é a contribuição da energia livre devido à interação entre a lectina (L) e o açúcar (A); $\Delta G_{\text {intramolecular,L }}$ e $\Delta G_{\text {intramolecular, }}$ são as contribuições para as energias livres internas da lectina e do açúcar; $\Delta G_{\text {solvatação,L }}$ e $\Delta G_{\text {solvatação,A }}$ são as contribuições para energia livre devido a presença do solvente.

A energia livre intermolecular e a energia livre intramolecular são usualmente aproximadas pelas respectivas entalpias. A energia livre intramolecular, para ambos sistemas, pode incluir um termo entrópico $\Delta S$ que registra as informações a respeito das ligações que podem ser rotacionadas mas que estão congeladas durante a ligação. A energia livre de solvatação pode ser calculada utilizando solventes implícitos, pela aproximação pair-based, ou através de solventes explícitos. Existem diversas formas de calcular as energias intramoleculares e intermoleculares, onde é possível utilizar méto- 
dos ab initio, semi-empíricos ou através de dinâmica molecular. Entre estes métodos, o mais custoso é o método ab initio, porém, como o próprio nome diz, não utiliza nenhuma parametrização. Segundo a literatura, métodos ab initio e semi-empíricos usualmente não são aplicáveis para sistemas grandes como proteínas. A mecânica molecular é um candidato natural para este tipo de aplicação pelo seu reduzido custo computacional. Esta metodologia consiste basicamente em utilizar um campo de força para simular o comportamento dinâmico de sistemas moleculares maiores através das equações de movimento de Newton, permitindo estudar a flexibilidade das moléculas e sua dinâmica de interação. Uma discussão mais aprofundada pode ser encontrada nas referências $[1,45]$. 


\section{Apêndice B}

\section{O Algoritmo de Verlet para a Dinâmica Molecular}

O código computacional PAW usa o algoritmo de Verlet [46] para fazer a evolução temporal das funções de onda e das posições dos núcleos atômicos. Utilizando um intervalo A cada passo, ele evolui no tempo um instante $\Delta$, que deve ser suficientemente pequeno para garantir a validade da dinâmica. Um valor que se mostra aceitável [47] para a evolução temporal esta dentro de uma amplitude de 10 unidades atômicas, ou 0,25 fs.

Vamos denotar como $x(0)$ para o estado atual do sistema, $x(-)$ para o estado anterior e $x(+)$ para o estado evoluído. A partir desta notação e do intervalo de tempo $\Delta$ temos:

$$
x_{n}(+)=2 x_{n}(0)-x_{n}(-)+F_{n}(0) \frac{\Delta^{2}}{m_{n}}
$$

\section{Evolução temporal da função de onda}

Com base no algoritmo de Verlet e no formalismo PAW, a propagação da função de onda(equação 2.30) é: 


$$
\left|\tilde{\Psi}_{n}(+)\right\rangle=2\left|\tilde{\Psi}_{n}(0)\right\rangle-\left|\tilde{\Psi}_{n}(-)\right\rangle-\frac{\Delta^{2}}{m_{\Psi}} \tilde{\mathcal{H}}\left|\tilde{\Psi}_{n}(0)\right\rangle+\frac{\Delta^{2}}{m_{\Psi} f_{n}} \sum_{m} \tilde{\mathcal{O}}(0)\left|\tilde{\Psi}_{m}(0)\right\rangle \wedge_{n, m}
$$

Aqui o último termo é responsável pelo vínculo de ortonormalidade da função de onda. Os multiplicadores de Lagrange $\wedge_{n, m}$ são determinados iterativamente a cada passo da dinâmica molecular,

$$
\left\langle\tilde{\Psi}_{n}(+)|\tilde{\mathcal{O}}(+)| \tilde{\Psi}_{m}(+)\right\rangle=\delta_{n, m}
$$

\section{Evolução Temporal do Movimento Nuclear}

Seguindo o algoritmo de Verlet, a evolução temporal dos núcleos é:

$$
R_{i}(+)=2 R_{i}(0)-R_{i}(-)+\frac{\Delta^{2}}{M_{R_{i}}} F_{R_{i}}
$$




\section{Apêndice C}

\section{Espectro UV/Vis}

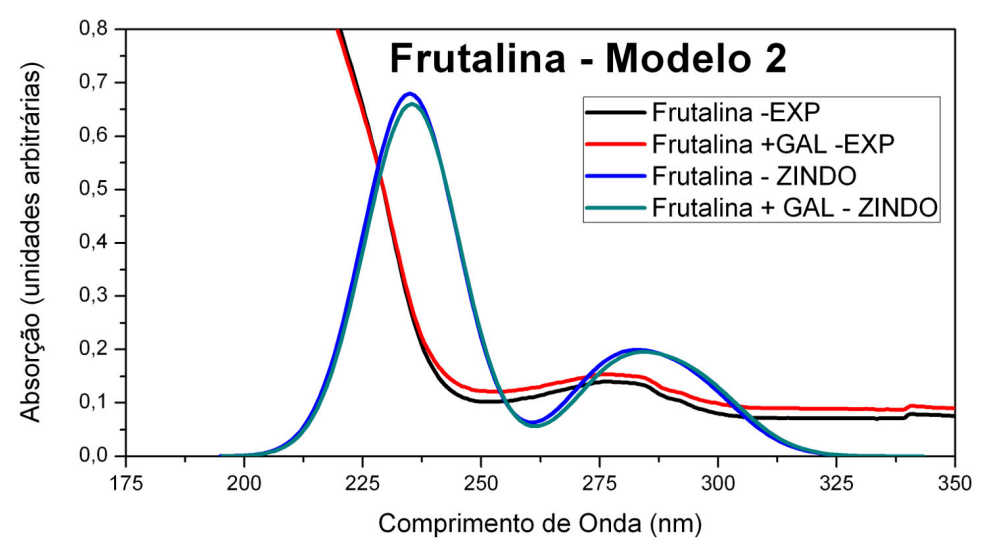

Figura C.1: Resultados obtidos para Absorção UV/Vis para o Modelo 2 em uma outra escala. 


\section{Apêndice D}

\section{DOS Projetadas}

Neste apêndice apresentamos as DOS projetadas para os sistemas com os carboidratos AMG, GYP e MMA. Como o comportamento geral de todas é o semelhante, optamos pela análise detalhada apenas para a GAL no capítulo de Resultados e Discussão.

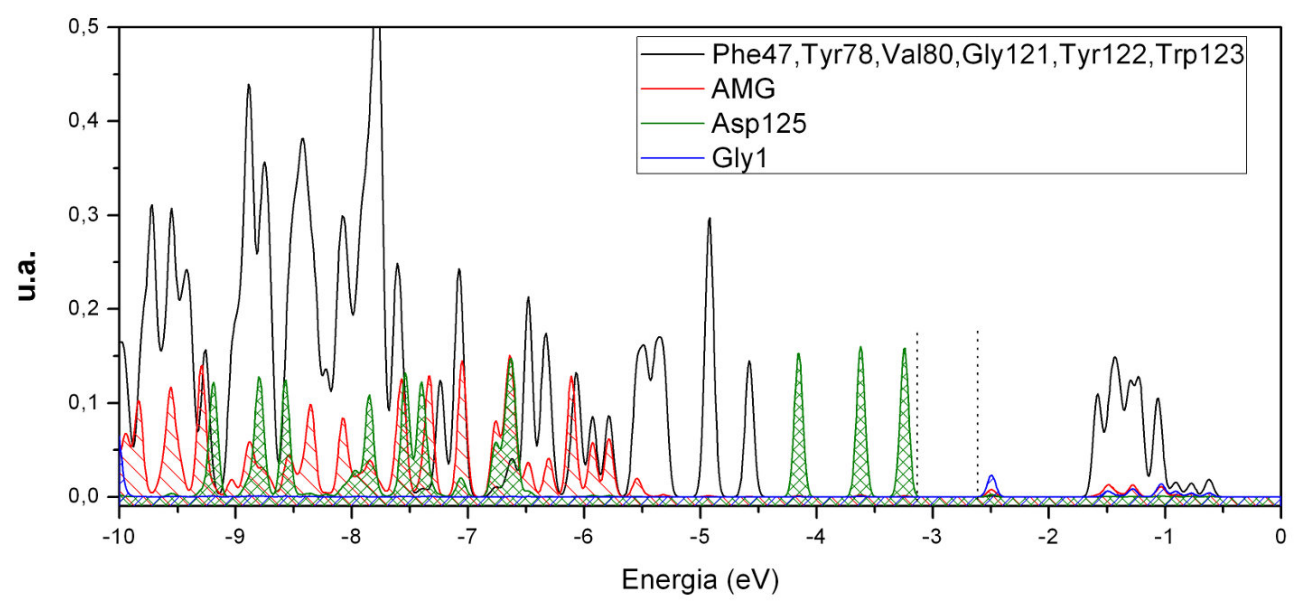

Figura D.1: DOS projetadas sobre a AMG (traço vermelho), Asp125 (traço verde), Gly1 (traço azul) e os outros aminoácidos (traço preto) utilizando o modelo 2. As energias HOMO e LUMO estão indicadas por traços pontilhados verticais. 


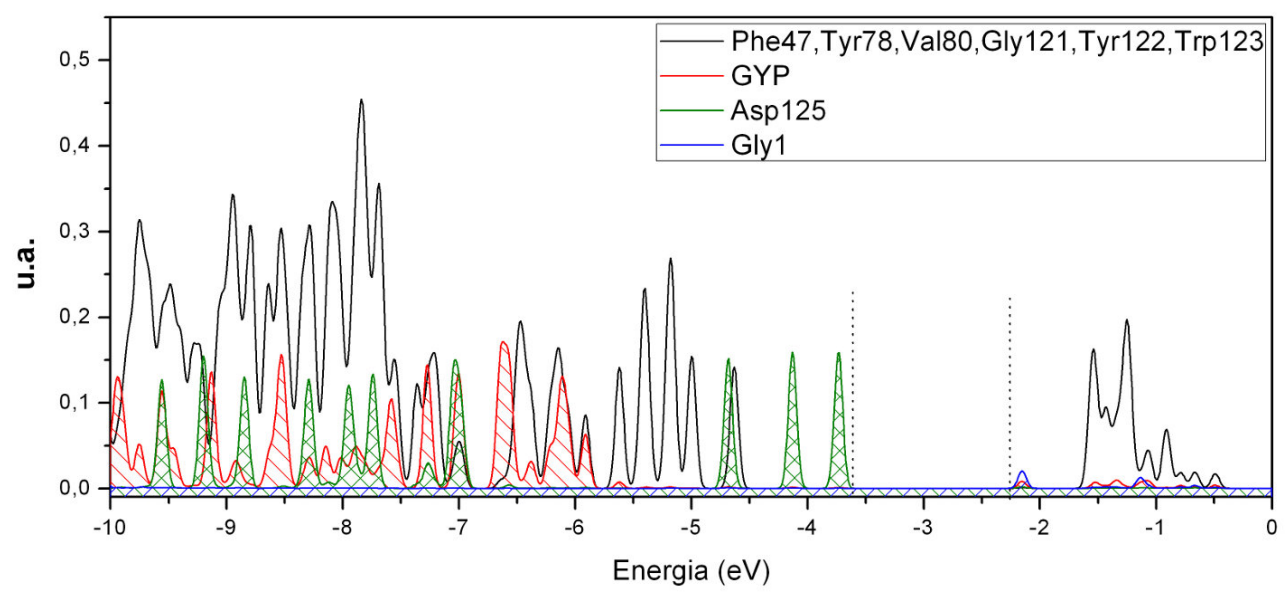

Figura D.2: DOS projetadas sobre a GYP (traço vermelho), Asp125 (traço verde), Gly1 (traço azul) e os outros aminoácidos (traço preto) utilizando o modelo 2. As energias HOMO e LUMO estão indicadas por traços pontilhados verticais.

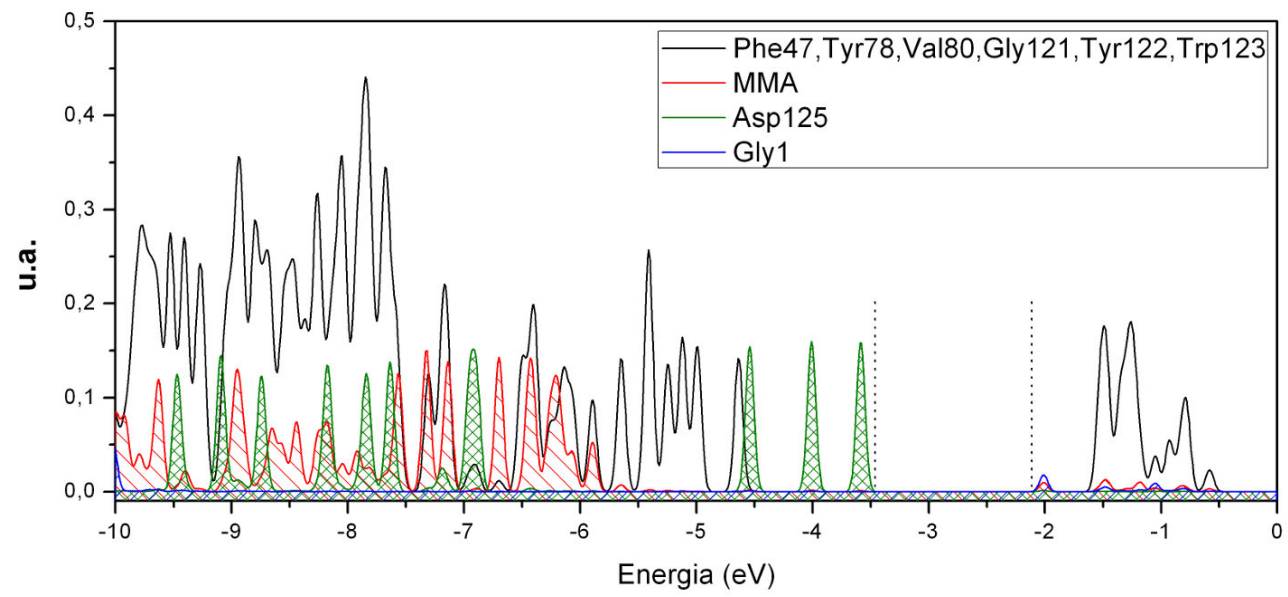

Figura D.3: DOS projetadas sobre a MMA (traço vermelho), Asp125 (traço verde), Gly1 (traço azul) e os outros aminoácidos (traço preto) utilizando o modelo 2. As energias HOMO e LUMO estão indicadas por traços pontilhados verticais. 


\section{Apêndice E}

\section{DOS Projetadas nas ligações de}

\section{Hidrogênio}

Neste apêndice apresentamos as DOS projetadas sobre os átomos responsáveis pela ligação de hidrogênio para os sistemas com os carboidratos AMG, GYP e MMA. Como o comportamento geral de todas é o semelhante, optamos pela análise detalhada apenas para a GAL no capítulo de Resultados e Discussão.

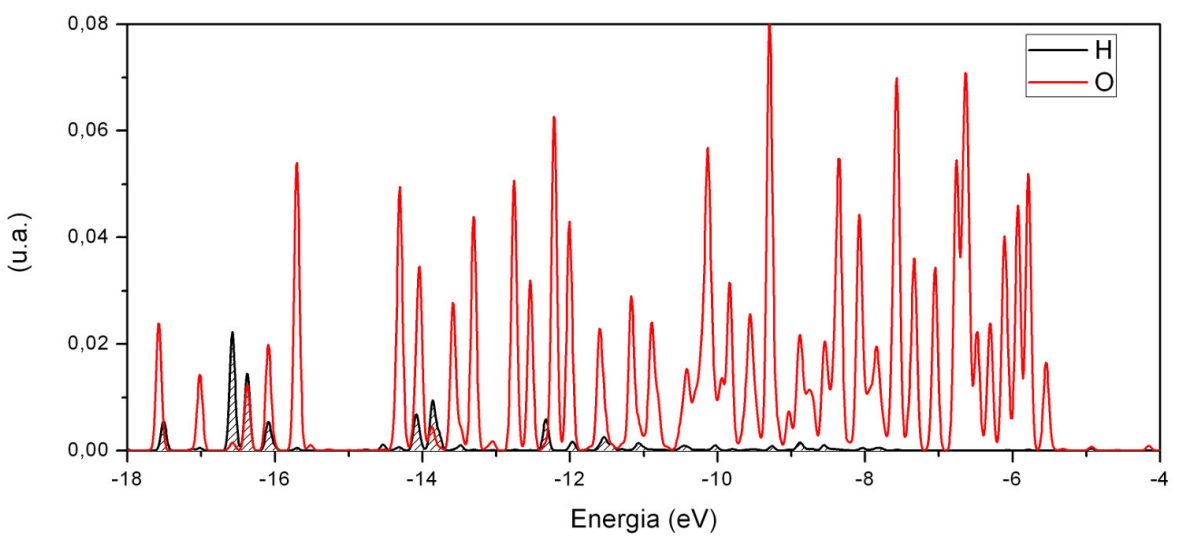

Figura E.1: DOS projetadas sobre os $\mathbf{O}$ do carboidrato e sobre os $\mathbf{H}$ do sítio ativo que são responsáveis pela formação das ligações de hidrogênio no sistema AMG. 


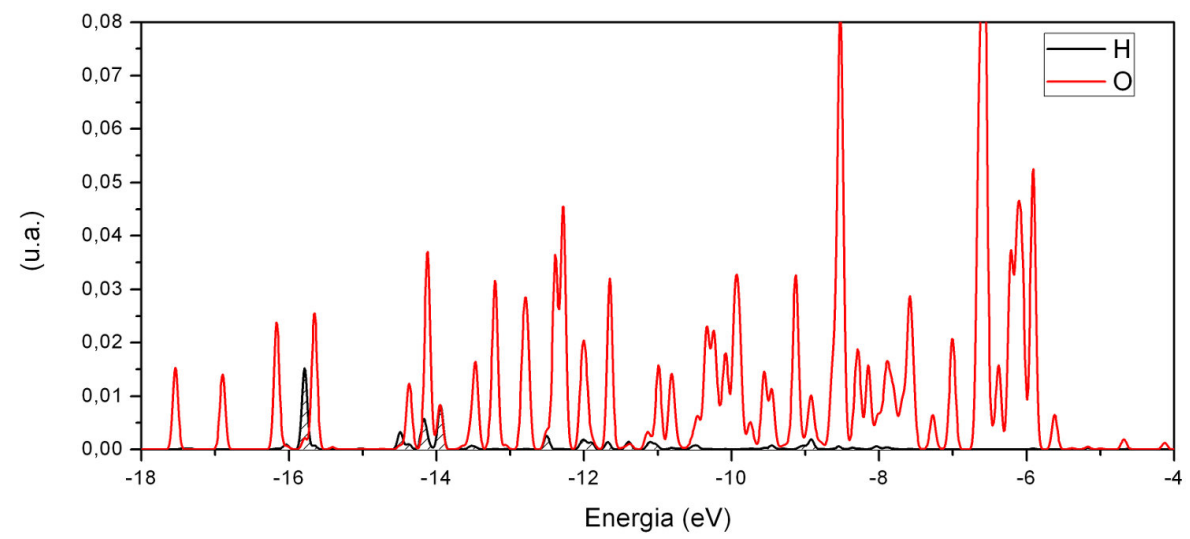

Figura E.2: DOS projetadas sobre os $\mathbf{O}$ do carboidrato e sobre os $\mathbf{H}$ do sítio ativo que são responsáveis pela formação das ligações de hidrogênio no sistema GYP.

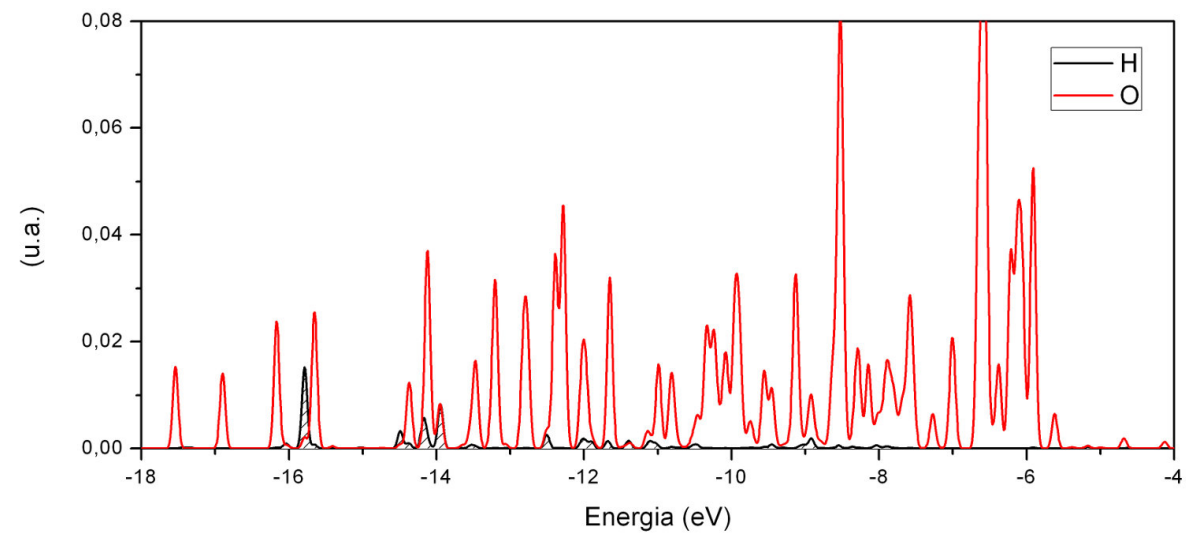

Figura E.3: DOS projetadas sobre os $\mathbf{O}$ do carboidrato e sobre os $\mathbf{H}$ do sítio ativo que são responsáveis pela formação das ligações de hidrogênio no sistema MMA. 


\section{Bibliografia}

[1] D. Neumann, C. Lehr, H. Lenhof, and O. Kohlbacher, Advanced Drug Delivery Reviews 56, 437 (2004).

[2] R. Laine, The information-storing potential of the sugar code. (Chapman Hall, London, 1997).

[3] C. L. J Haas, Expert Opin. Biol. Ther. 2, 287 (2002).

[4] A. Pusztai et al., Br. J. Nutr. 70, 313 (1993).

[5] P. Campana, D. Moraes, A. Monteiro-Moreira, and L. Beltramini, European Journal of Biochemistry 269, 753 (2002).

[6] R. Moreira and I. Ainouz, Biologia Plantarum 23, 186 (1981).

[7] A. Monteiro, C. CasteloBranco, L. Beltramini, and R. Moreira, European Journal of Cell Biology 74, 64 (1997).

[8] M. Chervenak and E. Toone, J. Am. Chem. Soc. 116, 10533 (1994).

[9] B. Lee, Biophys. Chem. 51, 271 (1994).

[10] K. Sharp, Protein Sci. 10, 661 (2000).

[11] A. Cornish-Bowden, J. Biosci. 27, 121 (2002).

[12] T. Dam and F. Brewer, Chem. Rev. 102, 387 (2002).

[13] A. Demchenko, Ultraviolet spectroscopy of Proteins (Springer, 1986).

[14] H. Tsujishita et al., Jour. Med. Chem. 40, 362 (1997). 
[15] Y. Cheong, G. Shim, D. Kang, and Y. Kim, J. Mol. Struct. 475, 219 (1999).

[16] E. Caffarena, J. Grigera, and P. Bisch, J. Mol. Graph. Model. 21, 227 (2002).

[17] W. Tempel, S. Tschampel, and R. Woods, J. Biol. Chem. 227, 6615 (2002).

[18] G. Bradbrook et al., X-ray and molecular dynamics studies of concanavlin-A glucoside and mannoside complexes 94, 1603 (1998).

[19] F. Schwarz, K. Puri, R. Bhat, and A. Surolia, J. Biol. Chem. 268, 7668 (1993).

[20] A. Marzocco and B. Torres, Bioquimica Básica (Guanabara Koogan, 2007).

[21] Z. V and et. al., Comunicação Privada (USP, 2009).

[22] P. Blochl, Physical Review B 50, 17953 (1994).

[23] R. Car and M. Parrinello, Physical Review Letters 55, 2471 (1985).

[24] P. Hohenberg and W. Kohn, Physical Review B 136, B864 (1964).

[25] J. Kohanoff, Electronic Structure Calculation for Solids and Molecules: Theory and Computational Methods (Cambridge University Press, 2006).

[26] K. Capelle, Brazilian Journal of Physics 36, 1318 (2006).

[27] W. Kohn and L. Sham, Physical Review 140, 1133 (1965).

[28] E. by Sidney Yip, Handbook of Materials Modeling (Springer, 2005).

[29] J. Perdew, K. Burke, and M. Ernzerhof, Physical Review Letters 78, 1396 (1997).

[30] J. Ridley and M. Zerner, Theoretica Chimica Acta 32, 111 (1973).

[31] Cerius 8 Materials Studio (Accelrys inc., 2001).

[32] GOLD - www.ccdc.cam.ac.uk (The Cambridge Crystallographic Data Centre, 2009).

[33] SYBYL - www.tripos.com (Tripos, 2009).

[34] Protein Data Bank - www.pdb.org (PDB, 2010). 
[35] R. Sankaranarayanan et al., Nature Structural Biology 3, 596 (1996).

[36] K. Rao, C. Suresh, U. Katre, S. Gaikwad, and M. Khan, Acta Crystallographica Section D-Biological Crystallography 60, 1404 (2004).

[37] A. Jeyaprakash et al., Journal of Molecular Biology 332, 217 (2003).

[38] A. Jeyaprakash et al., Journal of Molecular Biology 347, 181 (2005).

[39] Pymol - www.pymol.org (DeLano Scientific LLC, 2007).

[40] H. Petrilli, P. Blochl, P. Blaha, and K. Schwarz, Physical Review B 57, 14690 (1998).

[41] J. Schimpl, H. Petrilli, and P. Blochl, Journal of The American Chemical Society 125, 15772 (2003).

[42] M. B. Goncalves, R. Di Felice, O. K. Poleshchuk, and H. M. Petrilli, Hyperfine Interactions 181, 53 (2008).

[43] C. David Sherrilla, The Journal of Chemical Physics 132, 110902 (2010).

[44] G. Desiraju, Acc. Chem. Res. 35, 565 (2002).

[45] D. Frenkel and B. Smit, Understanding Molecular Simulations (Academic Press, San Diego, CA, 1996).

[46] L. Verlet, Physical Review 159 (1967).

[47] G. Pastore, E. Smargiassi, and F. Buda, Physical Review A 44 (1991). 